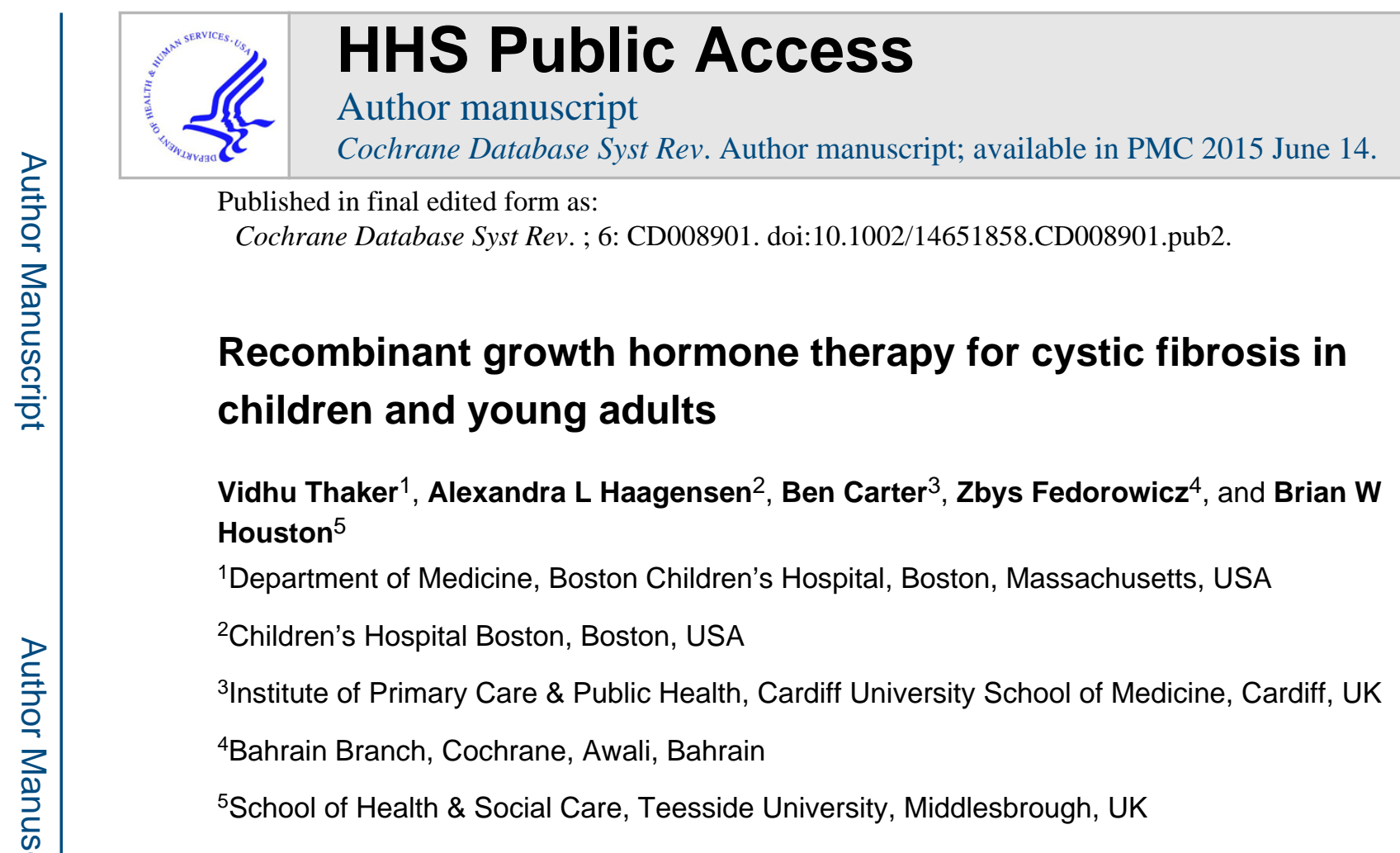

Abstract

Background-Cystic fibrosis is an inherited condition causing disease most noticeably in the lungs, digestive tract and pancreas. People with cystic fibrosis often have malnutrition and growth

Copyright $\odot 2015$ The Cochrane Collaboration. Published by John Wiley \& Sons, Ltd.

Contact address: Vidhu Thaker, Department of Medicine, Boston Children's Hospital, 300 Longwood Ave, Boston, Massachusetts, 02115, USA. vidhuthaker@gmail.com.

CONTRIBUTIONS OF AUTHORS

\begin{tabular}{|c|c|}
\hline \multicolumn{2}{|l|}{ Roles and responsibilities } \\
\hline Task & Author \\
\hline Protocol stage: draft the protocol & VT, VJ, AH, BH \\
\hline Review stage: select which trials to include $(2+1$ arbiter $)$ & VT, VJ, BH \\
\hline Review stage: extract data from trials (2 people) & $\mathrm{VT}, \mathrm{BH}, \mathrm{BC}$ \\
\hline Review stage: enter data into RevMan & VT, BC \\
\hline Review stage: carry out the analysis & VT, BC \\
\hline Review stage: interpret the analysis & $\mathrm{VT}, \mathrm{ZF}, \mathrm{BC}$ \\
\hline Review stage: draft the final review & $\mathrm{VT}, \mathrm{AH}, \mathrm{ZF}, \mathrm{BC}$ \\
\hline Update stage: update the review & $\mathrm{VT}, \mathrm{AH}, \mathrm{VJ}, \mathrm{BH}, \mathrm{ZF}, \mathrm{BC}$ \\
\hline
\end{tabular}

DECLARATIONS OF INTEREST

Alexandra Haagenson declares that she has participated in marketing review studies on growth hormone (as well as other pharmaceutical) advertisements.

The remaining authors declare that there are no financial conflicts of interest and they do not have any associations with any parties who may have vested interests in the results of this review.

DIFFERENCES BETWEEN PROTOCOL AND REVIEW

In the protocol, hand grip was defined as the test of measure of muscle strength. The studies included in the review used bicycle ergometry as the measure of muscle strength. The outcome measure was changed to include bicycle ergometry as it is a alternative standard measure of muscle strength and cardiorespiratory fitness used in exercise testing (ACSM 2006). 
delay. Adequate nutritional supplementation does not improve growth optimally and hence an anabolic agent, recombinant growth hormone, has been proposed as a potential intervention.

Objectives-To evaluate the effectiveness and safety of recombinant human growth hormone therapy in improving lung function, quality of life and clinical status of children and young adults with cystic fibrosis.

Search methods-We searched the Cochrane Cystic Fibrosis and Genetic Disorders Group's Trials Register comprising references identified from comprehensive electronic database searches and handsearches of relevant journals and abstract books of conference proceedings. Date of latest search: 11 February 2015.

We conducted a search of relevant endocrine journals and proceedings of the Endocrinology Society meetings using Scopus and Proceedings First. Date of latest search: 04 March 2015.

Selection criteria-Randomised and quasi-randomised controlled trials of all preparations of recombinant growth hormone compared to either no treatment, or placebo, or each other at any dose (high-dose and low-dose) or route and for any duration, in children or young adults aged up to 25 years diagnosed with cystic fibrosis (by sweat test or genetic testing).

Data collection and analysis-Two authors independently screened papers, extracted trial details and assessed their risk of bias.

Main results-Four controlled trials were included in this review (with 161 participants in total), each with an unclear risk of bias. Analysis of data obtained from these trials shows improvement in height for all comparisons, but improvements in weight and lean tissue mass were only reported in the comparison of standard dose recombinant growth hormone versus no treatment. One study showed moderate improvement at one time point in one parameter of pulmonary function tests, forced vital capacity (per cent predicted) when comparing standard dose recombinant growth hormone and no treatment, but there was no consistent benefit in lung function across all studies. Little evidence was found for improvement in quality of life. An improvement in fasting blood glucose levels was reported when comparing rhGH to placebo only. Exercise capacity improved in participants receiving standard dose recombinant growth hormone versus no treatment, but not for any other comparison. There is insufficient evidence to conclude any changes in hospitalisations, antibiotic use or significant adverse effects.

Authors' conclusions-Recombinant growth hormone therapy is effective in improving the intermediate outcomes in height, weight and lean tissue mass when compared with no treatment. One measure of pulmonary function test showed moderate improvement at a single time point, but no consistent benefit was seen across all studies. No significant changes in quality of life, clinical status or side-effects were observed in this review. Long-term, well-designed randomised controlled trials of recombinant growth hormone therapy in people with cystic fibrosis are required prior to evaluation of human growth hormone treatment for routine use.

\section{Medical Subject Headings (MeSH)}

Blood Glucose [metabolism]; Body Height [*drug effects]; Body Mass Index; Body Weight [drug effects; physiology]; Cystic Fibrosis [complications; *drug therapy]; Exercise Tolerance [drug effects; physiology]; Fasting [blood]; Human Growth Hormone [*therapeutic use]; Quality of 
Life; Randomized Controlled Trials as Topic; Recombinant Proteins [therapeutic use]; Vital Capacity [drug effects; physiology]

\section{MeSH check words}

Adolescent; Child; Humans; Young Adult

\section{PLAIN LANGUAGE SUMMARY}

The use of recombinant growth hormone to improve growth and health in children and young adults with cystic fibrosis

\section{Review question}

We reviewed the evidence about the effects of man-made human growth hormone on growth and health of people with cystic fibrosis.

\section{Background}

Cystic fibrosis is an inherited condition causing disease most noticeably in the lungs, digestive system (gut) and pancreas. People with cystic fibrosis are often underweight and have delayed growth. Nutritional supplements may not be enough to improve growth and it has been suggested that treatment with man-made human growth hormone might help. Human growth hormone is usually given once a day via a needle under the skin. It can improve the rate of growth and bone density in children and young adults, but may also affect glucose metabolism which has implications for children at risk of cystic fibrosisrelated diabetes. Treatment is also expensive, so a review needs to look at the risks and benefits of this treatment.

\section{Search date}

The evidence is current to: 11 February 2015.

\section{Study characteristics}

This review looked at the use of man-made human growth hormone to improve lung function, growth and quality of life for children and young adults with cystic fibrosis. It includes four trials with 161 volunteers who were selected for one treatment or the other randomly. The volunteers were $7-23$ years old, but most of them had not reached puberty. Three trials lasted for one year and one for six months. Hormone treatment was compared to no treatment in three trials and to placebo (liquid that didn't contain any growth hormone) in one trial. The trial that used a placebo compared this to two different dose levels of hormone treatment.

\section{Key results}

The trial results showed a modest improvement in height and weight over 6 to 12 months. However, we did not find any consistent evidence in the improvement of lung function, muscle strength, clinical condition or quality of life after treatment. We also did not find any effects on glucose metabolism or the long-term risk of diabetes due to the treatment. Given 
these results, we are not able to identify any clear benefit of therapy and believe that more research from well-designed, large trials is needed.

\section{Quality of the evidence}

We did not have enough information to decide if overall the trials were biased in such a way to affect the results. We were happy that all the outcomes that were measured were clearly reported in the trials, but there were some concerns that outcomes based on personal judgement, like quality of life scores, might be affected because the volunteers in the three trials comparing treatment to no treatment would know which group they were in.

\section{BACKGROUND}

\section{Description of the condition}

Cystic fibrosis $(\mathrm{CF})$ is the most common autosomal recessive genetic disease of the Caucasian population which affects approximately 1 in 2500 live births (Ratjen 2003). A genetic defect results in thickened secretions across cells and a number of clinical symptoms predominantly chronic lung disease and exocrine pancreatic insufficiency.

Inadequate gastrointestinal function results in the malabsorption of fat, essential vitamins and fatty acids. Long-standing lung disease increases caloric requirements which is compounded by a loss of appetite due to the disease, to medications and to the psychological stress of chronic disease (Kawchak 1996; O’Rawe 1992; Patel 2003; Reilly 1997).

Malnutrition and growth failure are commonly seen in CF; $20.2 \%$ of individuals with CF under 25 years of age are below the $10^{\text {th }}$ percentile for weight and $23.1 \%$ are below the $10^{\text {th }}$ percentile for height (CFF 2008).

In the past, failure to thrive was one of the presenting features of CF. Approximately $40 \%$ of infants were below the $5^{\text {th }}$ percentile for weight and length at diagnosis with some catch-up growth after diagnosis (Barkhouse 1989; Karlberg 1991; Lai 1998; Morison 1997). With the introduction of newborn screening in the USA, failure to thrive is less likely to be seen, but poor growth is still a problem (Assael 2009).

After infancy, the rate of growth of children with CF follows a normal pattern until nine years of age, albeit at lower centiles (Farrell 2001; Karlberg 1991); adolescent years show more severe growth impairment associated with: a delay in skeletal maturation; the delayed onset of puberty and pubertal growth spurt; and in attaining adult height (Haeusler 1994; Lucidi 2009; Morison 1997). Despite comprehensive care at specialized centres, studies show growth in individuals with CF below that of controls (Stettler 2000; Wiedemann 2007); consequently, the height of adults with CF is reduced (Byard 1994; CFF 2008; Lucidi 2009).

Malnutrition and short stature have been shown to contribute to a poor clinical outcome (Corey 1988). While the nutritional care of people with CF has improved significantly, data from the CFF Registry indicate that growth retardation by four years of age is a significant independent prognostic indicator of survival (Beker 2001). This suggests that improved growth may allow more lung mass and better lung function, which could be important, 
independent of the issue of improving weight gain. Furthermore, prospective studies have suggested that aggressive nutritional intervention may positively affect pulmonary function (Konstan 2003; Sharma 2001). Despite adherence to updated nutritional guidelines (Borowitz 2002; Sinaasappel 2002), there are still individuals with CF who cannot meet their energy needs or maintain the benefits of nutritional interventions (Dalzell 1992; Stettler 2000) and who are at risk of nutritional failure and deterioration of pulmonary function.

Individuals with $\mathrm{CF}$ show normal spontaneous and stimulated growth hormone $(\mathrm{GH})$ levels, but low levels of GH effector proteins (insulin like growth factor -1 (IGF-1)) and binding proteins (IGFBP-3) which correlate with height and body mass index (BMI). Thus, growth failure in CF may be due to relative GH insensitivity (Laursen 1999; Taylor 1997). In addition, the chronic inflammation in CF results in production of inflammatory chemicals like body interleukins (IL-1, IL-6) and tumour necrosis factor (TNF-alpha), which have also been shown to reduce levels of IGF-1 (De Benedetti 1997). There is strong evidence that low IGF-1 levels result in loss of lean body mass and respiratory muscle wasting which ultimately results in the deterioration of lung function and increasing morbidity (SermetGaudelus 2003).

\section{Description of the intervention}

Growth hormone acts to mediate growth and metabolic functions in the body. It is released from the pituitary gland in a pulsatile manner throughout the day. At night GH release peaks and stimulates the production of IGF-1 in the liver, which is its major effector protein and also serves to control its secretion (Williams 2011).

Recombinant human GH (rhGH) (somatotropin) has been available since 1985 and is selfadministered at home, usually as a subcutaneous injection. The frequency of dose is generally six to seven times per week, preferably at night to mimic the body's natural rhythm. The dose of the therapy generally varies between $0.1 \mathrm{mg}$ to $0.4 \mathrm{mg} / \mathrm{kg} /$ week depending on the clinical condition.

Treatment with rhGH is expensive. According to an NHS Health Technology Assessment Programme, the costs for treating children with four of the licensed conditions (growth hormone deficiency, Prader Willi Syndrome, idiopathic short stature and Turners syndrome) in England and Wales with rhGH would be approximately $£ 180$ million (Bryant 2002). For growth hormone deficiency, the cost of therapy (in 2000) for a nine-year old child for eight years would average more than $£ 50,000$ and that for a 12-year old child for five years over $£ 40,000$ (Bryant 2002). This raises the question of consideration of cost-benefit analysis for the use of therapy, especially if anticipated costs are higher as in CF.

Adverse effects of the therapy-Besides the discomfort and local reactions caused by daily injections, mild adverse effects like headache, nausea, fever and vomiting have been noted. Overall, the incidence of adverse effects in children treated with rhGH therapy is under three per cent (\%). Adverse effects associated with rhGH therapy are intracranial hypertension (pseudotumour cerebri), moderate and severe edema, slipped capital femoral epiphysis, worsening of scoliosis, gynaecomastia and hyperglycaemia (Wilson 2003). There have been some recent concerns that rhGH therapy may increase the tendency towards new 
tumour formation (Giovannucci 2002; Verhelst 2002), although there are no current documented results with short- and long-term follow-up in children and adults.

In trials assessing the results of rhGH therapy on glucose metabolism, a slight increase in fasting and post-prandial insulin and blood glucose levels has been demonstrated (Cutfield 2000; Jeffcoate 2002). In pre-pubertal children with $\mathrm{CF}$ at a high risk for CF-related diabetes, the long-term safety of rhGH therapy should be an important consideration.

\section{How the intervention might work}

Although people with CF demonstrate normal GH levels, low levels of IGF-1 have been found indicating a relative GH resistance (Laursen 1999). Treatment with rhGH can accelerate linear growth in pre-pubertal children with growth failure including those with $\mathrm{CF}$ (Hardin 2004). It also modifies body composition, promoting fat-free mass in the body. In the long term, rhGH treatment increases bone mass and bone mineral density which can be detected by dual energy X-ray absorptiometry (DEXA) scan.

Recombinant human growth hormone increases IGF-1 levels and improves growth velocity, lean tissue mass and bone density in children with CF (Hardin 1997; Huseman 1996). Improved linear growth can improve pulmonary function, exercise capacity, reduce infection rates and provide a better quality of life (Beker 2001; Corey 1988). It was also noted that rhGH reduced TNF-alpha in people with $\mathrm{CF}$ and reduces protein degradation (Hardin 2001).

\section{Why it is important to do this review}

Recombinant growth hormone therapy has potential side effects such as impairment in glucose metabolism. Presently there is no agreement on the use of rhGH therapy in individuals with CF. A systematic review of the use of rhGH in people with $\mathrm{CF}$ is needed to evaluate the treatment outcomes before justifying treatment. If a systematic review of the studies reveals a benefit in pulmonary function, the quality of life, and morbidity (including hospitalisations) for people with $\mathrm{CF}$, this will serve as an important adjunct to their current therapy.

This is an update of a previously published review (Thaker 2013).

\section{OBJECTIVES}

To evaluate the effectiveness and safety of rhGH therapy in improving lung function, quality of life and clinical status of children and young adults with CF.

\section{METHODS}

\section{Criteria for considering studies for this review}

Types of studies-Randomised controlled trials (RCTs) and quasi-randomised controlled trials. 
Types of participants-Participants of either sex up to the age of 25 years with a confirmed diagnosis of CF (e.g. by sweat test or molecular diagnosis) who have not received rhGH therapy in the previous six months.

Types of interventions-Recombinant human growth hormone therapy of any dose compared to placebo, no treatment or a different dose regimen.

\section{Types of outcome measures}

\section{Primary outcomes:}

1. Pulmonary function tests

i. forced expiratory volume at one second $\left(\mathrm{FEV}_{1}\right)(\%$ predicted or litres)

ii. forced vital capacity (FVC) (\% predicted or litres)

iii. maximal inspiratory pressure (PImax)

iv. maximal expiratory pressure (PEmax)

2. Nutritional parameters

i. height $(\mathrm{cm})$ and height $\mathrm{z}$ score or standard deviation score (SDS)

ii. weight $(\mathrm{kg})$ and weight $\mathrm{z}$ score or SDS

iii. height velocity

iv. weight velocity

v. lean body mass measured by DEXA scan

3. Quality of life (QoL) (measured by a validated tool such as the Cystic Fibrosis Questionnaire-Revised version (CFQ-R (Quittner 2009)) and the Cystic Fibrosis Quality of Life Questionnaire (CFQoL (Gee 2000))

\section{Secondary outcomes:}

1. Impact of rhGH therapy on blood glucose abnormality

i. impact on fasting insulin levels in non-diabetic participants (by measuring insulin levels)

ii. fasting and post-prandial blood glucose levels (haemoglobin A1c levels and oral glucose tolerance tests)

iii. change in exogenous insulin requirements and blood sugar control in diabetic participants

2. Muscular strength and exercise capacity

i. changes in overall muscle strength (as measured by hand grip or bicycle ergometry (post hoc change))

ii. six-minute walk 
3. Serum insulin-like growth factor-1(IGF-1) levels and insulin-like growth factor binding protein 3 (IGFBP-3) levels

4. Change in disease exacerbation

i. hospitalisation
a. frequency
b. duration

ii. need for antibiotics
a. oral
b. intravenous

5. Any adverse effects reported

i. mild, requiring no treatment (e.g. transient glucosuria, transient splenomegaly and muscular prominence)

ii. moderate, requiring treatment (e.g. benign intracranial hypertension, effects on glucose metabolism)

iii. life-threatening or severe (requiring hospitalisation) (e.g. slipped capital epiphyses, incidence of malignant disease)

6. Cost

\section{Search methods for identification of studies}

Electronic searches-We identified relevant studies from the Group's Cystic Fibrosis Trials Register using the terms: treatment of growth failure AND (rhGH OR not stated).

The Cystic Fibrosis Trials Register is compiled from electronic searches of the Cochrane Central Register of Controlled Trials (CENTRAL) (updated each new issue of The Cochrane Library), quarterly searches of MEDLINE, a search of EMBASE to 1995 and the prospective handsearching of two journals - Pediatric Pulmonology and the Journal of Cystic Fibrosis. Unpublished work is identified by searching the abstract books of three major cystic fibrosis conferences: the International Cystic Fibrosis Conference; the European Cystic Fibrosis Conference and the North American Cystic Fibrosis Conference. For full details of all searching activities for the register, please see the relevant sections of the Cochrane Cystic Fibrosis and Genetic Disorders Group Module.

Date of the latest search: 11 February 2015.

We conducted a search of relevant endocrine journals and proceedings of the Endocrinology Society meetings. We used Scopus and Proceedings First to conduct this search (Appendix 2).

Date of the latest search: 04 March 2015.

The web site www.clinicaltrials.gov was searched for ongoing clinical trials (Appendix 3). 
Date of latest search: 06 March 2015.

Searching other resources-The bibliographic references of identified studies were reviewed for references to additional studies.

\section{Data collection and analysis}

Selection of studies-Two authors (VT and BH) independently assessed the abstracts of studies resulting from the searches. We obtained full copies of all relevant and potentially relevant studies (those appearing to meet the inclusion criteria, and for which there were insufficient data in the title and abstract to make a clear decision). The two review authors (VT and BH) then independently assessed the full text papers and resolved any disagreement on the eligibility of included studies through discussion and consensus or, if necessary, through a third author $(\mathrm{VJ})$. We then excluded those records that did not meet the inclusion criteria and we noted the reasons for their exclusion in the 'Characteristics of excluded studies' table in the review.

Data extraction and management-We entered study details into the 'Characteristics of included studies' table in the review and collected outcome data using a pre-determined form designed for this purpose. Two authors (VT and BH) independently extracted data and only included data for which there was a consensus. We resolved any disagreements by consulting with a third review author (VJ).

The following details were extracted:

1. Trial methods:

i. method of allocation;

ii. allocation concealment;

iii. masking of participants, trialists and outcome assessors;

iv. exclusion of participants after randomisation and proportion and reasons for losses at follow-up.

2. Participants:

i. country of origin and study setting;

ii. sample size;

iii. age;

iv. gender;

v. inclusion and exclusion criteria.

3. Intervention:

i. study duration;

ii. type;

iii. concentration, dose and frequency; 
iv. duration of intervention in follow-up.

4. Control:

i. type;

ii. concentration, dose and frequency;

iii. duration of intervention in follow-up.

5. Outcomes:

i. primary and secondary outcomes mentioned in the Types of outcome measures section of this review.

If stated, the sources of funding of any of the included studies were recorded.

We used this information to help assess heterogeneity and the external validity of any included trials.

We used the Review Manager software developed by the Cochrane Collaboration for data organising and analysis (RevMan 2011).

Assessment of risk of bias in included studies-Each review author graded the selected trials using a simple contingency form and followed the domain-based evaluation described in Chapter 8 of the Cochrane Handbook for Systematic Reviews of Interventions (Higgins 2011a). The authors compared the evaluations and discussed and resolved any inconsistencies in these evaluations.

We assessed the following domains as having either a low, unclear or high risk of bias:

1. sequence generation;

2. allocation concealment;

3. blinding (of participants, personnel and outcome assessors);

4. incomplete outcome data;

5. selective outcome reporting;

6. other bias.

We categorized the risk of bias in any included study according to the following:

- low risk of bias (plausible bias unlikely to seriously alter the results) if all criteria were met;

- unclear risk of bias (plausible bias that raises some doubt about the results) if one or more criteria were assessed as unclear; or

- high risk of bias (plausible bias that seriously weakens confidence in the results) if one or more criteria were not met.

We report these assessments in the table 'Risk of bias in included studies' in the review. 
Measures of treatment effect-For dichotomous outcomes, we reported the results as the relative risk (RR) with 95\%confidence intervals (CI). For continuous outcomes, we reported the mean relative change from baseline for each group or mean post-intervention values and their standard deviations (SD). We used the Cochrane Review Manager software to analyse the data (RevMan 2011). We reported data as the mean difference (MD) or standardised mean difference (SMD) if different units are used with 95\% CIs.

We processed data according to the intention-to-treat principle, using in the denominator the number of randomised participants. We assumed missing values for outcome measures to represent a poor outcome for both groups.

Unit of analysis issues-We did not include any cluster RCTs, and we reported repeated measures studies that collected multiple time points for outcomes at clinically relevant time points as discussed in Section 16.3.4 of the Cochrane Handbook for Systematic Reviews of Interventions (Higgins 2011b).

We have included data from the first period of cross-over trials. We have excluded data from later periods of cross-over studies as the duration of treatment effect and the disease effect are more likely to develop over different time periods and the appropriate wash-out period cannot be clearly defined.

Dealing with missing data-We contacted primary research investigators about missing data from included and ongoing trials. We have provided a narrative synthesis of information where data were not provided. We will update the review with new information when this becomes available.

Assessment of heterogeneity-We assessed clinical heterogeneity by examining the characteristics of the studies, the similarity between the types of participants, the interventions and the outcomes as specified in the criteria for included studies. We used the $\mathrm{I}^{2}$ statistic to assess heterogeneity. If we found moderate levels of heterogeneity for the primary outcomes ( $\mathrm{I}^{2}$ greater than $50 \%$ ), we would have explored reasons for heterogeneity using subgroup analysis. We considered heterogeneity to be significant when the $\mathrm{P}$ value was less than 0.10 (Higgins 2003).

Assessment of reporting biases-We planned to assess publication bias according to the recommendations on testing for funnel plot asymmetry (Egger 1997) and as described in section 10.4.3.1 of the Cochrane Handbook for Systematic Reviews of Interventions (Sterne 2011); however, we were unable to do so due to a lack of data available for analysis.

Data synthesis-For the synthesis and meta-analysis of any quantitative data we used the random-effects model. We did not consider it appropriate to combine data for any outcome due to the differences in participant characteristics where trial data were reported at the same time points.

We sought statistical support from the Cystic Fibrosis and Genetic Disorders Group. Two review authors (VT, BC) analysed data reported in the included studies and relevant to the 
primary and secondary outcomes of this review using the Review Manager software (RevMan 2011). We report results as suggested in Chapter 9 of the Cochrane Handbook for Systematic Reviews of Interventions (Deeks 2011).

Subgroup analysis and investigation of heterogeneity-We did not perform any subgroup analyses at this time due to the small amount of data, the inability to obtain raw data and the absence of heterogeneity. In future updates, if further studies are identified, we will undertake subgroup analyses for the following groups:

1. Tanner stage of puberty (Tanner 1962);

2. sex;

3. baseline nutritional or anthropometric status;

4. lung function $\left(\mathrm{FEV}_{1}<50 \%, 50 \%\right.$ to $80 \%$ and $\left.>80 \%\right)$.

Sensitivity analysis-We planned to perform sensitivity analyses when we were able to combine a sufficient number of studies and when we noted a high degree of statistical heterogeneity that could not be reasonably explained. No meta-analyses were performed for this review. If further data become available in future, we plan to undertake sensitivity analyses to assess the robustness of our review results by repeating the analysis with the following adjustments: exclusion of studies with unclear or inadequate allocation concealment; unclear or inadequate blinding of outcomes assessment; and completeness of follow-up.

\section{RESULTS}

\section{Description of studies}

Results of the search-The electronic searches retrieved 40 references. After examination of the titles and abstracts of these references, we eliminated from the review any studies that did not match our inclusion criteria and were clearly ineligible. We obtained full text copies of the 22 potentially eligible studies and subjected these to further evaluation. The review authors discussed the eligibility of these studies, resolved any remaining uncertainties by consensus. Ten studies were found likely eligible; four are included in the review (Hütler 2002; Schibler 2003; Schnabel 2007; Stalvey 2011) and six are listed as 'Awaiting classification' pending verification of data (Bucuvalas 2001; Hardin 2001; Hardin 2005a; Hardin 2005b; Hardin 2006; Schnabel 1997). We excluded 12 studies (Alemzadeh 1998; Darmaun 2004; Eubanks 2002; Hardin 1997; Hardin 1998; Hardin 2005c; Huseman 1996; Kissner 2000; Marchand 2000; Sackey 1995; Safai-Kutti 1991; Vanderwel 2006). This process is shown in a PRISMA diagram (Figure 1). Our search of the clinical trials database (clinicaltrials.gov) retrieved two additional ongoing studies, which will be assessed for inclusion as soon as they are published (Hardin 2008; Lippe 2008).

\section{Included studies}

Methods: Four published studies are included in this review. Two of the studies were randomised controlled studies of parallel design (Schnabel 2007; Stalvey 2011). One was a 
cross-over study with two periods of treatment without any washout period in between (Hütler 2002). One study was quasi-randomised, where sex- and age-matched pairs were recruited and randomly assigned to treatment (Schibler 2003).

One of the studies was double-blinded and used three treatment arms - low-dose, high-dose, and placebo (Schnabel 2007). The double-blind phase in the treatment arms lasted for 24 weeks, following which the controls were randomly assigned to one of the two doses of the rhGH for an additional 24 weeks. Another study was of cross-over design where participants received rhGH or no treatment for six months and then crossed over to the alternative treatment for a further six months (Hütler 2002). The minimum duration of treatment in two studies was one year (Schibler 2003; Stalvey 2011).

Participants and settings: A total of 161 participants provided data for the four included studies. All studies included diagnosed cases of CF, either by sweat testing or presence of the CFTR gene. The age range of participants was from 7 years to 23 years, although most of the studies recruited younger participants in Tanner Stage 1 of sexual maturity staging. The height and weight percentile of the participants ranged from below the 10th to below the 25th percentile for age and gender. Most of the study participants were in a stable disease state with no colonisation with Burkholderia cepacia (B. cepacia) and no recent use of systemic or oral steroids. Most of the studies excluded participants with evidence of glucose intolerance or active CF-related diabetes (CFRD). All of the studies were carried out at tertiary care $\mathrm{CF}$ centres in outpatient settings. Two of the studies were single centre (Hütler 2002; Schibler 2003); two were conducted at more than one site (Schnabel 2007; Stalvey 2011).

Interventions: The intervention was daily subcutaneous injections of rhGH. One study used the brand Nutropin $\mathrm{AQ}^{\circledR}{ }^{\circledR}$ (Genentech Inc.) in the dose of $0.3 \mathrm{mg} / \mathrm{kg} / \mathrm{week}$ (Stalvey 2011). One study used rhGH (Saizen ${ }^{\circledR}$, Merck Serono S.A.) in the dose of $1 \mathrm{IU} / \mathrm{kg} /$ week (Schibler 2003). In another study, 0.77 to $0.98 \mathrm{IU} / \mathrm{kg} /$ week of rhGH (Genotropin ${ }^{\circledR}$, Pharmacia GmbH, Stockholm, Sweden) was used (Hütler 2002). In the remaining study, two doses of rhGH (so-matotropin) were used - low dose, $0.039 \mathrm{mg} / \mathrm{kg} / \mathrm{day}(0.273 \mathrm{mg} / \mathrm{kg} / \mathrm{week})$ and high dose, $0.070 \mathrm{mg} / \mathrm{kg} / \mathrm{day}(0.49 \mathrm{mg} / \mathrm{kg} /$ week) (Schnabel 2007).

Outcomes measured: All the studies measured two of the primary outcomes included in the review - pulmonary function tests and nutritional parameters. One study measured QoL based on QoL questionnaires (Schnabel 2007). Most of the studies addressed blood glucose abnormality, either in quantitative values or information in the text. One study measured changes in serum markers, either IGF-1 or IGFBP3 (Schnabel 2007). The same study measured changes in disease exacerbation or use of antibiotics, or both (Schnabel 2007). Three studies measured exercise capacity - albeit using different parameters (Hütler 2002; Schibler 2003; Schnabel 2007). None of the studies evaluated the cost of the therapy.

Studies Awaiting Classification-Six studies are awaiting classification (Bucuvalas 2001; Hardin 2001; Hardin 2005a; Hardin 2005b; Hardin 2006; Schnabel 1997). We are waiting for responses from the authors on the verification of data before we can include 
these studies in the review. Further information on these studies is available in the Characteristics of studies awaiting classification.

Excluded studies-Twelve studies were excluded from the review; seven as they were not randomised (Alemzadeh 1998; Hardin 1997; Hardin 1998; Hardin 2005c; Huseman 1996; Sackey 1995; Vanderwel 2006), one as glutamine was used in conjunction with rhGH (Darmaun 2004), two because an appetite stimulant (megestrol acetate) was used and not rhGH (Eubanks 2002; Marchand 2000), one discussed as study of progestational agents and not rhGH (Kissner 2000), and one was a study of oral zinc supplementation and not rhGH (Safai-Kutti 1991). Further information on these studies is available in the Characteristics of excluded studies.

\section{Risk of bias in included studies}

We classified the risks of bias for the four included studies in this review as previously described (Assessment of risk of bias in included studies).

We judged all of the included studies as having an 'unclear' risk of bias overall. We based these assessments to a certain extent on the inadequate reporting of several of the criteria that are considered to be important in the evaluation of methodological rigour in terms of study design and conduct. For further details, please see the risk of bias tables in Characteristics of included studies, the risk of bias graph (Figure 2) and the risk of bias summary (Figure 3).

\section{Allocation}

Generation of allocation sequence: Stalvey reported the use of a permuted block randomisation scheme developed by an interactive voice response development system at each site, hence we judged this study to have a low risk of bias (Stalvey 2011). None of the remaining three studies described details of the generation of allocation sequence and hence we classified these as having an unclear risk of bias (Hütler 2002; Schibler 2003; Schnabel 2007).

Concealment of allocation: Stalvey stated that "For this open-label trial, there was no allocation concealment."; so we judged this to have a high risk of bias (Stalvey 2011). None of the remaining studies described how the allocation sequence was concealed, which did not allow us to determine whether intervention allocations could have been foreseen in advance of, or during, enrolment. We therefore judged these three studies to have an unclear risk of bias for this criteria (Hütler 2002; Schibler 2003; Schnabel 2007).

Inadequate reporting quality did not permit us to make a clear judgement across both domains in any of the included studies.

Blinding: Three of the four included studies did not report on the measures used to blind trial participants and personnel from knowledge of which intervention a participant received or supply any information relating to whether the intended blinding was effective (Hütler 2002; Schibler 2003; Stalvey 2011). All of these studies used injections of rhGH with no treatment as the control. It is unlikely that the participants and healthcare providers could 
have been blinded. Therefore the judgement given for this domain in these studies was 'unclear'.

In one of the studies, participants were grouped into low-dose, high-dose and placebo (Schnabel 2007). It is noted in the manuscript that participants and healthcare providers were blinded and hence the overall judgement is 'low risk'.

It is unclear in all studies whether the outcome assessors or data analysts were blinded.

Incomplete outcome data: There were no withdrawals and no missing or incomplete data in one of the included studies (Hütler 2002). The Schibler study describes the withdrawal of one control evaluated for lung transplantation, likely due to worsening of the disease (Schibler 2003). We judged these studies as having a low risk of bias. The Schnabel study reports the analysis of 63 out of the 67 participants enrolled, but with no details on the withdrawals (Schnabel 2007). This study is judged to have an unclear risk of bias. Stalvey enrolled 68 participants and reports results on efficacy on 53 participants only (Stalvey 2011). Several reasons including loss to follow-up, death of one participant and improper study practices at one centre have been reported for the discrepancy. This study has been classified as high risk of bias due to loss of $22 \%$ participants in the efficacy analysis (Stalvey 2011).

Selective reporting: Although no study protocols were available, based on information presented in the methods sections of each of the reports, the investigators appear to have reported on all of their stated objectives and expected outcomes, a number of which were pre-specified inclusion criteria for this systematic review. We therefore judge there to be a low risk of bias from selective reporting for these studies (Hütler 2002; Schibler 2003; Schnabel 2007, Stalvey 2011).

Other potential sources of bias: All of the included studies were supported in some part by pharmaceutical companies, Pharmacia GmbH (Hütler 2002); Merck Serono SA (Schibler 2003); Pharmacia GmbH (Schnabel 2007) and Genetech Inc. (Stalvey 2011). The effect, if any, of this support on the results is unclear.

\section{Effects of interventions}

Recombinant growth hormone (standard dose) versus placebo-Only one study was conducted initially over 24 weeks as a double-blind study with two different doses of rhGH compared with placebo followed by another 24 weeks of open-labelled hormone use (Schnabel 2007). Data from the end of first 24 weeks (double-blinded) are reported in the review; in this section the data for standard dose of rhGH versus placebo are presented.

\section{Primary outcomes}

\section{Pulmonary function tests}

a. $\boldsymbol{F E V} V_{1}$ : Schnabel reported change in $\mathrm{FEV}_{1}$ from baseline (Schnabel 2007). At six months the $\%$ change in $\mathrm{FEV}_{1}$ from baseline was not statistically significant, $\mathrm{MD} 2.50(95 \% \mathrm{CI}$ -8.60 to 13.60) (Analysis 1.1), nor was the change in SD score, MD 0.07 (95\% CI -0.16 to 
0.30) (Analysis 1.2). From these data there was no evidence of a suggested treatment effect from rhGH in any $\mathrm{FEV}_{1}$ outcome.

b. FVC: Schnabel also reported FVC as the \% change from baseline; this was also not significant, MD $3.80 \%$ (95\% CI -4.72 to 12.32 ) (Analysis 1.3 ).

\section{Nutritional parameters}

a. Height: Schnabel reported data on height $\mathrm{z}$ score at six months (Schnabel 2007). These data show a non-significant difference between rhGH and placebo, MD 2.50 (95\% CI -0.77 to 5.77) (Analysis 1.4).

b. Weight: Schnabel also reported the change in weight from baseline in $\mathrm{kg}$ at six months (Schnabel 2007). This result was not statistically significant, MD 1.00 (95\% CI -0.08 to 2.08) (Analysis 1.5).

c. Height velocity: Schnabel reported height velocity (SD score) at six months (Schnabel 2007). When entered in the analysis these data showed a significant difference in favour of rhGH, MD 2.10 (95\% CI 0.54 to 3.66) (Analysis 1.6).

d. Weight velocity: Schnabel did not report on this outcome (Schnabel 2007).

e. Lean body mass: The Schnabel study reported data on lean body mass using a DEXA scan at six months (Schnabel 2007), but the difference between treatment and placebo groups was not statistically significant, MD $1.00 \mathrm{~kg}$ (95\% CI -0.40 to 2.40) (Analysis 1.7).

3. QoL: The Schnabel study also reported QoL using standardised CFHR-QoL questionnaires, but did not provide data we could enter into the analysis (Schnabel 2007). Within the published paper, Schnabel reported no major differences among the treatment groups (Schnabel 2007).

\section{Secondary outcomes}

\section{Impact of rhGH therapy on blood glucose abnormality}

a. Impact on fasting insulin levels in non-diabetic participants: Schnabel did not report on this outcome (Schnabel 2007).

b. Fasting and post-prandial blood glucose levels: Fasting blood glucose are reported by Schnabel at six months (Schnabel 2007). Data show a significant increase in the rhGH treatment group, MD 12.40 (95\% CI 3.76 to 21.04) (Analysis 1.8). However, the difference in post-prandial glucose levels is not significant, MD $12.10 \mathrm{mg} / \mathrm{dl}$ (95\% CI -7.18 to 31.38) (Analysis 1.9).

c. Change in exogenous insulin requirements and blood sugar control in diabetic participants: None of the participants in the Schnabel trial had diabetes (Schnabel 2007). 


\section{Muscular strength and exercise capacity}

a. Changes in overall muscle strength: Exercise capacity and muscle strength were measured by Schnabel using a bicycle ergometer (Schnabel 2007). Data showed a nonstatistically significant difference, MD 9.80 watts (95\% CI -0.90 to 20.50) (Analysis 1.10). Schnabel also measured peak oxygen utilisation during exercise ( $\mathrm{VO} 2 \mathrm{max}$ ) in $\mathrm{ml} / \mathrm{min}$ (Schnabel 2007). When entered in the analysis data for this outcome were also not statistically significant, MD 10.10 (95\% CI -3.85 to 24.05) (Analysis 1.11).

b. Six-minute walk: Schnabel did not report on this outcome (Schnabel 2007).

3. Serum IGF-1 levels and IGFBP-3 levels: Schnabel reported levels of IGF-1 and IGFBP-3 at six months in SD scores (Schnabel 2007). There was a significant difference in IGF-1 in favour of rhGH, MD 1.37 (95\% CI 0.68 to 2.06) (Analysis 1.12), but no significant difference between groups for IGFBP-3, MD 0.65 (95\% CI -0.10 to 1.40) (Analysis 1.13).

\section{Change in disease exacerbation}

a. Hospitalisation - frequency and duration: Schnabel did not report on this outcome (Schnabel 2007).

b. Need for antibiotics: Schnabel reported that there were similar numbers of pulmonary exacerbations in each of the treatment arms, RR 1.50 (95\% CI 0.49 to 4.59) (Analysis 1.14).

5. Adverse effects: Schnabel reports the number participants experiencing at least one adverse event in the groups and number of participants with severe adverse events, but not categorised as outlined in the review protocol. There was no difference in the total number participants experiencing at least one adverse event between the two groups, RR 1.08 (95\% CI 0.67 to 1.72) (Analysis 1.15). The range of adverse events was wide (pulmonary exacerbation, haemoptysis, pneumothorax, productive cough, Candida sepsis, distal intestinal obstruction syndrome, hyperglycaemia, convulsion, Port-a-cath blockage and ligament rupture) but the paper only reported these by number of events and not by the number of participants experiencing these events so we are not able to analyse these here.

a. Mild (requiring no treatment): Schnabel did not report on this outcome separate from total adverse events (Schnabel 2007).

b. Moderate (requiring treatment): Schnabel reported an equal number of adverse effects observed in all the treatment arms with the commonest adverse effect being pulmonary exacerbations as reported above (Analysis 1.14).

c. Life-threatening or severe (requiring hospitalisation): There was no significant difference in the severe adverse effects reported between the two comparison groups, or for severe adverse events, RR 1.25 (95\% CI 0.39 to 4.05) (Analysis 1.15)

6. Cost: Schnabel did not report on this outcome (Schnabel 2007). 


\section{Recombinant growth hormone (standard dose) versus no treatment}

Three of the included studies compared use of daily subcutaneous injections of rhGH with no treatment (Hütler 2002; Schibler 2003; Stalvey 2011). In the Hütler study, groups receiving rhGH or no treatment were crossed over after six months; only extractable data from the first treatment period is included in the review (Hütler 2002). All other studies had a period of at least one year where the intervention or no treatment control were administered.

\section{Primary outcomes}

\section{Pulmonary function tests}

a. $\boldsymbol{F E V} V_{1}$ : Three studies reported $\mathrm{FEV}_{1}$ at six or 12 months in various formats: $\mathrm{FEV}_{1}$ (\% predicted) (Stalvey 2011); change in $\mathrm{FEV}_{1}$ (\% predicted) from baseline (Schibler 2003); change from baseline in $\mathrm{FEV}_{1}$ (litres) (Hütler 2002). At 12 months the $\mathrm{FEV}_{1}$ (\%predicted) difference between the treatment and no treatment groups was MD -11.00 (95\% CI -22.65 to 0.65 ) (Analysis 2.1). The change in $\mathrm{FEV}_{1}$ (\% predicted) between the treatment and no treatment groups was reported at two time-points: Schibler reported this outcome at six months, MD -2.20 (95\% CI -5.40 to 1.00 ); and at 12 months, MD 1.20 (95\% CI -2.41 to 4.81) (Analysis 2.2). Hütler reported the change in $\mathrm{FEV}_{1}$ from baseline at six months, $\mathrm{MD}$ 0.04 (95\% CI -0.17 to 0.25 ) (Analysis 2.3). From these data there was no evidence of a suggested treatment effect from rhGH in any $\mathrm{FEV}_{1}$ outcome.

b. FVC: Two studies reported data for FVC at six or 12 months in the following formats: FVC (\% predicted) (Stalvey 2011) and change in FVC (\% predicted) from baseline (Schibler 2003). Analyses of data for FVC (\% predicted) from 56 participants at 12 months shows MD -6.00 (95\%CI -16.62 to 4.62) (Analysis 2.4). Schibler reported the change in FVC from baseline between treatment and control at six months, MD 1.40 (95\%CI -1.39 to 4.19$)$ and at 12 months, MD 3.20 (95\% CI 0.48 to 5.92) (Analysis 2.5). There was evidence of a suggested treatment effect found in the change in FVC at 12 months, where rhGH treatment improved FVC.

c. $\boldsymbol{P I}_{\text {max }}$ : None of the included studies reported on this outcome.

d. $P E_{\max }:$ None of the reported studies reported on this outcome.

\section{Nutritional parameters}

a. Height: Three studies have reported data on height at six or 12 months in following formats: z score (Stalvey 2011); change in height from baseline (cm) (Hütler 2002; Stalvey 2011); and height velocity (cm/year) (Stalvey 2011). Height z score improved significantly between rhGH treatment and no treatment at 12 months, MD 0.50 (95\% CI 0.23 to 0.77 ) (Analysis 2.6). There were improvements in height $(\mathrm{cm})$ at both six and 12 months; change in height from baseline at six months, SMD $1.11(95 \% \mathrm{CI}-0.30$ to 2.52$)(\mathrm{P}=0.12)$ and at 12 months, SMD 1.53 (95\% CI 0.96 to 2.10) (P < 0.00001) (Analysis 2.7).

b. Weight: Three of the included studies have reported data on changes in weight at six or 12 months; as weight $\mathrm{z}$ score in one study (Schibler 2003) and change in weight from 
baseline in two studies (Hütler 2002; Stalvey 2011). Data from the study with weight z score showed no statistically significant difference at six months, MD $-0.89(95 \% \mathrm{CI}-1.84$ to $0.07)(\mathrm{P}=0.07)$ or at 12 months, $\mathrm{MD} 0.08(95 \% \mathrm{CI}-0.82$ to 0.98$)\left(\mathrm{P}=0.005, \mathrm{I}^{2}=0 \%\right)$ (Analysis 2.8). Change in weight from baseline measured in $\mathrm{kg}$ was not significant at six months, MD 1.00 (95\% CI -0.22 to 0.22$)(\mathrm{P}=0.11)$, but was significant at 12 months, MD 1.00 (95\% CI 0.18 to 1.82$)(\mathrm{P}=0.02)$ (Analysis 2.9$)$. The above meta-analyses suggest some improvement in the participants who received rhGH.

c. Height velocity: One study reported height velocity (cm/year) at 12 months (Stalvey 2011). Data from this study show a significant increase in favour of rhGH therapy, MD 2.90 (95\% CI 2.04 to 3.76) $(\mathrm{P}<0.00001)$ (Analysis 2.10).

d. Weight velocity: None of the studies have reported data on weight velocity.

e. Lean body mass: All included studies have reported data on lean body mass using a DEXA scan, one at six months (Hütler 2002) and two at 12 months (Schibler 2003; Stalvey 2011). Data from the Hütler study at six months show a MD of 2.20 (95\% CI 1.27 to 3.13) (P< 0.0001) (Hütler 2002). The data at 12 months are not combined as the participants in the Schibler study were predominantly boys in an age group that likely spans puberty (10 to 23 years), but pubertal status of these participants was not reported (Schibler 2003). Puberty may influence lean tissue mass independent of rhGH therapy; hence, no meta-analysis was performed. Schibler reports an MD of lean tissue mass as 2.50 (95\% CI 1.85 to 3.15) (P value < 0.0001) (Schibler 2003). Analysis of data from Stalvey shows an MD in lean tissue mass of 1.40 (95\% CI 0.60 to 2.20) (P < 0.0001) (Stalvey 2011). Each of these individual data sets show a significant increase in the lean tissue mass at the end of the study period (Analysis 2.11).

3. QoL: None of the included studies have reported data on QoL outcomes.

\section{Secondary outcomes}

\section{Impact of rhGH therapy on blood glucose abnormality}

a. Impact on fasting insulin levels in non-diabetic participants: Serum insulin levels were measured at 12 months in one study (Stalvey 2011). Analysis showed no significant change, $\mathrm{MD}-0.30 \mathrm{mg} / \mathrm{dl}$ (95\% CI -3.74 to 3.14) (Analysis 2.12).

b. Fasting and post-prandial blood glucose levels: Fasting blood glucose levels are reported by two studies at 12 months (Schibler 2003; Stalvey 2011). These data were not combined in a meta-analysis and are presented separately, albeit on the same graph. There is a significant variation in the age range of the participants in the two studies, in the Schibler study ages ranged from 10 years to 23 years (Schibler 2003); and in the Stalvey study ages ranged from 5.2 years to 13.4 years (Stalvey 2011). It is possible that the older age group represents an advancement of the disease that is also associated with increasing incidence of glucose intolerance. Analysis of data from Schibler showed a statistically significant difference in the fasting blood glucose levels, MD $12.50 \mathrm{mg} / \mathrm{dl}$ (95\% CI 5.12 to 19.88) (P < 0.0001) (Schibler 2003). However, this difference is not clinically relevant as diagnosis of 
glucose intolerance can be made only if FBG $>126 \mathrm{mg} / \mathrm{dl}$. The MD of the data from the Stalvey study is $1.10 \mathrm{mg} / \mathrm{dl}$ (95\% CI -5.61 to 7.81) (P value 0.75) (Stalvey 2011).

Therefore, there was unclear evidence for effect of rhGH on fasting blood glucose (Analysis 2.13).

Data for post-prandial blood sugar from one study at 12 months show no significant difference, $\mathrm{MD}-27.00 \mathrm{mg} / \mathrm{dl}(95 \% \mathrm{CI}-60.26$ to 6.26$)(\mathrm{P}=0.11)$ (Analysis 2.14$)$. The same study reported the change of haemoglobin A1c levels from baseline, MD 0.14 (95\% CI -0.30 to 0.58$)(\mathrm{P}=0.54)$ (Schibler 2003) (Analysis 2.15).

\section{c. Change in exogenous insulin requirements and blood sugar control in diabetic} participants: One study included five participants with impaired glucose tolerance (IGT) (three in the treatment group and two in the control group) (Stalvey 2011). Two participants in the treatment group had normal oral glucose tolerance tests (OGTT) at the end of the study. In each of the study groups, three participants developed IGT and one developed CFrelated diabetes mellitus (CFRD) at the end of treatment period (12 months). On further follow-up to 18 months without any intervention, two additional participants in the rhGH treatment group developed IGT and one CFRD. At similar follow-up in the control group, one participant developed IGT. Other studies excluded participants with IGT or diabetes and do not report the incidence of new cases.

\section{Muscular strength and exercise capacity}

a. Changes in overall muscle strength: Exercise capacity and muscle strength were measured in two studies using a bicycle ergometer (Hütler 2002; Schibler 2003). The paper by Hütler provided a graph showing the increase in the peak power output in terms of absolute (18\%) and age-predicted (14\%) values (Hütler 2002). The study by Schibler reported an increase in the maximum exercise capacity measured in watts (Wmax), representing an increase in muscle mass, in favour of the rhGH treatment group, MD at six months 23.10 watts (95\% CI 15.58 to 30.62) (P < 0.0001) and at 12 months, MD 31.90 watts (95\% CI 22.68 to 41.12) ( $\mathrm{P}<0.0001$ ) (Analysis 2.16). Peak oxygen utilisation during exercise (VO2 max) was measured in the same studies, albeit in different units (Hütler 2002; Schibler 2003). Data from Hütler at six months show MD $3.65 \mathrm{ml} / \mathrm{min}(95 \%$ CI 0.60 to 6.70) and from Schibler at 12 months, MD $6.10 \mathrm{ml} / \mathrm{kg} / \mathrm{min}$ (95\% CI 4.29 to 7.91) in favour of rhGH treatment (Analysis 2.17).

b. Six-minute walk: Stalvey measured exercise capacity using the six-minute walk test (Stalvey 2011). There was no significant improvement in 33 participants treated with rhGH versus 29 participants who received no treatment, MD 25.90 metres ( $95 \% \mathrm{CI}-43.57$ to 95.37) (Analysis 2.18).

3. Serum IGF-1 levels and IGFBP-3 levels: These results were not reported in the included studies. 


\section{Change in disease exacerbation}

a. Hospitalisation - frequency and duration: None of the studies presented data for this outcome.

b. Need for antibiotics - oral and intravenous: Stalvey stated that the number of pulmonary exacerbations were reported equally by the two groups (Stalvey 2011).

5. Adverse effects: Stalvey reported that 10 participants experienced drug-related adverse events, RR 18.73 (95\% CI 1.14 to 307.37) (Analysis 2.19).

a. Mild, requiring no treatment: None of the studies mention the presence of adverse effects which did not require treatment. It is important to mention that subcutaneous injection of rhGH can be perceived as a burden of treatment. In one study, seven participants reported injection-site bruising, RR 13.38 (95\% CI 0.79 to 225.34) (Analysis 2.19).

b. Moderate, requiring treatment: Stalvey reported a similar number of pulmonary exacerbations in the two groups. Additionally, they reported five participants in the rhGH group and seven participants in the control group with hyperglycaemia, RR 0.63 (95\% CI 0.22 to 1.80 ) (Analysis 2.19); one of those in the rhGH group had to discontinue the study (Stalvey 2011). One additional participant in the rhGH group had papilledema and headache after five months of rhGH therapy, RR 2.68 (95\% CI 0.11 to 63.45) and RR 2.68 (95\% CI 0.11 to 63.45 ) respectively (Analysis 2.19); the authors conclude this event was rhGH therapy-related benign intracranial hypertension which resolved with discontinuation of treatment (Stalvey 2011).

c. Life-threatening or severe (requiring hospitalisation): Stalvey reported one death due to respiratory failure three months after the 12-month visit, RR 2.68 (95\%CI 0.11 to 63.45); however, the authors postulate this is unrelated to the study (Stalvey 2011). Hospitalisations as a result of disease exacerbations have been reported earlier.

6. Cost: There was a difference in reports on the cost-benefit analysis of therapy. Therapy with rhGh is expensive and Schibler reports that the cost of the treatment may not be justified for the modest increase in exercise capacity and lean body mass (Schibler 2003).

\section{High-dose rhGH versus placebo}

One study reported the use of high-dose rhGH treatment compared with placebo with data reported at six months (Schnabel 2007). The group of participants receiving placebo in this comparison are the same as that used in the prior comparison with standard dose.

\section{Primary outcomes}

\section{Pulmonary function tests}

a. $F E V_{1}$ : There was no statistically significant difference between the high-dose rhGH group and controls in $\mathrm{FEV}_{1}$ (\% predicted), MD 3.30 (95\% CI -8.16 to 14.76) $(\mathrm{P}=0.57$ ) or change in $\mathrm{FEV}_{1} \mathrm{SD}$ score, $\mathrm{MD}-0.01(95 \% \mathrm{CI}-0.24$ to 0.22$)(\mathrm{P}=0.93)$ (Analysis 3.1; Analysis 3.2). 
b. FVC: There was no statistically significant difference between high-dose rhGH participants and controls in FVC (\% predicted), MD 6.70 (95\% CI -1.41 to 14.81) (P = 0.11) (Analysis 3.3).

\section{Nutritional parameters}

a. Height: Data were not available for comparison of height of the two groups in this study (Schnabel 2007).

b. Weight: No significant difference in the change in weight from baseline was noted in the two groups, MD 0.80 (95\% CI -0.44 to 2.04) $(\mathrm{P}=0.21)$ (Analysis 3.4).

c. Height velocity: There is a significant benefit of rhGH treatment in height velocity (change from baseline) when measured with SD score, MD 3.60 (95\% CI 0.30 to 6.90) $(\mathrm{P}=$ 0.03) (Analysis 3.5) and cm/year, MD 3.30 (95\% CI 1.17 to 5.43) ( $\mathrm{P}=0.002)$ (Analysis 3.6).

d. Weight velocity: No data for weight velocity were available for analysis (Schnabel 2007).

e. Lean body mass: No statistically significant difference in the lean tissue mass is seen between the high-dose rhGH group and the placebo group, MD 0.80 (95\% CI -0.67 to 2.27) $(\mathrm{P}=0.29)$ (Analysis 3.7).

3. QoL: The Schnabel study also reported QoL using standardised CFHR-QoL questionnaires, but did not provide data we could enter into the analysis (Schnabel 2007). Within the published paper, Schnabel reported no major differences among the treatment groups (Schnabel 2007).

\section{Secondary outcomes}

\section{Impact of rhGH therapy on blood glucose abnormality}

a. Impact on fasting insulin levels in non-diabetic participants: No study data are available for this outcome (Schnabel 2007).

b. Fasting and post-prandial blood glucose levels: No statistically significant difference in the fasting blood glucose levels was noted in the high-dose rhGH group and the placebo group, MD 8.00 (95\% CI -0.30 to 16.30) $(\mathrm{P}=0.06$ ) (Analysis 3.8) or post-prandial blood sugar, MD $4.60(95 \% \mathrm{CI}-23.32$ to 32.52$)(\mathrm{P}=0.75)$ (Analysis 3.9).

c. Change in exogenous insulin requirements and blood sugar control in diabetic participants: None of the participants in the Schnabel trial were diabetic (Schnabel 2007).

\section{Muscular strength and exercise capacity}

a. Changes in overall muscle strength: Bicycle ergometry was used for evaluation of muscle strength (Schnabel 2007). No significant difference was found in the exercise capacity in the two groups, MD 4.40 watts (95\% CI -13.20 to 22.00) $(\mathrm{P}=0.62)$ (Analysis 
3.10) or maximal oxygen consumption ( $\mathrm{VO} 2$ maximum ( $\mathrm{ml} / \mathrm{min}))$, MD $24.00(95 \% \mathrm{CI}$ -10.61 to 58.61$)(\mathrm{P}=0.17)$ (Analysis 3.11).

b. Six-minute walk: This test was not used in the Schnabel study (Schnabel 2007).

3. Serum IGF-1 levels and IGFBP-3 levels: Comparison of serum hormone levels showed significant differences between high-dose rhGH and placebo in favour of high-dose rhGH treatment: IGF-1 (SD scores), MD 2.03 (95\%CI 1.18 to 2.88) ( $\mathrm{P}$ < 0.0001) (Analysis 3.12); and IGFBP-3 (SD scores), MD 0.81 (95\% CI 0.11 to 1.51) $(\mathrm{P}=0.02)$ (Analysis 3.13).

4. Change in disease exacerbation: Hospitalisation and antibiotic usage, oral or intravenous, were not reported in the Schnabel study (Schnabel 2007). However, the report does state that pulmonary exacerbations were the most common observed category of adverse event, RR 1.93 (95\% CI 0.66 to 5.61) (Analysis 3.14).

5. Adverse effects: Schnabel reports the number participants experiencing at least one adverse event in the groups and number of participants with severe adverse events, but not categorised as outlined in the review protocol. There was no difference in the total number participants experiencing at least one adverse event between the two groups, RR 1.02 (95\% CI 0.62 to 1.67) (Analysis 3.15). The range of adverse events was wide (pulmonary exacerbation, haemoptysis, pneumothorax, productive cough, Candida sepsis, distal intestinal obstruction syndrome, hyperglycaemia, convulsion, Port-a-cath blockage and ligament rupture) but the paper only reported these by number of events and not by the number of participants experiencing these events so we are not able to analyse these here.

a. Mild, requiring no treatment: Schnabel did not report on this outcome separate from total adverse events (Schnabel 2007).

b. Moderate, requiring treatment: Schnabel reported an equal number of adverse effects observed in all the treatment arms with the commonest adverse effect being pulmonary exacerbations as reported above (Analysis 3.14).

c. Life-threatening or severe (requiring hospitalisation): There was no significant difference in the severe adverse effects reported between the two comparison groups, or for severe adverse events, RR 1.10 (95\% CI 0.32 to 3.83) (Analysis 3.15).

6. Cost: No data were presented on cost of the therapy in the Schnabel study (Schnabel 2007).

High-dose versus standard-dose rhGH-One study compared high-dose rhGH versus standard-dose rhGH (Schnabel 2007). The group of participants receiving high-dose and standard-dose rhGH in this comparison are the same as those presented in the prior comparisons using high-dose and standard dose compared to placebo. 


\section{Primary outcomes}

\section{Pulmonary function tests}

a. $\boldsymbol{F E V _ { 1 }}$ : Data on $\mathrm{FEV}_{1}$ change from baseline are reported in two different formats: $\mathrm{FEV}_{1}$ (\% predicted), MD 1.20 (95\% CI -1.04 to 3.44) ( $\mathrm{P}=0.29$ ) (Analysis 4.1); and change from baseline $\mathrm{FEV}_{1}$ (SD score), MD -0.01 (95\% CI -0.20 to 0.18$)(\mathrm{P}=0.95)$ (Analysis 4.2). Neither of these outcomes are statistically different in the high-dose versus the standarddose rhGH participants.

b. FVC: There was no statistically significant difference in FVC \% predicted between the high-dose and the standard-dose groups, MD $6.70(95 \% \mathrm{CI}-1.29$ to 14.69$)(\mathrm{P}=0.10)$ (Analysis 4.3).

\section{Nutritional parameters}

a. Height: Data on absolute height were not reported in the Schnabel trial (Schnabel 2007).

b. Weight: No significant difference in weight change from the baseline was found in comparing high-dose rhGh to standard-dose therapy, MD 0.80 (95\% CI -0.43 to 2.03$)(\mathrm{P}=$ 0.20) (Analysis 4.4).

c. Height velocity: A significant improvement in the high-dose rhGH group was found from the analysis of height velocity (SD scores), MD 3.60 (95\% CI 0.37 to 6.83) $(\mathrm{P}=0.02)$ (Analysis 4.5) and in $\mathrm{cm} / \mathrm{year}$, MD 3.30 (95\% CI 1.18 to 5.42) ( $\mathrm{P}=0.002$ ) (Analysis 4.6).

d. Weight velocity: No data on this outcome were reported in the Schnabel study (Schnabel 2007).

e. Lean body mass: No significant difference was found in the lean body mass between the high-dose and the standard-dose group, $\mathrm{MD}-0.20(95 \% \mathrm{CI}-1.69$ to 1.29$)(\mathrm{P}=0.79)$

(Analysis 4.7).

3. QoL: No data on this outcome were reported in the Schnabel study (Schnabel 2007).

\section{Secondary outcomes}

\section{Impact of rhGH therapy on blood glucose abnormality}

a. Impact on fasting insulin levels in non-diabetic participants: These data were not reported in the Schnabel study (Schnabel 2007).

b. Fasting and post-prandial blood glucose levels: No significant differences were found in the blood glucose levels, fasting MD $-0.40 \mathrm{mg} / \mathrm{dl}$ (95\% CI -13.05 to 4.25) (Analysis 4.8) or post-prandial, MD $4.60 \mathrm{mg} / \mathrm{dl}$ (95\% CI -23.23 to 32.43) (Analysis 4.9).

c. Change in exogenous insulin requirements and blood sugar control in diabetic participants: None of the participants in the Schnabel study were diabetics or on insulin treatment (Schnabel 2007). 


\section{Muscular strength and exercise capacity}

a. Changes in overall muscle strength: Muscle strength was measured by bicycle ergometry (Schnabel 2007). Two reported outcomes on muscle strength do not show any significant differences between the two groups: exercise capacity MD 4.40 watts $(95 \% \mathrm{CI}-13.12$ to 21.92) (Analysis 4.10); and maximal oxygen consumption, MD 24.00 (95\% CI -10.57 to 58.57) (Analysis 4.11).

b. Six-minute walk: This test was not used in the Schnabel study (Schnabel 2007).

3. Serum IGF-1 levels and IGFBP-3 levels: There is a statistically significant difference in the IGF-1 levels (SD scores) in favour of the high-dose rhGH therapy, MD 2.03 (95\% CI 1.18 to 2.88) (Analysis 4.12) and IGFBP-3 levels (SD scores), MD 0.81 (95\% CI 0.11 to 1.51) (Analysis 4.13).

4. Change in disease exacerbation: No data are reported on the hospitalisation or use of oral or intravenous antibiotics in the Schnabel study (Schnabel 2007). However, the report does state that pulmonary exacerbations were the most common observed category of adverse event, RR 1.28 (95\% CI 0.52 to 3.18) (Analysis 4.14).

5. Adverse effects: Schnabel reports the number participants experiencing at least one adverse event in the groups and number of participants with severe adverse events, but not categorised as outlined in the review protocol. There was no difference in the total number participants experiencing at least one adverse event between the two groups, RR 0.94 (95\% CI 0.58 to 1.52) (Analysis 4.15). The range of adverse events was wide (pulmonary exacerbation, haemoptysis, pneumothorax, productive cough, Candida sepsis, distal intestinal obstruction syndrome, hyperglycaemia, convulsion, Port-a-cath blockage and ligament rupture) but the paper only reported these by number of events and not by the number of participants experiencing these events so we are not able to analyse these here.

a. Mild, requiring no treatment: Schnabel did not report on this outcome separate from total adverse events (Schnabel 2007).

b. Moderate, requiring treatment: Schnabel reported an equal number of adverse effects observed in all the treatment arms with the commonest adverse effect being pulmonary exacerbations as reported above (Analysis 4.14).

c. Life-threatening or severe (requiring hospitalisation): There was no significant difference in the severe adverse effects reported between the two comparison groups, or for severe adverse events, RR 0.88 (95\% CI 0.27 to 2.83) (Analysis 4.15).

6. Cost: This outcome is not reported in the Schnabel study (Schnabel 2007). 


\section{DISCUSSION}

\section{Summary of main results}

Four studies with a total 161 participants were included in the review. Three studies used rhGH in a standard dose of approximately $0.3 \mathrm{mg} / \mathrm{kg} /$ week compared with no treatment (Hütler 2002; Schibler 2003; Stalvey 2011); one study had three treatment arms - placebo, standard dose ( $0.3 \mathrm{mg} / \mathrm{kg} /$ week) and high dose $(0.5 \mathrm{mg} / \mathrm{kg} /$ week) (Schnabel 2007).

Recombinant growth hormone was administered by daily subcutaneous injections. Two studies included participants for a minimum of 12 months in the randomised phase followed by either open-label administration for a longer period or clinical follow-up without treatment administration. The review includes data up to 12 months for these studies (Schibler 2003; Stalvey 2011). Data from two other studies were included at six months at the end of the randomised phase (Hütler 2002; Schnabel 2007). Data from the open-label phase were not included in the analysis for any of the above studies. Improvements were reported in at least some of the height measurements at six and 12 months for all comparisons (Analysis 1.6; Analysis 2.6; Analysis 2.7; Analysis 2.10; Analysis 3.5; Analysis 3.6; Analysis 4.5; Analysis 4.6). However, improvements in weight (Analysis 2.8) and lean tissue mass (Analysis 2.11) were only reported in the comparison of rhGH versus no treatment. The change in body composition does not appear to translate to pulmonary function, as there was only a small improvement in FVC (\% predicted) (Analysis 2.5) and no improvement in other reported measures of lung function. Little evidence was found for improvement in QoL.

A significant change in fasting blood glucose levels was reported from one study when comparing rhGH to placebo (Analysis 1.8), but no significant changes in blood glucose levels (fasting or postprandial) could be ascertained in any other comparison. No significant increase in serum insulin levels (Analysis 2.12) or haemoglobin A1c (Analysis 2.15) were noted, but these were only reported in one comparison. Exercise capability was measured in three studies in different formats (measurements of exercise capacity, peak oxygen consumption or six-minute walk test) and exercise capacity showed significant improvement in the rhGH treated participants compared to those receiving no treatment (Analysis 2.16; Analysis 2.17). However, there was unclear evidence from other comparisons of any beneficial treatment effect (Analysis 1.10; Analysis 1.11; Analysis 2.18; Analysis 3.10; Analysis 3.11; Analysis 4.10; Analysis 4.11). As expected, an increase was noted in the serum levels of IGF-1 and IGFBP-3 when rhGH was administered (Analysis 1.12; Analysis 3.12; Analysis 3.13; Analysis 4.12; Analysis 4.13). Hospitalisation was not reported in any study and limited data were available for adverse events. There is unclear evidence of the cost-effectiveness of the therapy.

No evidence of a difference in outcomes was found between the standard dose versus high dose in one under-powered study (Schnabel 2007).

\section{Overall completeness and applicability of evidence}

The small number of participants in each of the studies limits the overall completeness and ultimately the generalisation of the evidence to the wider CF population. The majority of the 
studies excluded those with pre-existing diabetes or those with impaired glucose intolerance. Recombinant growth hormone is known to cause disturbances in glucose metabolism and people with CF have a high incidence of CFRD which increases with age. The exclusion of these people introduced selection bias and limits the external validity of the evidence.

In clinical practice, rhGH is given to pre-pubertal adolescents for longer than one year. Therefore, the short duration and follow-up of the included studies in this review does not allow complete assessment of the effects of the treatment in a clinical context.

\section{Quality of the evidence}

Limitations in study design and implementation-The key factors that are likely to have had a degree of impact on the quality of the evidence for the outcomes sought in this review can be linked to the design and implementation of the included studies, and in particular to the effective concealment of the allocation sequence and adequate blinding of investigators and outcome assessors. The absence of a placebo and blinding in most of the studies increases the risk of performance and detection bias. It was not possible to blind the control group due to the invasive nature of the treatment. The review captured objective outcomes such as pulmonary function tests, nutritional parameters, blood glucose changes, serum hormone levels and disease status. It is postulated that these outcomes have a low risk of bias despite the absence of placebo or blinding. The impact of a lack of blinding cannot be ruled out on subjective outcomes such as QoL and exercise capacity.

The duration of the endpoints in the studies included in this review were up to 12 months, which is not reflective of clinical practice. Administration of rhGH causes acceleration of growth in the first year of administration, but it is unclear whether this effect will be sustained. It is also not clear whether participants in the control group will achieve the same height and weight without therapy, if followed up for a longer time period.

Indirectness of the evidence-Although the participants in the included studies were a general representative sample as defined in the inclusion criteria, studies consistently excluded children with impaired glucose tolerance or pre-existing diabetes. It is well known that the prevalence of diabetes in the CF population is larger than in the general population and by the age of 30 the prevalence rate has been estimated as 50\% (O'Riordan 2010). Therefore, we have concerns that the findings here may not be indicative of the effects of the intervention on this population. For more details of the populations investigated and directness of participants identified in the review (see 'Characteristics of included studies').

Imprecision of results-Studies identified for inclusion in this systematic review considered only two doses of growth hormone; across these studies, there were a number of outcomes that were measured and indeed able to be pooled. Heterogeneity occurred in a number of analyses, but this was likely to be due to the small number of included studies. In the data we present, the precision of the estimates could be determined by the width of the confidence interval surrounding it, relative to the distance from a null effect. There was a clear effect and little inconsistency for the following outcomes: height; weight; lean tissue mass; and blood serum level. However, for the remaining outcomes there was considerable doubt of any benefit for rhGH over control. Only a single study was included in the first, 
third and fourth comparisons, so we advise caution when interpreting these results since they reflect few participants.

Inconsistency of the results-The low number of studies which investigated the effect of rhGH compared to no treatment did permit some pooling of data. Therefore, any inferences about the inconsistency of the results could only be drawn from this comparison. Most of the meta-analyses carried out for this comparison illustrated a low degree of unexplained heterogeneity and allowed us to conclude that the differences in treatment effect seen between the studies may not be important. In the instances where heterogeneity was considered to potentially impact on the findings, additional sensitivity analyses were carried out as described in section 9.5.2 of the Cochrane Handbook for Systematic Reviews of Interventions (Deeks 2011), where the overall treatment benefit would be concluded on the basis of both the original and subsequent sensitivity analysis findings.

Publication bias-Although all effort was made to search for unpublished data, it is possible that unpublished studies with unfavourable results may not have been identified in the search, which could potentially alter the results of the review. Three of the included trials were funded in part by industry sponsored grants. We were unable to contact the authors of the studies to understand the process of funding and whether industry support was limited to the supply of the medication or extended to statistical and analysis support. We were also unable to contact authors of unpublished studies listed in the database clinicaltrials.gov.

In view of the low number of studies included in this review an assessment of publication bias was not possible.

\section{Potential biases in the review process}

We made every attempt to limit bias in the review process by ensuring a comprehensive search for potentially eligible studies. The authors' independent assessments of eligibility of studies for inclusion in this review and the extraction of data minimized the potential for additional bias beyond that detailed in the 'Risk of bias in included studies' tables. The incompleteness of some of the reports and our inability to obtain clarification of certain study details or to resolve ambiguities in the reports may have contributed to some bias in their assessment, but where these conditions applied, this was explicitly stated in the text of our review. The effects of language bias on the identification and selection of studies for inclusion in a systematic review is widely recognised and therefore we ensured that any studies that were not in the English language were translated so that they could be assessed for eligibility.

\section{Agreements and disagreements with other studies or reviews}

A recent systematic review was performed on use of rhGh in people with CF (Phung 2010). The review was commissioned by the Agency for Health Care Research and Quality (AHRQ), United States of America. The search strategy included a search of the Cochrane Central Register, Cochrane Database of Systematic Reviews and MEDLINE without language restrictions. The review design followed the standard PRISMA protocol and used a standardised data extraction form completed independently by two reviewers. However, the 
details of the format and risk of bias analysis of the included studies are not available for review. All the included studies were graded as 'low risk of bias' although details of randomisation, allocation concealment, blinding of participants and outcome assessors are not available for most of the included studies. For our review, the search strategy was wider in including EMBASE and Scopus to identify ongoing trials. We have presented detailed information on the studies in the risk of bias analysis which makes the assessment of the outcome results more robust.

In the Phung review, 10 controlled trials and eight observational studies were included. The results of retrospective and observational studies, whilst providing valuable information on a range of clinical variables, do not constitute reliable high level evidence for the effects of the interventions considered in this review. In addition to the controlled trials we have included in our review, Phung included one trial which was retrospective (Hardin 2005c) and another which used glutamine in addition to rhGH (Darmaun 2004). We disagree with the inclusion of these two trials and pooling of data in the analysis. It is to be noted that participants in the Darmaun trial received intravenous glutamine prior to receiving rhGH for a duration of four weeks (Darmaun 2004). The inclusion of these data with the other trials in a meta-analysis is not appropriate due to the varying duration of treatment. Additionally, combining data for six months and 12 months is not appropriate. We identified substantial heterogeneity when such an analysis was attempted and have chosen to present the data for six months and 12 months in different subgroups. The quality of nine out of 10 controlled trials included in the AHRQ review was assessed as "fair" based on validity assessment of the EPC guide. There are no details of the assessment of the individual studies in that review based on the criteria of the EPC guidelines; unlike the assessment of those studies included in this review (Figure 3 ). We have not included four of the studies included in this review as we could not contact the authors and verify the authenticity of the data (Studies awaiting classification). These studies will be included when we are able to clarify the data from the study authors. We agree with the assessment of the studies which appear in both reviews. One study was assessed by both the reviews to be of high quality (Schnabel 2007), whilst all others were assessed as fair.

However, despite the differences in the conduct of the two reviews, the results were similar. It is acknowledged that the role of rhGH in the care of people with CF is unclear at this point. Phung reported improvements in height, weight and bone mineral capacity and some improvements in pulmonary functions (Phung 2010). We have only found some improvements in height, not in weight at 12 months. We would like to emphasize that the only improvement noticed in both the reviews in pulmonary function is in FVC and the generalisation of this result as "rhGH improved almost all intermediate results of pulmonary functions, height and weight in patients with CF" may be misleading (Phung 2010). The lack of information on the effects of rhGH on blood glucose (fasting, postprandial and random), haemoglobin A1c, IGF-1 and IGFBP3 and long-term side effects are acknowledged. 


\section{AUTHORS' CONCLUSIONS}

\section{Implications for practice}

People with CF are at risk of malnutrition and growth failure. Therapy with rhGH (an anabolic agent) is being proposed to boost growth and hence improve pulmonary outcomes, even though no evidence of deficiency of growth hormone has been documented in this population. There have been modest improvements in anthropometric measures (height, weight, height and weight velocity and lean tissue mass) documented with rhGH therapy. The question of whether this improvement translates into better pulmonary outcomes, reduction in morbidity and improved QoL has not been answered from the evidence available at this time due to paucity of data. Larger studies with detailed evaluation of benefits, adverse effects and a cost-benefit analysis are recommended prior to including rhGH therapy in the routine care of people with CF.

\section{Implications for research}

Large, multicentre, randomised, placebo-controlled, parallel-designed studies to investigate the use of rhGH in people with CF will add important information regarding the role of this therapy. In future studies, emphasis must be placed on reporting on hospitalisation, QoL, mortality, glucose metabolism and other adverse effects. Inclusion of these adverse outcomes and the role of rhGH therapy in preventing morbidity may be helpful in a costbenefit analysis of the therapy. Use of standardised outcome measures in future studies can help in making the results applicable to a larger population. Longer duration of therapy will permit evaluation of effect of rhGH therapy on puberty, slipped capital epiphysis or tendency to malignancy in this population. As rhGH therapy is implicated in glucose metabolism, the use of the therapy in people with existing glucose abnormalities will help establish adverse effects of the therapy in those with a tendency towards CFRD. Future studies should include glucose tolerance tests to study impaired glucose tolerance as haemoglobin A1c is not an accurate measure in people with CF.

Future randomised controlled studies must be well-designed, well conducted, and adequately delivered with subsequent reporting, including high-quality descriptions of all aspects of methodology. Rigorous reporting needs to conform to the Consolidated Standards of Reporting Trials (CONSORT) statement (www.consort-statement.org/) which will enable appraisal and interpretation of results, and accurate judgements to be made about the risk of bias, and the overall quality of the evidence. Although it is uncertain whether reported quality mirrors actual study conduct, it is noteworthy that studies with unclear methodology have been shown to produce biased estimates of treatment effects. Adherence to guidelines, such as the CONSORT statement, would help ensure complete reporting.

\section{Supplementary Material}

Refer to Web version on PubMed Central for supplementary material. 


\section{ACKNOWLEDGEMENTS}

The authors would like to thank Nikki Jahnke of the Cochrane Cystic Fibrosis and Genetic Disorders Group for her support throughout the development of this review.

\section{SOURCES OF SUPPORT}

Internal sources

- $\quad$ No sources of support supplied

External sources

- $\quad$ NIH Training Grant, USA.

Training grant T32DK007699/DK/NIDDK awarded to Vidhu Thaker.

- $\quad$ National Institute for Health Research, UK.

This systematic review was supported by the National Institute for Health Research, via Cochrane Infrastructure funding to the Cochrane Cystic Fibrosis and Genetic Disorders Group.

\section{REFERENCES}

* Indicates the major publication for the study

\section{References to studies included in this review}

Hütler M, Schnabel D, Staab D, Tacke A, Wahn U, et al. Effect of growth hormone on exercise tolerance in children with cystic fibrosis. Medicine and Science in Sports and Exercise. 2002; 34(4): 567-572. [CFGD Register: GN125]. [PubMed: 11932561]

Schibler, A.; von der Heiden, R.; Birrer, P.; Mullis, PE. Moderate improved exercise capacity in patients with cystic fibrosis after treatment with recombinant human growth hormone [abstract]. Proceedings of the 12th European Respiratory Society Annual Congress; 2002 Sept 14-18; Stockholm. 2002. p. P3287[: GN121b]

*. Schibler A, von der Heiden R, Birrer P, Mullis PE. Prospective randomised treatment with recombinant human growth hormone in cystic fibrosis. Archives of Diseases of Childhood. 2003; 88(12):1078-1081. [CFGD Register: GN121c].

von der Heiden, R.; Kraemer, R.; Birrer, P.; Waldegg, G.; Mullis, PE. Effect of growth hormone (rhGH) treatment on working capacity, body composition, lung function and immunological parameters in patients with cystic fibrosis (CF) [abstract]. Proceedings of the 21st European Cystic Fibrosis Conference; 1997 June 1-6; Davos, Switzerland. 1997. p. 132[: GN121a]

Grasemann C, Ratjen F, Schnabel D, Reutershahn E, Vester U, Grasemann H. Effect of growth hormone therapy on nitric oxide formation in cystic fibrosis patients. European Respiratory Journal. 2008; 31(4):815-821. [CFGD Register: GN127e]. [PubMed: 18094013]

Grasemann H, Grasemann C, Schnabel D, Ratjen F. Growth hormone therapy results in increased LArginine and nitrate concentrations in serum but decreased exhaled oxide in patients with cystic fibrosis [abstract]. Pediatric Pulmonology. 2006; 41(Suppl 29):335. [CFGD Register: GN127b].

Grasemann, H.; Grasemann, C.; Schnabel, D.; Ratjen, F. Recombinant human growth hormone therapy results in increased systemic nitric oxide (NO) formation but decreased exhaled NO in patients with cystic fibrosis [abstract]. Proceedings of the American Thoracic Society International Conference; 2006 May 19-24; California USA. 2006. p. A408[CFGD Register: GN127a]

*. Schnabel D, Grasemann C, Staab D, Wollmann H, Ratjen F. A multicenter, randomized, doubleblind placebo-controlled trial evaluating the metabolic and respiratory effects of growth hormone in children with cystic fibrosis [abstract]. Pediatric Pulmonology. 2006; 41(Suppl 29):393. [CFGD Register: GN127c].

*. Schnabel D, Grasemann C, Staab D, Wollmann H, Ratjen F. A multicenter, randomized, doubleblind, placebo-controlled trial to evaluate the metabolic and respiratory effects of growth hormone in children with cystic fibrosis. Pediatrics. 2007; 119(6):e1230-e1238. [CFGD Register: GN127d]. [PubMed: 17545356] 
Geller DE, Anbar RD, Konstan MW, Stalvey MS, Jacobs JR, Bakker B. Growth hormone effects on pulmonary function in prepubertal children with cystic fibrosis [abstract]. Pediatric Pulmonology. 2008; 43(Suppl 31):368. [: GN128b].

*. Stalvey MS, Anbar RD, Konstan MW, Jacobs JR, Bakker B, Lippe B, et al. A multi-center controlled trial of growth hormone treatment in children with cystic fibrosis. Pediatric Pulmonology. 2012; 47(3):252-263. [CFGD Register: GN128c; DOI: 10.1002/ppul.21546; PUBMED:21905270]. [PubMed: 21905270]

Stalvey MS, Geller DE, Anbar RD, Konstan MW, Jacobs JR, Bakker B. Growth hormone (GH) increases height, weight and lean body mass (LBM) in prepubertal children with cystic fibrosis (CF): results of a multicenter randomized control trial [abstract]. Pediatric Pulmonology. 2007; 42(Suppl 30):393. [CFGD Register: GN128a]. [PubMed: 17352399]

\section{References to studies excluded from this review}

Alemzadeh R, Upchurch L, McCarthy V. Anabolic effects of growth hormone treatment in young children with cystic fibrosis. Journal of the American College of Nutrition. 1998; 17(5):419-424. [PubMed: 9791837]

Darmaun D, Hayes V, Schaeffer D, Welch S, Mauras N. Effects of glutamine and recombinant human growth hormone on protein metabolism in prepubertal children with cystic fibrosis. Journal of Clinical Endocrinology and Metabolism. 2004; 89(3):1146-1152. [CFGD Register: GN90b]. [PubMed: 15001600]

Schaeffer D, Darmaun D, Punati J, Mauras N, Hayes VY. Use of glutamine and recombinant human growth hormone (RHGH) in children with cystic fibrosis [abstract]. Pediatric Pulmonology. 2000; 30(Suppl 20):323. [: GN90a].

Eubanks V, Atchison J, Arani R, Clancy JP, Sorscher EJ, Wooldridge N, et al. Effects of megestrol acetate on energy intake, weight gain, body composition and resting energy expenditure in cystic fibrosis patients [abstract]. Pediatric Pulmonology. 2000; 30(Suppl 20):322-33. [CFGD Register: GN86a; CRS-ID: 5500100000001740].

Eubanks V, Koppersmith N, Wooldridge N, Clancy JP, Lyrene R, Arani RB, et al. Effects of megestrol acetate on weight gain, body composition, and pulmonary function in patients with cystic fibrosis. Journal of Pediatrics. 2002; 140(4):439-444. [CFGD Register: GN86b; CRS-ID: 5500100000002066]. [PubMed: 12006958]

Hardin DS, Sy JP. Effects of growth hormone treatment in children with cystic fibrosis: the National Cooperative Growth Study experience. Journal of Pediatrics. 1997; 131(1 Pt 2):S65-S69. [PUBMED: 9255232]. [PubMed: 9255232]

Hardin DS, Stratton R, Kramer JC, Reyes de la Rocha S, Govaerts K, Wilson DP. Growth hormone improves weight velocity and height velocity in prepubertal children with cystic fibrosis. Hormone and Metabolic Research. 1998; 30(10):636-641. [PUBMED: 9851673]. [PubMed: 9851673]

Hardin DS, Ferkol T, Ahn C, Dreimane D, Dyson M, Morse M, et al. A retrospective study of growth hormone use in adolescents with cystic fibrosis. Clinical Endocrinology. 2005; 62(5):560-566. [PUBMED: 15853825]. [PubMed: 15853825]

Huseman CA, Colombo JL, Brooks MA, Smay JR, Greger NG, Sammut PH, et al. Anabolic effect of biosynthetic growth hormone in cystic fibrosis patients. Pediatric Pulmonology. 1996; 22(2):9095. [PUBMED: 8875581]. [PubMed: 8875581]

Kissner DG. Role of progestational agents in the treatment of undernourished patients with cystic fibrosis [letter]. Pediatric Pulmonology. 2000; 29(3):244. [CFGD Register: GN93; CRS-ID: 5500100000001942]. [PubMed: 10686049]

Marchand V, Baker SS, Baker RD. Leptin level in children with cystic fibrosis, effect megestrol acetate treatment [abstract]. Journal of Pediatric Gastroenterology and Nutrition. 1999; 29:512. [CFGD Register: GN94b; CRS-ID: 5500100000002076].

Marchand V, Baker SS, Stark TJ, Baker RD. Randomized, double-blind, placebo-controlled pilot trial of megestrol acetate in malnourished children with cystic fibrosis. Journal of Pediatric Gastroenterology and Nutrition. 2000; 31(3):264-269. [CFGD Register: GN94a; CRS-ID: 5500100000001905]. [PubMed: 10997370] 
Sackey AH, Taylor CJ, Barraclough M, Wales J, Pickering M. Growth hormone as a nutritional adjunct in cystic fibrosis: results of a pilot study. Journal of Human Nutrition. 1995; 8(3):1851891.

Safai-Kutti S, Selin E, Larsson S, Jagenburg R, Denfors I, Sten G, et al. Zinc therapy in children with cystic fibrosis. Beitrage Zur Infusiontherapie. 1991; 27:104-114. [CFGD Register: GN36; CRSID: 5500100000000479].

Vanderwel M, Hardin DS. Growth hormone normalizes pubertal onset in children with cystic fibrosis. Journal of Pediatric Endocrinology \& Metabolism. 2006; 19(3):237-244. [PUBMED: 16607924]. [PubMed: 16607924]

\section{References to studies awaiting assessment}

Bucuvalas JC, Chernausek SD, Alfaro MP, Krug S, Ritschel W, Wilmott RW. Insulin-like growth factor -I enhances linear growth in undernourished prepubertal children with cystic fibrosis [abstract]. Pediatric Pulmonology. 1998; 26(Suppl 17):355. [CFGD Register: GN123a; CRS-ID: 5500100000001298].

*. Bucuvalas JC, Chernausek SD, Alfaro MP, Krug SK, Ritschel W, Wilmott RW. Effect of insulinlike growth factor-1 treatment in children with cystic fibrosis. Journal of Pediatric Gastroenterology and Nutrition. 2001; 33(5):576-581. [CFGD Register: GN123b; CRS-ID: 5500100000002045]. [PubMed: 11740232]

Hardin DS, Ellis K, McConnell RA, Seilheimer DK. Growth hormone improves lean body mass in prepubertal CF children [abstract]. Pediatric Pulmonology. 1998; 26(Suppl 17):357. [CFGD Register: GN122a].

Hardin DS, Ellis KJ, Dyson M, Rice J, McConnell R, Seilheimer DK. Growth hormone decreases protein catabolism in children with cystic fibrosis. Journal of Clinical Endocrinology and Metabolism. 2001; 86(9):4424-4428. [CFGD Register: GN122d]. [PubMed: 11549686]

*. Hardin DS, Ellis KJ, Dyson M, Rice J, McConnell R, et al. Growth hormone improves clinical status in prepubertal children with cystic fibrosis: results of a randomized controlled trial. Journal of Pediatrics. 2001; 139(5):636-642. [CFGD Register: GN122e]. [PubMed: 11713439]

Hardin DS, Ellis KJ, McConnel R, Seilheimer DK. Growth hormone improves clinical status in cystic fibrosis children [abstract]. Pediatric Pulmonology. 1999; 28(Suppl 19):297. [CFGD Register: GN122b]. [PubMed: 10497379]

*. Hardin DS, Rice J, Ahn C, Ferkol T, Howenstine M, et al. Growth hormone treatment enhances nutrition and growth in children with cystic fibrosis receiving enteral nutrition. Journal of Pediatrics. 2005; 146(3):324-328. [CFGD Register: GN122h]. [PubMed: 15756212]

Hardin DS, Ahn C, Prestidge C, Seilheimer DK, Ellis KJ. Growth hormone improves bone mineral content in children with cystic fibrosis. Journal of Pediatric Endocrinology \& Metabolism. 2005; 18(6):589-595. [PubMed: 16042327]

Hardin DS, Adams-Huet B, Brown D, Chatfield B, Dyson M, Ferkol T, et al. Online Supplement to 'Growth hormone treatment improves growth and clinical status in prepubertal children with cystic fibrosis: results of a multicenter randomized controlled trial'. Journal of Clinical Endocrinology \& Metabolism. 2006; 91(12):4925-4929. [CFGD Register: GN122j]. [PubMed: 17018651]

Hardin DS, Adams-Huet B, Brown D, Chatfield B, Dyson M, et al. Growth hormone treatment improves growth and clinical status in prepubertal children with cystic fibrosis: results of a multicenter randomized controlled trial. Journal of Clinical Endocrinology and Metabolism. 2006; 91(12):4925-4929. [CFGD Register: GN122i]. [PubMed: 17018651]

Hardin DS, Rice J, Ahn C, Chatfield B, Dyson M, Howenstein M, et al. Growth hormone improves pulmonary function, weight, and height - results from a multicenter study [abstract]. Pediatric Pulmonology. 2002; 34(Suppl 24):337. [CFGD Register: GN122f].

Schnabel D, Staab D, Tacke A, Brosicke H, Gruters A, Wahm U. Anabolic effects of growth (WH)therapy in patients with cystic fibrosis (CF) [abstract] [Anabole Effekte der Wachstums(WH)Therapie bei Patienten mit zystischer Fibrose (CF)]. Monatsschrift fur Kinderheilkunde. 1997; 145:S40. [: GN124]. 


\section{References to ongoing studies}

Phase II Study of Growth Hormone in Children With Cystic Fibrosis. Ongoing study. 2001

A Study to Evaluate Nutropin AQ for the Treatment of Growth Restriction in Children With Cystic Fibrosis. Ongoing study. 2003

\section{Additional references}

ACSM's Guidelines for Exercise Testing and Prescription. 7th Edition.. Baltimore: Lippincott, Williams, \& Wilkins; 2006. American College of Sports Medicine.

Assael BM, Casazza G, Iansa P, Volpi S, Milani S. Growth and long-term lung function in cystic fibrosis: a longitudinal study of patients diagnosed by neonatal screening. Pediatric Pulmonology. 2009; 44(3):209-215. [PUBMED: 19230003]. [PubMed: 19230003]

Barkhouse LB, Fahey J, Gillespie CT, Cole DE. Quantitating the effect of cystic fibrosis on linear growth by mathematical modelling of longitudinal growth curves. Growth, Development, and Ageing. 1989; 53(4):185-1890. [PUBMED: 2638347].

Beker LT, Russek-Cohen E, Fink RJ. Stature as a prognostic factor in cystic fibrosis survival. Journal of the American Dietetic Association. 2001; 101(4):438-442. [PubMed: 11320950]

Borowitz D, Baker RD, Stallings V. Consensus report on nutrition for pediatric patients with cystic fibrosis. Journal of Pediatric Gastroenterology and Nutrition. 2002; 35(3):246-259. [PubMed: 12352509]

Bryant J, Cave C, Mihaylova B, Chase D, McIntyre L, Gerard K, et al. Clinical effectiveness and costeffectiveness of growth hormone in children: a systematic review and economic evaluation. Health Technology Assessment. 2002; 6(18):1-168.

Byard PJ. The adolescent growth spurt in children with cystic fibrosis. Annals of Human Biology. 1994; 21(3):229-240. [PubMed: 8060112]

Cystic Fibrosis Foundation, Bethesda, Maryland. Cystic Fibrosis Foundation Patient Registry. Annual Data Report. 2008

Corey M, McLaughlin FJ, Williams M, Levison H. A comparison of survival, growth, and pulmonary function in patients with cystic fibrosis in Boston and Toronto. Journal of Clinical Epidemiology. 1988; 41(6):583-591. [PUBMED: 3260274]. [PubMed: 3260274]

Cutfield WS, Wilton P, Bennmarker H, Albertsson-Wikland K, Chatelain P, Ranke MB, et al. Incidence of diabetes mellitus and impaired glucose tolerance in children and adolescents receiving growth-hormone treatment. Lancet. 2000; 355(9204):610-613. [PUBMED: 10696981]. [PubMed: 10696981]

Dalzell AM, Shepherd RW, Dean B, Cleghorn GJ, Holt TL, Francis PJ. Nutritional rehabilitation in cystic fibrosis: a 5 year follow-up study. Journal of Pediatric Gastroenterology and Nutrition. 1992; 15(2):141-145. [PubMed: 1403461]

De Benedetti F, Alonzi T, Moretta A, Lazzaro D, Costa P, Poli V, et al. Interleukin 6 causes growth impairment in transgenic mice through a decrease in insulin-like growth factor-I. A model for stunted growth in children with chronic inflammation. Journal of Clinical Investigation. 1997; 99(4):643-650. [PUBMED: 9045866]. [PubMed: 9045866]

Deeks, JJ.; Higgins, JPT.; Altman, DG. on behalf of the Cochrane Statistical Methods Group. Chapter 9: Analysing data and undertaking meta-analyses. In: Higgins, JPT.; Green, S., editors. Cochrane Handbook for Systematic Reviews of Interventions Version 5.1.0. The Cochrane Collaboration; 2011. Available from www.cochrane-handbook.org. [updated March 2011]

Farrell PM, Kosorok MR, Rock MJ, Laxova A, Zeng L, Lai HC, et al. Early diagnosis of cystic fibrosis through neonatal screening prevents severe malnutrition and improves long-term growth. Wisconsin Cystic Fibrosis Neonatal Screening Study Group. Pediatrics. 2001; 107(1):1-13. [PUBMED: 11134427]. [PubMed: 11134427]

Gee L, Abbott J, Conway S, Etherington C, Webb A. Development of a disease specific health related quality of life measure for adults and adolescents with cystic fibrosis. Thorax. 2000; 55(11):946954. [PubMed: 11050265] 
Giovannucci E, Haiman CA, Platz EA, Hankinson SE, Pollak MN, Hunter DJ. Dinucleotide repeat in the insulin-like growth factor-I gene is not related to risk of colorectal adenoma. Cancer Epidemiology, Biomarkers and Prevention. 2002; 11(11):1509-1510.

Haeusler G, Frisch H, Waldhor T, Gotz M. Perspectives of longitudinal growth in cystic fibrosis from birth to adult age. European Journal of Pediatrics. 1994; 153(3):158-163. [PubMed: 8181496]

Hardin DS. GH improves growth and clinical status in children with cystic fibrosis -- a review of published studies. European Journal of Endocrinology / European Federation of Endocrine Societies. 2004; 151(Suppl 1):S81-S85. [PubMed: 15339250]

Higgins, JPT.; Altman, DG. on behalf of the Cochrane Statistical Methods Group and the Cochrane Bias Methods Group. Chapter 8: Assessing risk of bias in included studies. In: Higgins, JPT.; Green, S., editors. Cochrane Handbook for Systematic Reviews of Interventions Version 5.1.0. The Cochrane Collaboration; 2009. Available from www.cochrane-handbook.org. [updated March 2011]

Higgins, JPT.; Deeks, JJ.; Altman, DG. on behalf of the Cochrane Statistical Methods Group. Chapter 16: Special topics in statistics. In: Higgins, JPT.; Green, S., editors. Cochrane Handbook for Systematic Reviews of Interventions Version 5.1.0. The Cochrane Collaboration; 2011. Available from www.cochrane-handbook.org. [updated March 2011]

Jeffcoate W. Growth hormone therapy and its relationship to insulin resistance, glucose intolerance and diabetes mellitus: a review of recent evidence. Drug Safety. 2002; 25(3):199-212. [PubMed: 11945115]

Karlberg J, Kjellmer I, Kristiansson B. Linear growth in children with cystic fibrosis. I. Birth to 8 years of age. Acta Paediatrica Scandinavica. 1991; 80(5):508-514. [PUBMED: 1872173]. [PubMed: 1872173]

Kawchak DA, Zhao H, Scanlin TF, Tomezsko JL, Cnaan A, Stallings VA. Longitudinal, prospective analysis of dietary intake in children with cystic fibrosis. Journal of Pediatrics. 1996; 129(1):119129. [PUBMED: 8757571]. [PubMed: 8757571]

Konstan MW, Butler SM, Wohl ME, Stoddard M, Matousek R, Wagener JS, et al. Growth and nutritional indexes in early life predict pulmonary function in cystic fibrosis. Journal of Pediatrics. 2003; 142(6):624-630. [PubMed: 12838189]

Lai HC, Kosorok MR, Sondel SA, Chen ST, FitzSimmons SC, Green CG, et al. Growth status in children with cystic fibrosis based on the National Cystic Fibrosis Patient Registry data: evaluation of various criteria used to identify malnutrition. Journal of Pediatrics. 1998; 132(3 Pt 1):478-485. [PUBMED: 9544905]. [PubMed: 9544905]

Laursen EM, Lanng S, Rasmussen MH, Koch C, Skakkebaek NE, Muller J. Normal spontaneous and stimulated GH levels despite decreased IGF-I concentrations in cystic fibrosis patients. European Journal of Endocrinology / European Federation of Endocrine Societies. 1999; 140(4):315-321. [PUBMED: 10097250]. [PubMed: 10097250]

Lucidi V, Alghisi F, Raia V, Russo B, Valmarana L, Valmarana R, et al. Growth assessment of paediatric patients with CF comparing different auxologic indicators: A multicentre Italian study. Journal of Pediatric Gastroenterology and Nutrition. 2009; 49(3):335-342. [PUBMED: 19543116]. [PubMed: 19543116]

Morison S, Dodge JA, Cole TJ, Lewis PA, Coles EC, Geddes D, et al. Height and weight in cystic fibrosis: a cross sectional study. UK Cystic Fibrosis Survey Management Committee. Archives of Disease in Childhood. 1997; 77(6):497-500. [PUBMED: 9496182]. [PubMed: 9496182]

O'Rawe A, McIntosh I, Dodge JA, Brock DJ, Redmond AO, Ward R, et al. Increased energy expenditure in cystic fibrosis is associated with specific mutations. Clinical Science. 1992; 82(1): 71-76. [PUBMED: 1310920]. [PubMed: 1310920]

O'Riordan SM, Dattani MT, Hindmarsh PC. Cystic fibrosis-related diabetes in childhood. Hormone Research in Paediatrics. 2010; 73(1):15-24. [PUBMED: 20190536]. [PubMed: 20190536]

Patel L, Dixon M, David TJ. Growth and growth charts in cystic fibrosis. Journal of the Royal Society of Medicine. 2003; 96(Suppl 43):35-41. [PubMed: 12906324]

Phung OJ, Coleman CI, Baker EL, Scholle JM, Girotto JE, Makanji SS, et al. Recombinant human growth hormone in the treatment of patients with cystic fibrosis. Pediatrics. 2010; 126(5):e1211e1226. [PUBMED: 20921071]. [PubMed: 20921071] 
Quittner AL, Modi AC, Wainwright C, Otto K, Kirihara J, Montgomery AB. Determination of the minimal clinically important difference scores for the Cystic Fibrosis Questionnaire-Revised respiratory symptom scale in two populations of patients with cystic fibrosis and chronic Pseudomonas aeruginosa airway infection. Chest. 2009; 135(6):1610-1618. [PubMed: 19447923]

Ratjen F, Döring G. Cystic Fibrosis. Lancet. 2003; 361(9358):681-689. [PubMed: 12606185]

Reilly JJ, Edwards CA, Weaver LT. Malnutrition in children with cystic fibrosis: the energy-balance equation. Journal of Pediatric Gastroenterology and Nutrition. 1997; 25(2):127-136. [PubMed: 9252897]

The Nordic Cochrane Centre, The Cochrane Collaboration. Review Manager (RevMan). Version 5.1. Copenhagen: The Nordic Cochrane Centre, The Cochrane Collaboration; 2011.

Sermet-Gaudelus I, Souberbielle JC, Azhar I, Ruiz JC, Magnine P, Colomb V, et al. Insulin-like growth factor I correlates with lean body mass in cystic fibrosis patients. Archives of Disease in Childhood. 2003; 88(11):956-961. [PUBMED: 14612353]. [PubMed: 14612353]

Sharma R, Florea VG, Bolger AP, Doehner W, Florea ND, Coats AJ, et al. Wasting as an independent predictor of mortality in patients with cystic fibrosis. Thorax. 2001; 56(10):746-750. [PubMed: 11562511]

Sinaasappel M, Stern M, Littlewood J, Wolfe S, Steinkamp G, Heijerman HG, et al. Nutrition in patients with cystic fibrosis: a European Consensus. Journal of Cystic Fibrosis. 2002; 1(2):51-75. [PubMed: 15463811]

Sterne, JAC.; Egger, M.; Moher, D. on behalf of the Cochrane Bias Methods Group. Chapter 10: Addressing reporting biases. In: Higgins, JPT.; Green, S., editors. Cochrane Handbook for Systematic Reviews of Interventions Version 5.1.0. The Cochrane Collaboration; 2011. Available from www.cochrane-handbook.org. [updated March 2011]

Stettler N, Kawchak DA, Boyle LL, Propert KJ, Scanlin TF, Stallings VA, et al. Prospective evaluation of growth, nutritional status, and body composition in children with cystic fibrosis. American Journal of Clinical Nutrition. 2000; 72(2):407-413. [PUBMED: 10919935]. [PubMed: 10919935]

Tanner, JM. Growth at Adolescence. Springfield, IL: Charles C Thomas; 1962.

Taylor AM, Bush A, Thomson A, Oades PJ, Marchant JL, Bruce-Morgan C, et al. Relation between insulin-like growth factor-I, body mass index, and clinical status in cystic fibrosis. Archives of Disease in Childhood. 1997; 76(4):304-309. [PUBMED: 9166020]. [PubMed: 9166020]

Verhelst J, Abs R. Long-term growth hormone replacement therapy in hypopituitary adults. Drugs. 2002; 62(16):2399-2412. [PubMed: 12396230]

Wiedemann B, Paul KD, Stern M, Wagner TO, Hirche TO. Evaluation of body mass index percentiles for assessment of malnutrition in children with cystic fibrosis. European Journal of Clinical Nutrition. 2007; 61(6):759-768. [PUBMED: 17213872]. [PubMed: 17213872]

Melmed, S.; Polonsky, K.; ReedLarsen, P.; Kronenberg, H. Williams Textbook of Endocrinology. 12th Edition. St. Louis, Missouri, USA: Elsevier, W.B. Saunders; 2011.

Wilson TA, Rose SR, Cohen P, Rogol AD, Backeljauw P, Brown R, et al. Update of guidelines for the use of growth hormone in children: the Lawson Wilkins Pediatric Endocrinology Society Drug and Therapeutics Committee. Journal of Pediatrics. 2003; 143(4):415-421. [PUBMED: 14571209]. [PubMed: 14571209]

\section{References to other published versions of this review}

Thaker V, Haagensen AL, Carter B, Fedorowicz Z, Houston BW. Recombinant growth hormone therapy for cystic fibrosis in children and young adults. Cochrane Database of Systematic Reviews. 2013; (Issue 6) 


\section{APPENDICES}

\section{Appendix 1. Glossary}

\begin{tabular}{|c|c|}
\hline Term & Explanation \\
\hline benign & of mild type or character that does not threaten health or life \\
\hline electrolytes & $\begin{array}{l}\text { any of the ions (as of sodium or calcium) that in biological fluid regulate or affect most } \\
\text { metabolic processes }\end{array}$ \\
\hline endothelial & $\begin{array}{l}\text { of, relating to, or produced from the endothelium (the layer of flat cells lining the closed } \\
\text { spaces of the body such as the inside of blood vessels, lymphatic vessels, the heart, and } \\
\text { body cavities) }\end{array}$ \\
\hline epithelium & $\begin{array}{l}\text { a membranous cellular outside layer of tissue that covers a free surface or lines a tube or } \\
\text { cavity of an animal body and serves especially to enclose and protect the other parts of the } \\
\text { body, to produce secretions and excretions, and to function in assimilation }\end{array}$ \\
\hline exocrine glands & $\begin{array}{l}\text { a gland (as a sweat gland, a salivary gland, or a kidney) that releases a secretion external to } \\
\text { or at the surface of an organ by means of a canal or duct }\end{array}$ \\
\hline exogenous & growing from or on the outside \\
\hline glucosuria & presence of glucose in the urine \\
\hline hyperglycaemia & abnormally high blood sugar levels \\
\hline intracranial hypertension & increase in the pressure in the brain fluid, called cerebrospinal fluid, above normal \\
\hline longitudinal growth & increase in length \\
\hline mammalian cell line & cells derived from a mammal \\
\hline malignant & tending to deteriorate, infiltrate, metastasize and terminate fatally \\
\hline percentile & (or centile) is the value of a variable below which a certain percent of observations fall \\
\hline polypeptide hormone & hormone made up of several amino acids \\
\hline post-prandial & after a meal \\
\hline prognostic indicator & of, relating to, or serving as ground for a prognosis \\
\hline scoliosis & a lateral curvature of the spine \\
\hline slipped capital epiphyses & $\begin{array}{l}\text { orthopedic condition in which the growth center of the hip (the capital femoral epiphysis) } \\
\text { slips backwards on the top of the femur (the thighbone) }\end{array}$ \\
\hline splenomegaly & enlargement of spleen \\
\hline transient & temporary \\
\hline
\end{tabular}

\section{Appendix 2. SCOPUS search strategy}

Database: SCOPUS <1995 to March 2012>

\section{Search Strategy:}

1. Recombinant growth hormone/ Title-Abs-Key

2. rhGH/Title-Abs-Key

3. Growth hormone/Tittle-Abs-Key

4. Human Growth hormone/Title-Abs-Key

5. Somatropin/Title-Abs-Key

6. Somatotropin/Title-Abs-Key 

7. Somatotrophin/Title-Abs-Key
8. Nutropin/Title-Abs-Key
9. Genotropin/Title-Abs-Key
10. Humatropin/Title-Abs-Key
11. Norditropin/Title-Abs-Key
12. $\mathrm{OR} / 1-11$
13. cystic fibrosis/Title-Abs-Key
14. 12 AND 13
15. Child*/Title-Abs-Key
16. Adolescen*/Title-Abs-Key
17. 14 AND 15 OR 16

\section{Appendix 3. Clinicaltrials.gov search strategy}
1. Growth hormone
2. Recombinant growth hormone
3. somatotropin
4. $\mathrm{rhGH}$
5. $\mathrm{OR} / 1-5$
6. cystic fibrosis
7. 5 AND 6 


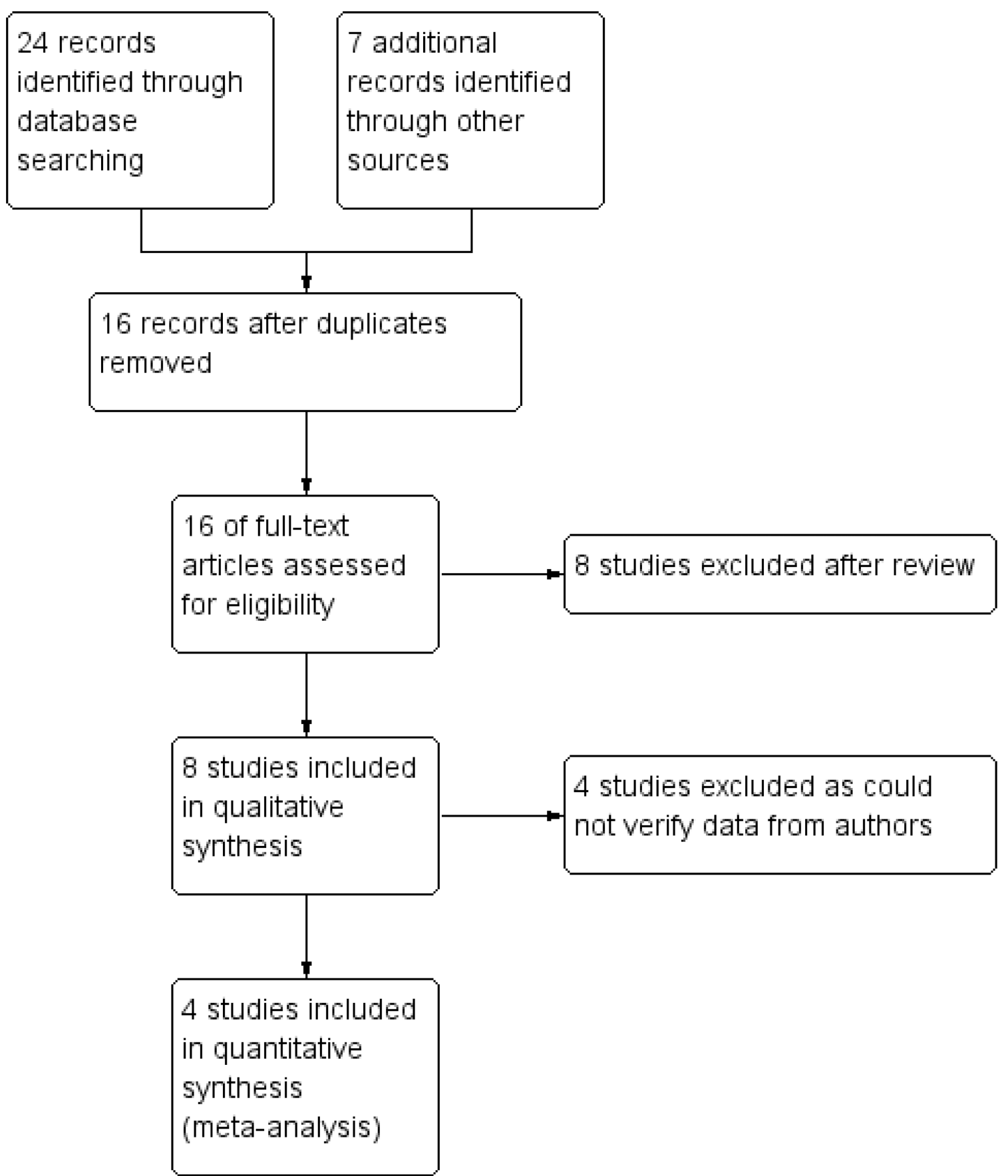

Figure 1.

Study flow diagram. 


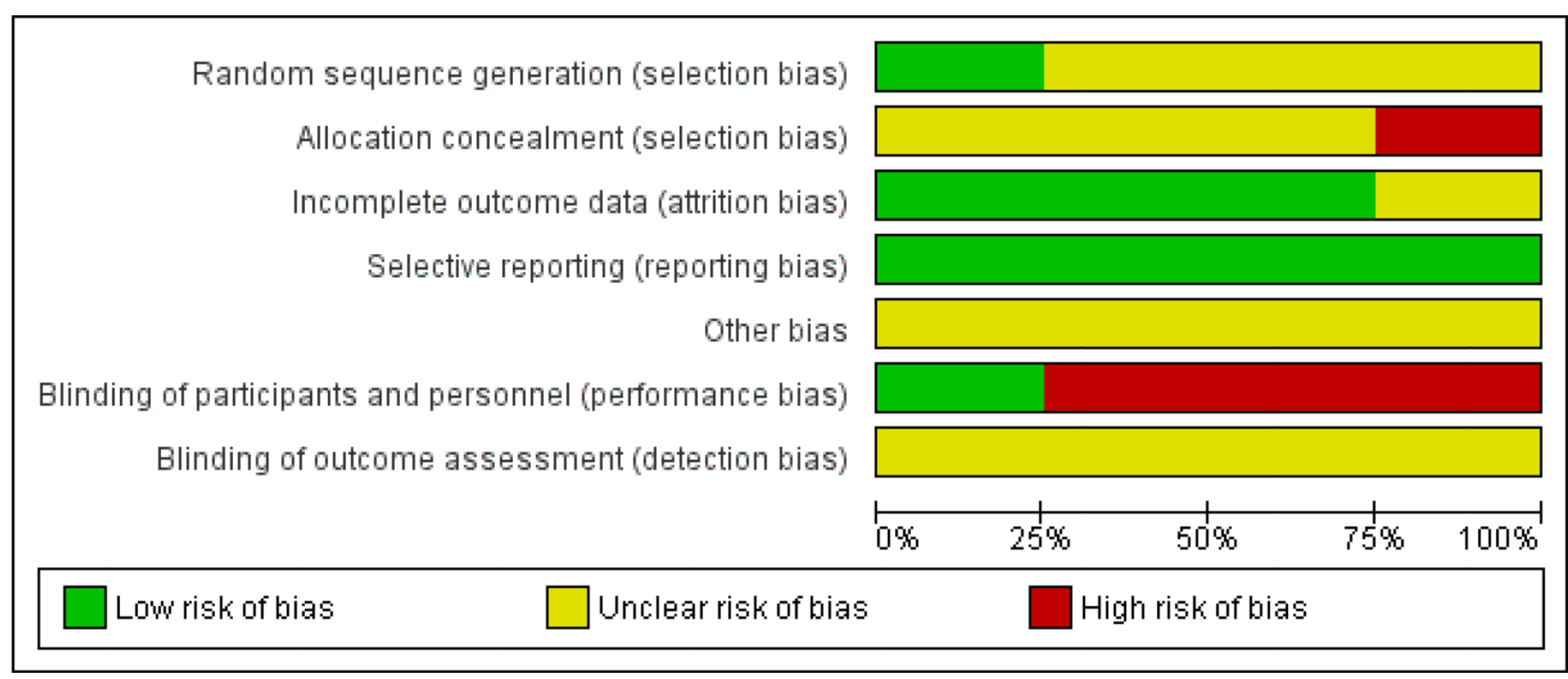

Figure 2.

Risk of bias graph: review authors' judgements about each risk of bias item presented as percentages across all included studies. 


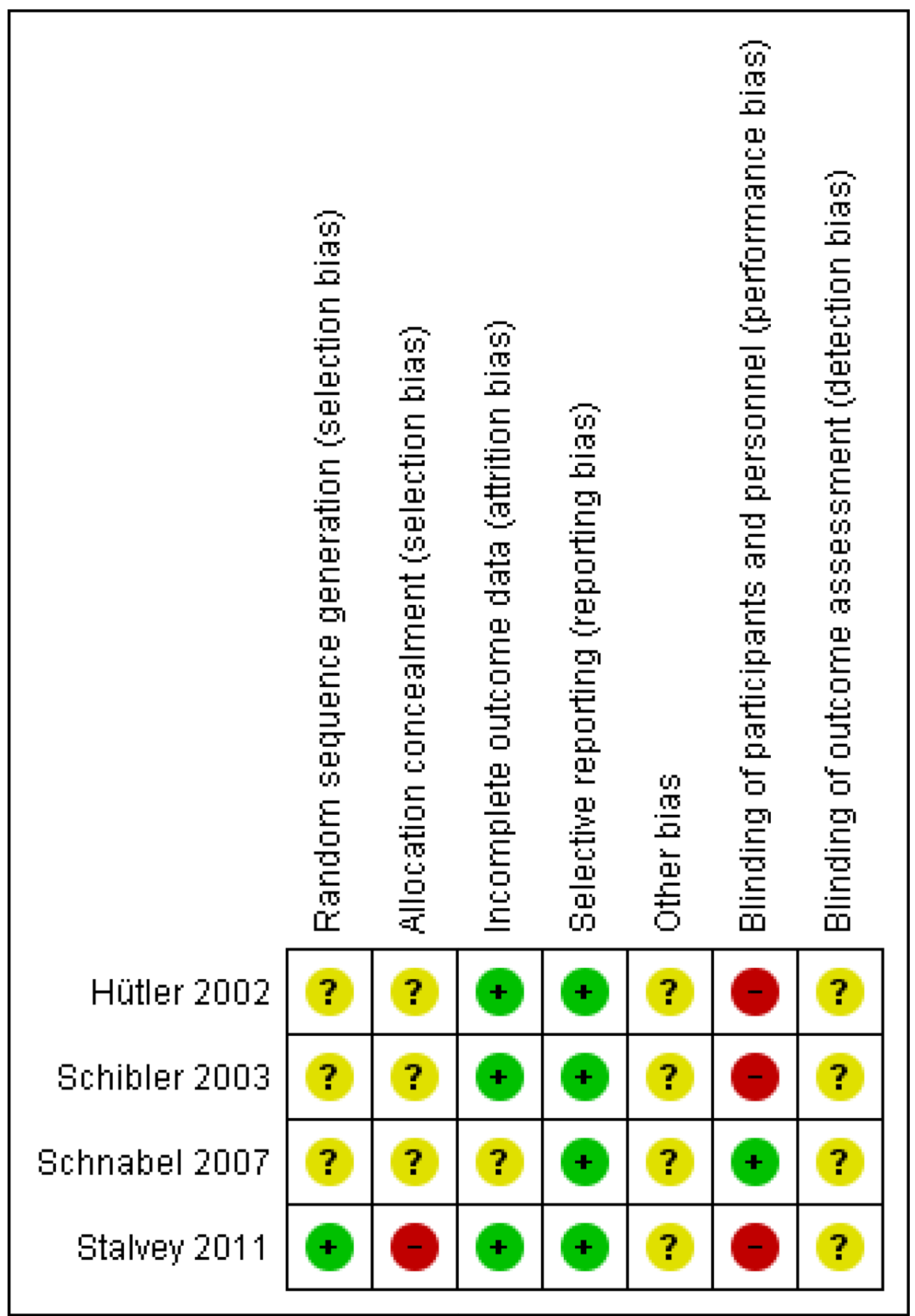

Figure 3.

Risk of bias summary: review authors' judgements about each risk of bias item for each included study. 


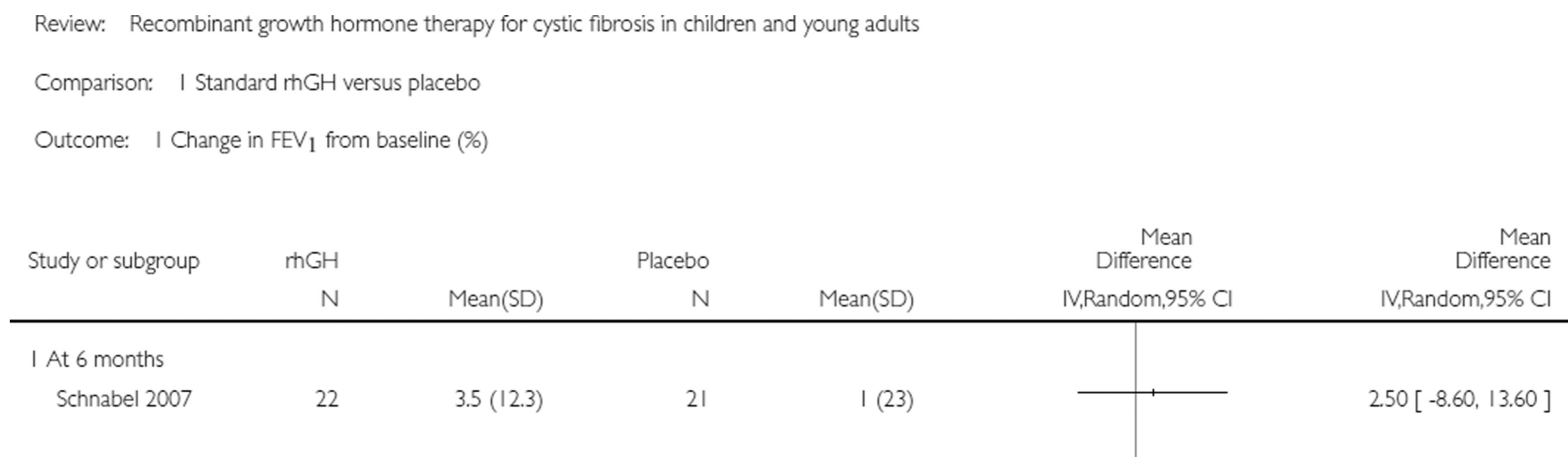

|r.

$2.50[-8.60,13.60]$

Analysis 1.1.

Comparison 1 Standard rhGH versus placebo, Outcome 1 Change in FEV1 from baseline $(\%)$. 


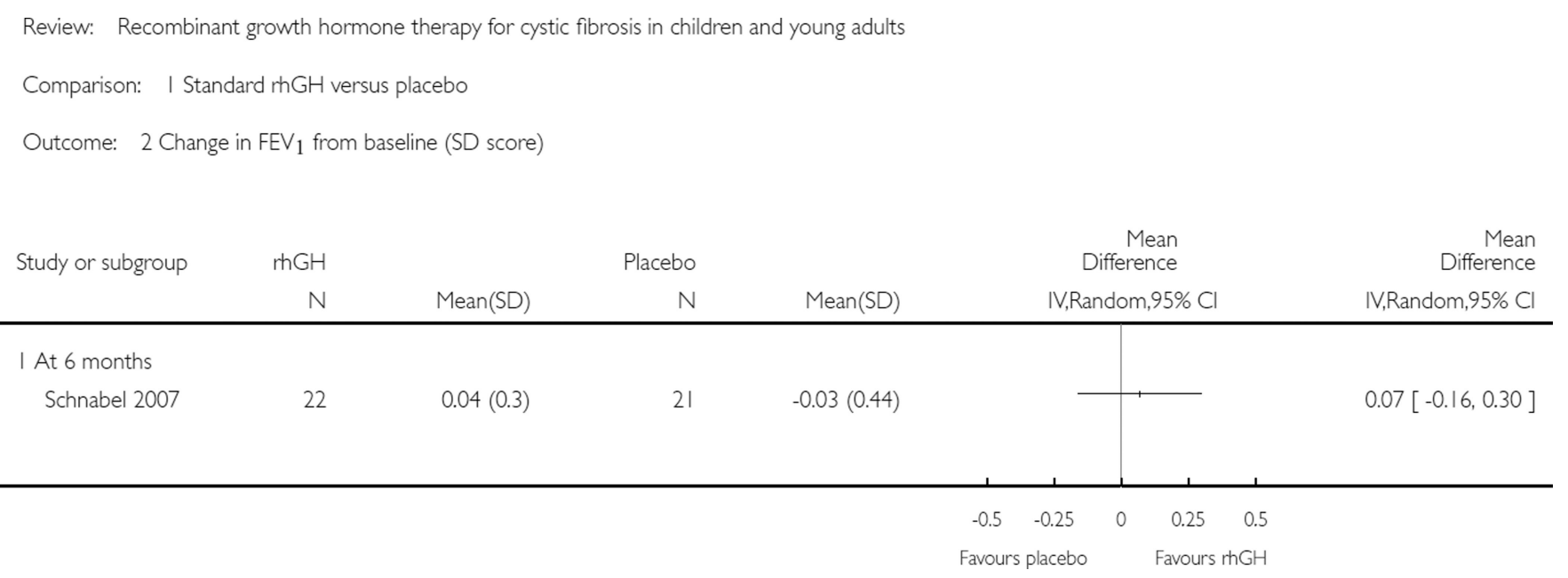

Analysis 1.2.

Comparison 1 Standard rhGH versus placebo, Outcome 2 Change in FEV1 from baseline (SD score). 


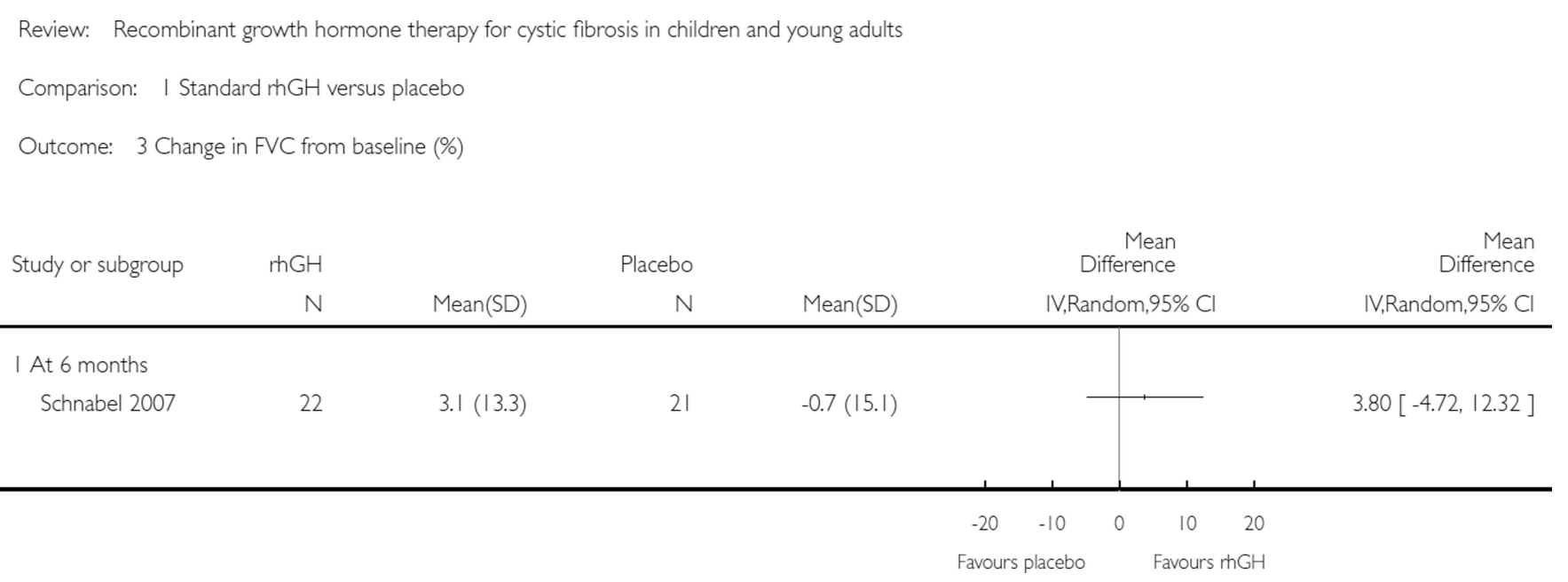

Analysis 1.3.

Comparison 1 Standard rhGH versus placebo, Outcome 3 Change in FVC from baseline $(\%)$. 


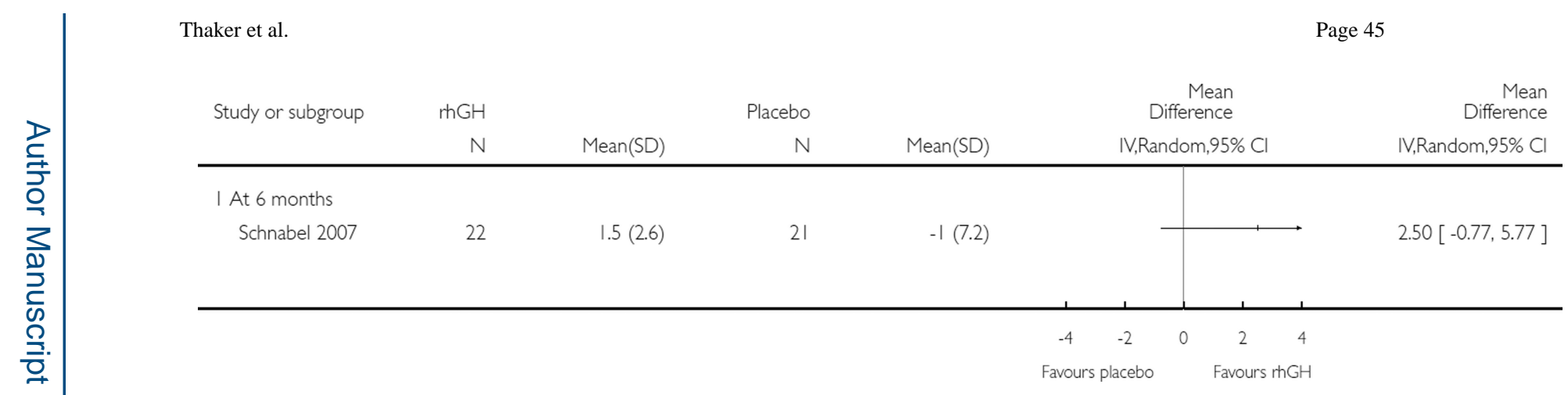

Analysis 1.4.

Comparison 1 Standard rhGH versus placebo, Outcome 4 Height z score. 
Review: Recombinant growth hormone therapy for cystic fibrosis in children and young adults

Comparison: I Standard mGH versus placebo

Outcome: 5 Change in weight from baseline $(\mathrm{kg})$

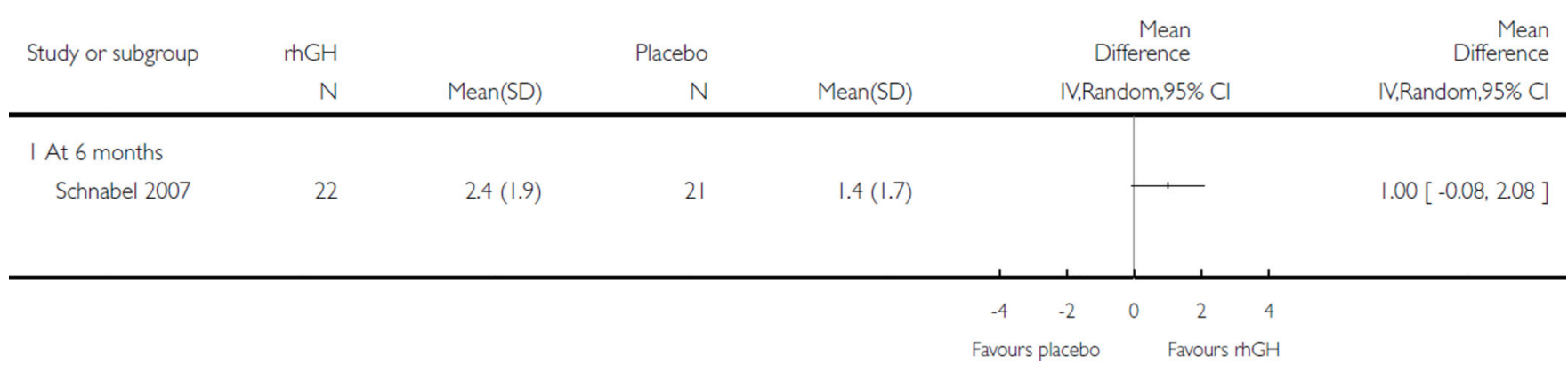

Analysis 1.5.

Comparison 1 Standard rhGH versus placebo, Outcome 5 Change in weight from baseline $(\mathrm{kg})$. 


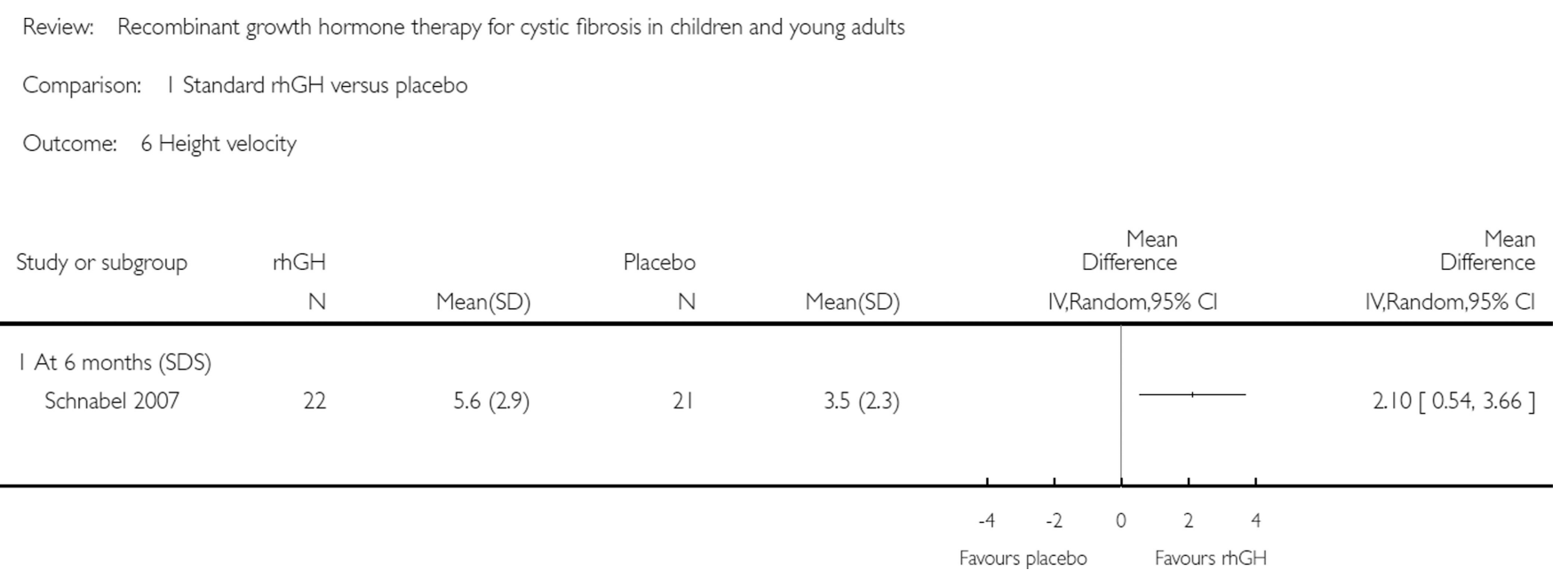

Analysis 1.6.

Comparison 1 Standard rhGH versus placebo, Outcome 6 Height velocity. 
Review: Recombinant growth hormone therapy for cystic fibrosis in children and young adults

Comparison: I Standard rhGH versus placebo

Outcome: 7 Lean tissue mass $(\mathrm{kg})$

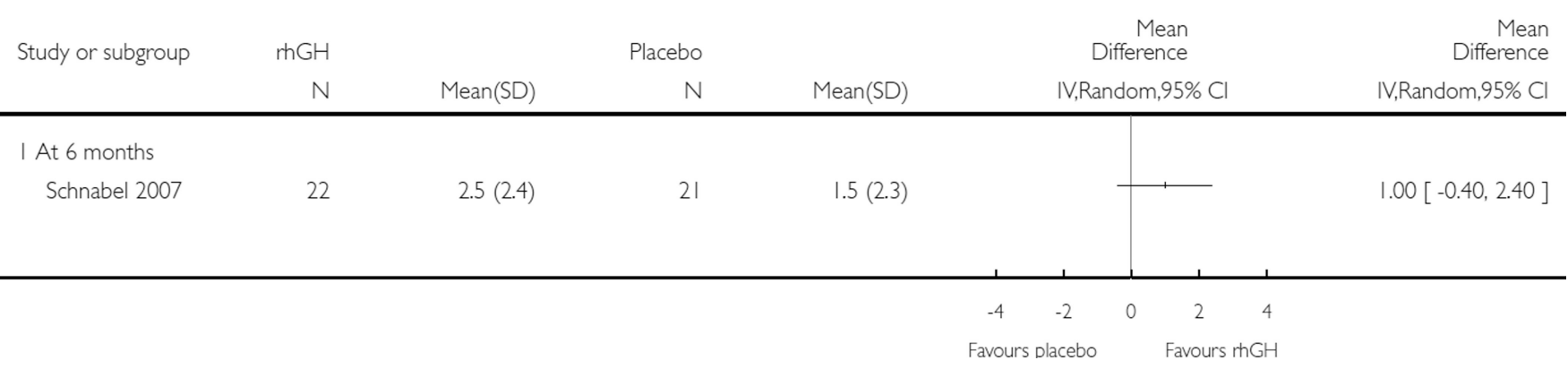

Analysis 1.7.

Comparison 1 Standard rhGH versus placebo, Outcome 7 Lean tissue mass (kg). 


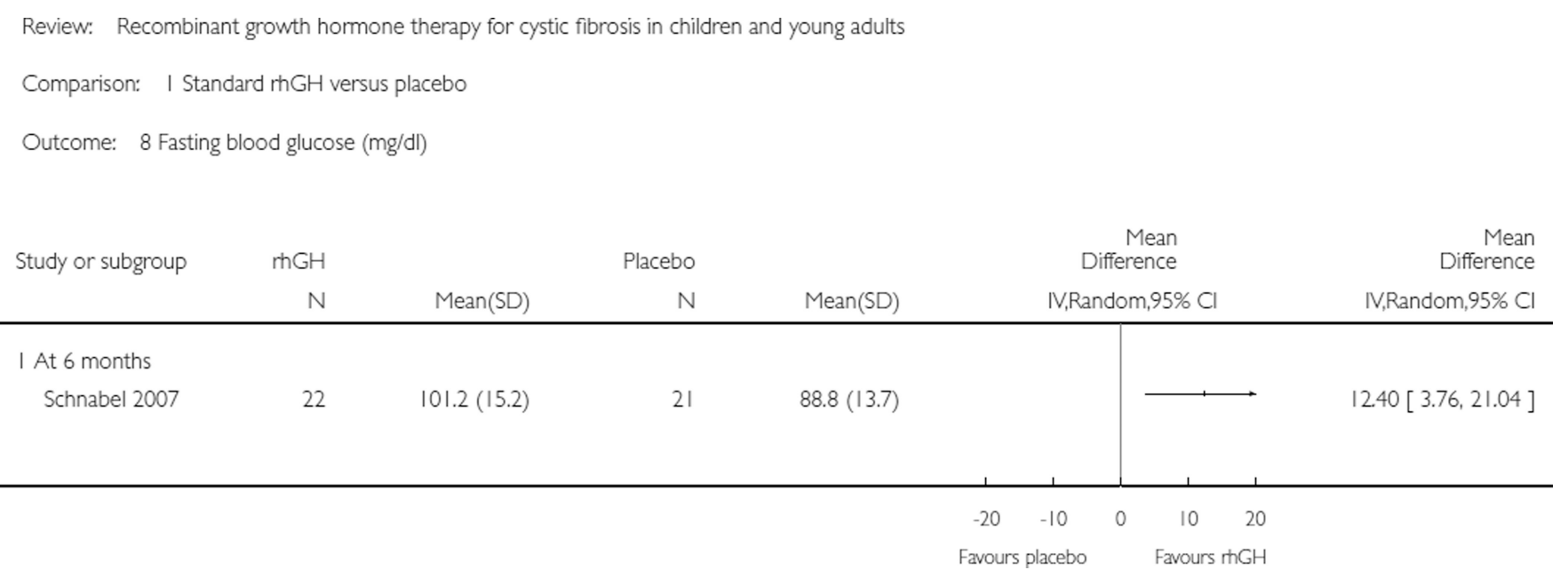

Analysis 1.8.

Comparison 1 Standard rhGH versus placebo, Outcome 8 Fasting blood glucose (mg/dl). 
Review: Recombinant growth hormone therapy for cystic fibrosis in children and young adults

Comparison: I Standard hGH versus placebo

Outcome: 9 Postprandial blood glucose $(\mathrm{mg} / \mathrm{dl})$

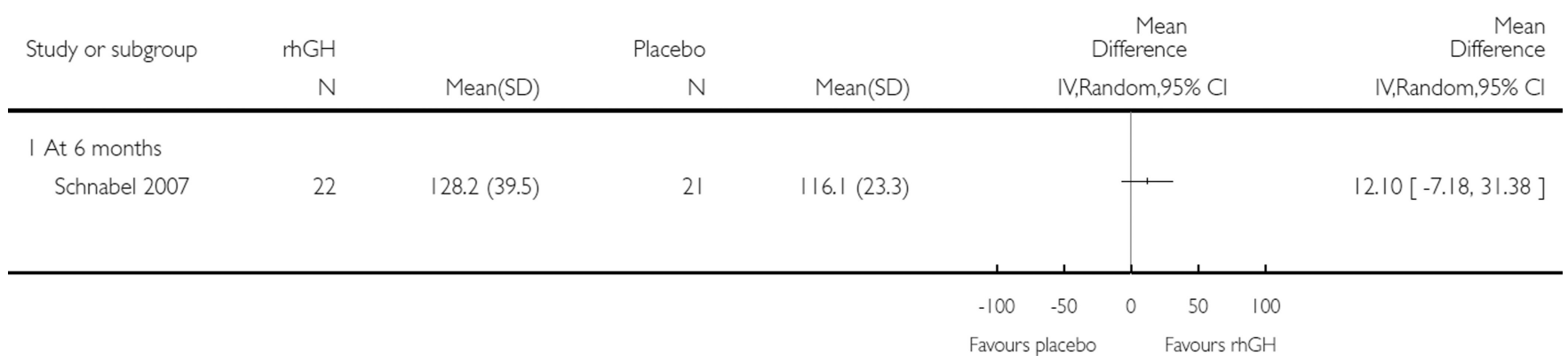

Analysis 1.9.

Comparison 1 Standard rhGH versus placebo, Outcome 9 Postprandial blood glucose (mg/ dl). 
Review: Recombinant growth hormone therapy for cystic fibrosis in children and young adults

Comparison: I Standard hGH versus placebo

Outcome: 10 Exercise capacity (watts)

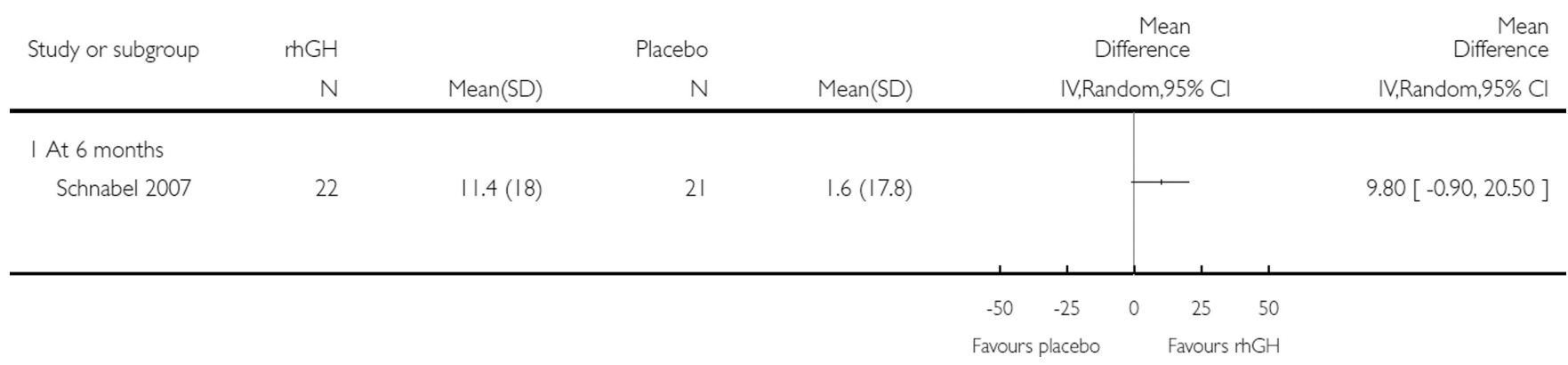

Analysis 1.10.

Comparison 1 Standard rhGH versus placebo, Outcome 10 Exercise capacity (watts). 


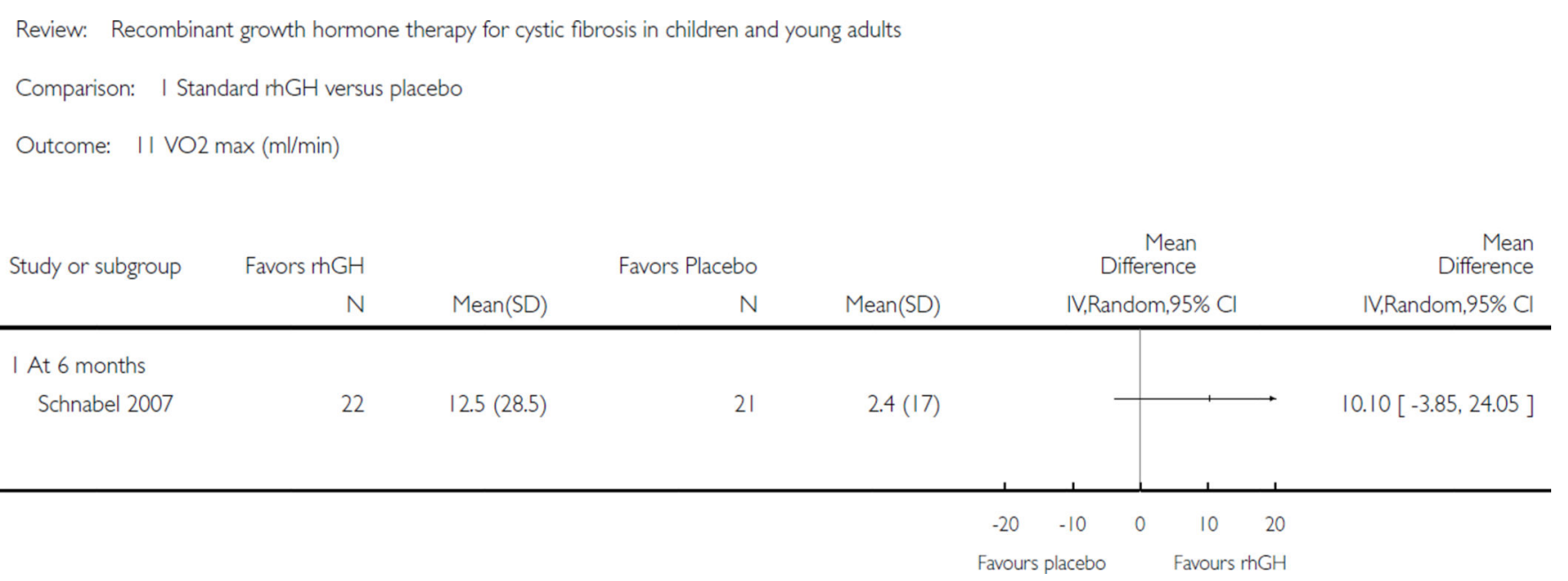

Analysis 1.11.

Comparison 1 Standard rhGH versus placebo, Outcome $11 \mathrm{VO} 2 \mathrm{max}(\mathrm{ml} / \mathrm{min})$. 


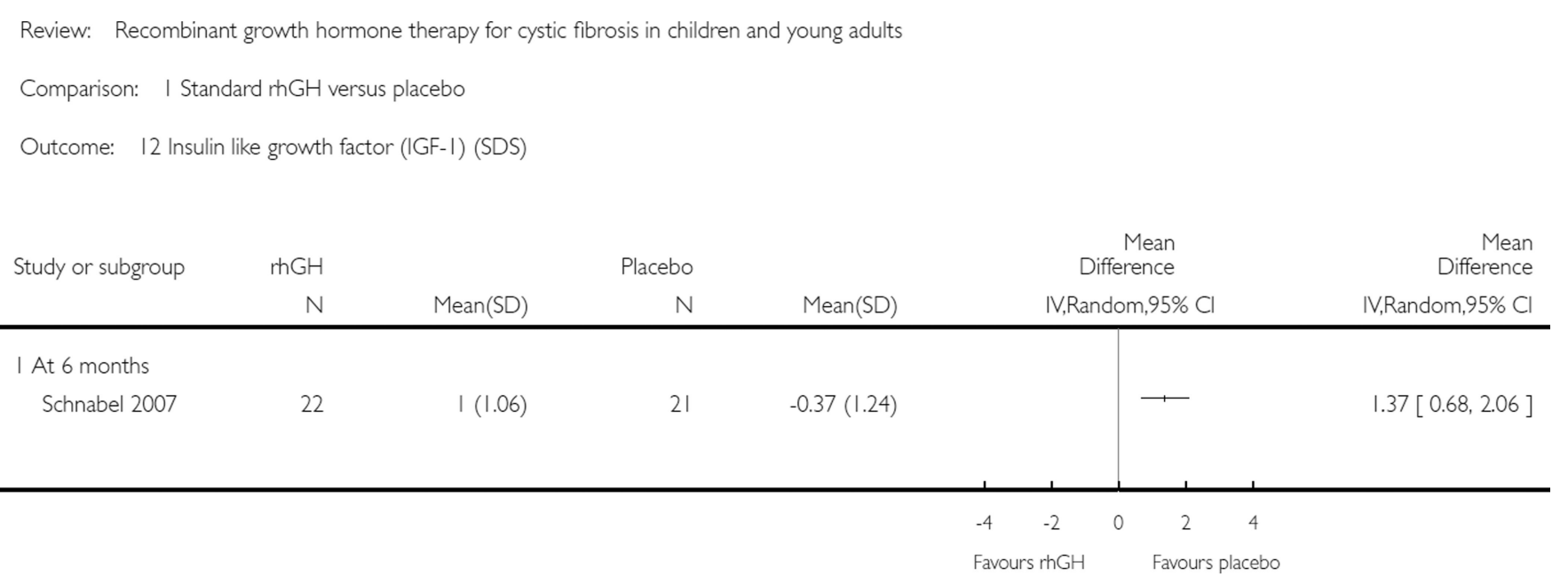

Analysis 1.12.

Comparison 1 Standard rhGH versus placebo, Outcome 12 Insulin like growth factor (IGF-1) (SDS). 
Review: Recombinant growth hormone therapy for cystic fibrosis in children and young adults

Comparison: I Standard $\mathrm{hGH}$ versus placebo

Outcome: 13 IGFBP-3 (SDS)

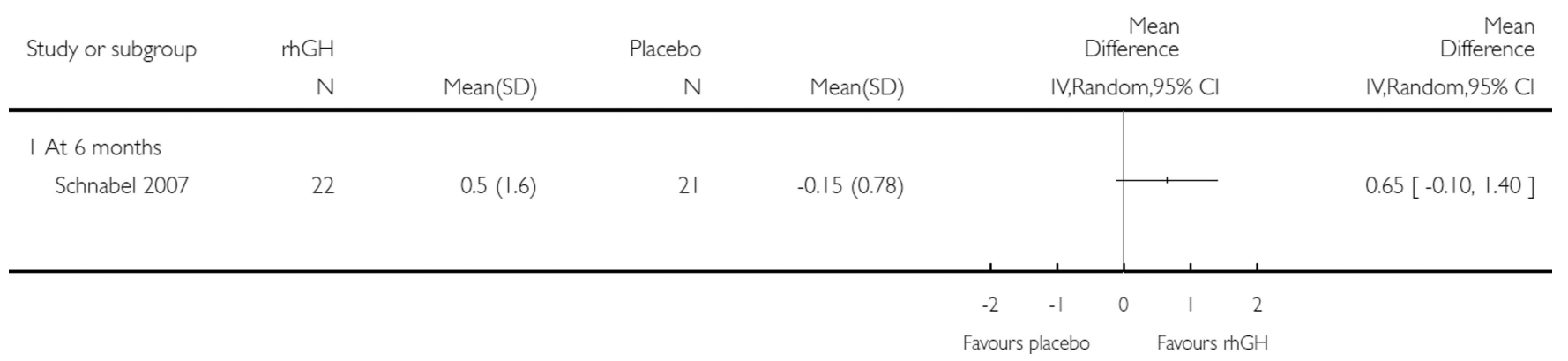

Analysis 1.13.

Comparison 1 Standard rhGH versus placebo, Outcome 13 IGFBP-3 (SDS). 


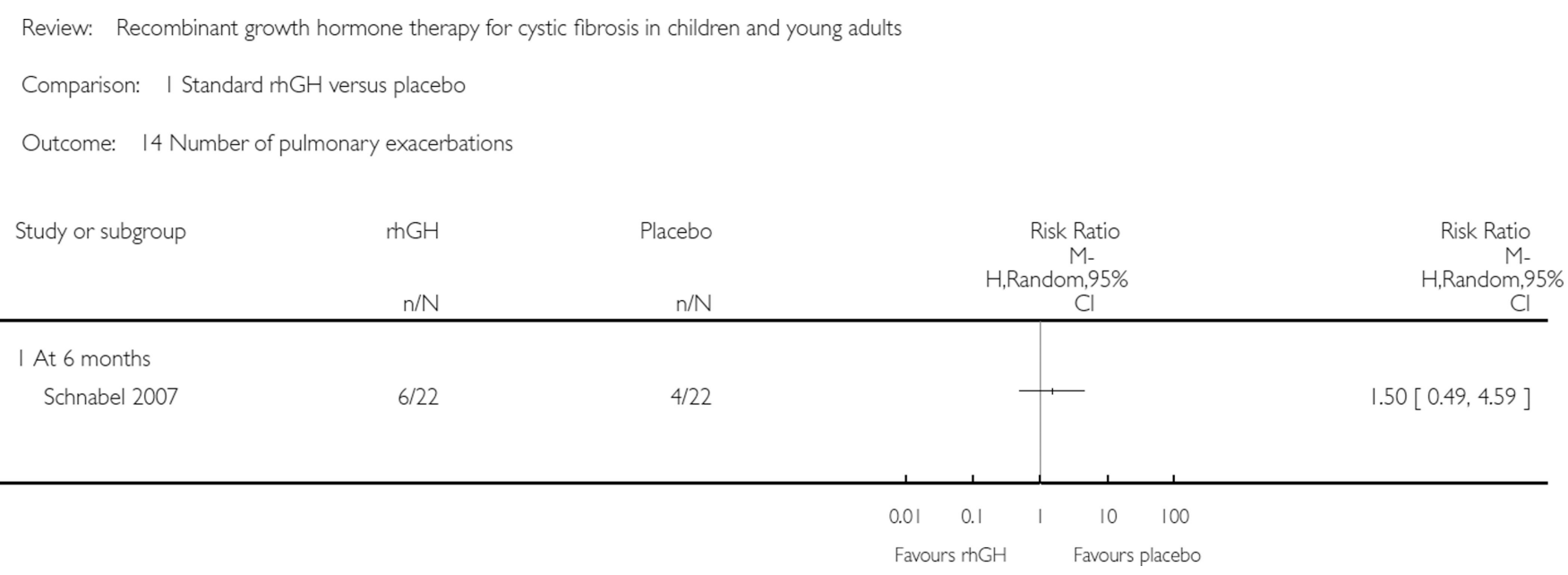

Analysis 1.14.

Comparison 1 Standard rhGH versus placebo, Outcome 14 Number of pulmonary exacerbations. 


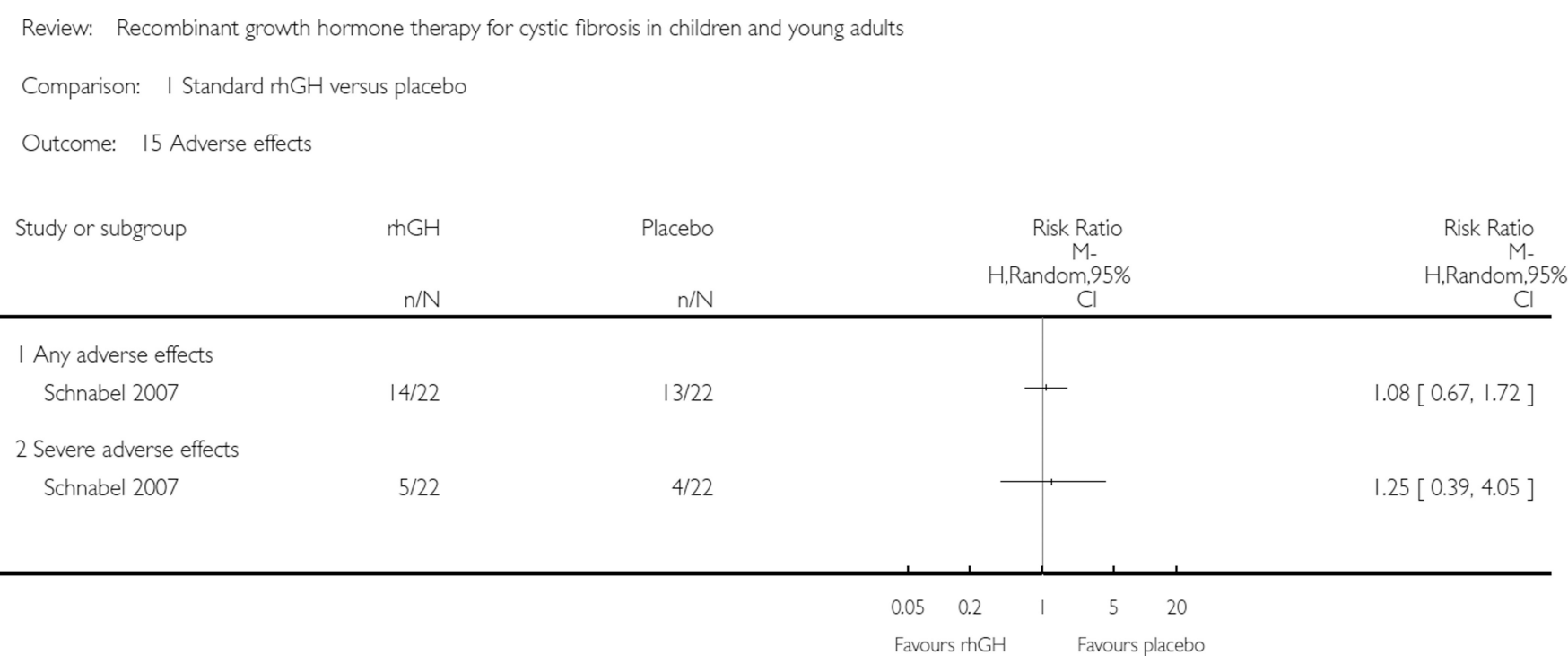

\section{Analysis 1.15.}

Comparison 1 Standard rhGH versus placebo, Outcome 15 Adverse effects. 


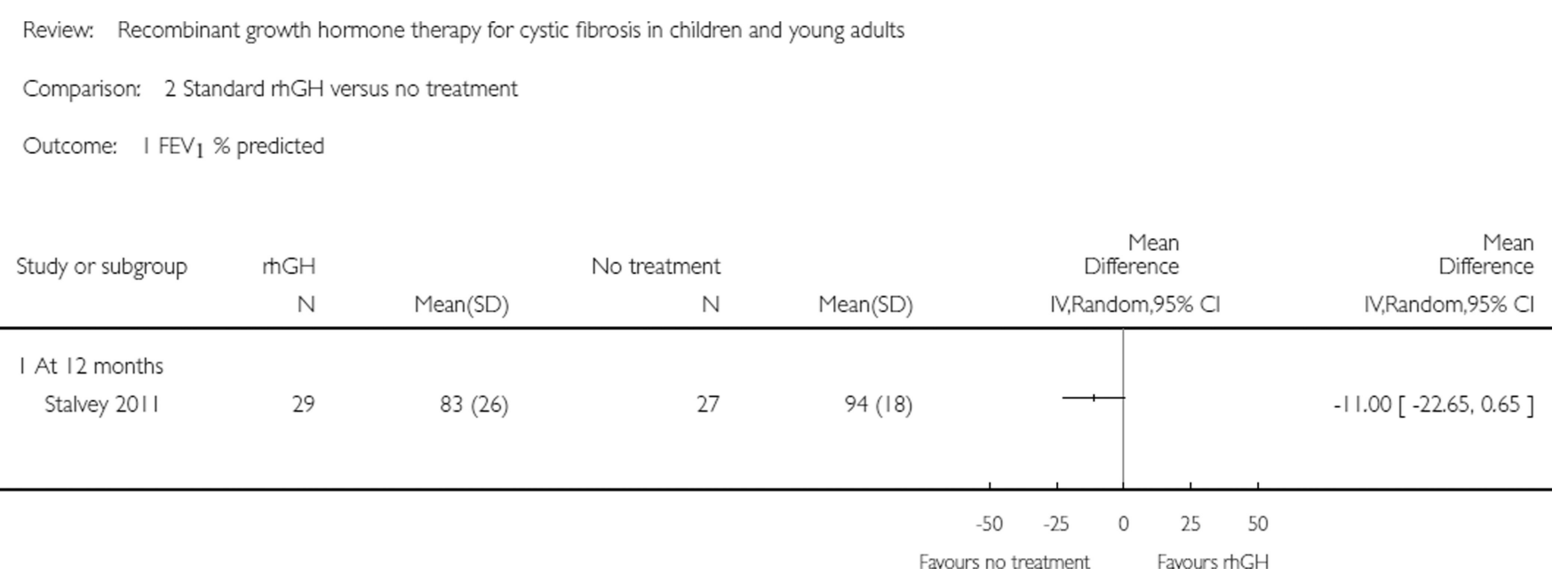

\section{Analysis 2.1.}

Comparison 2 Standard rhGH versus no treatment, Outcome 1 FEV1 \% predicted. 


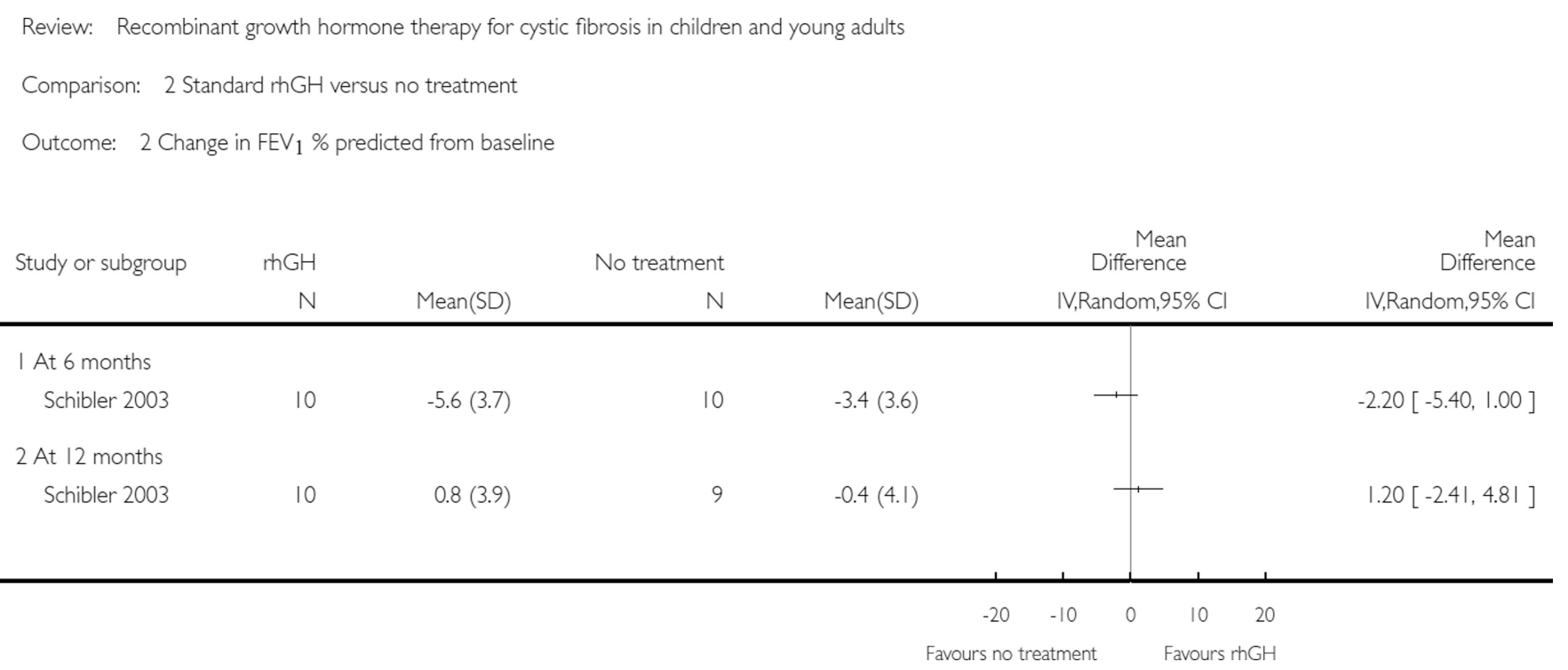

Analysis 2.2.

Comparison 2 Standard rhGH versus no treatment, Outcome 2 Change in FEV1 \% predicted from baseline. 


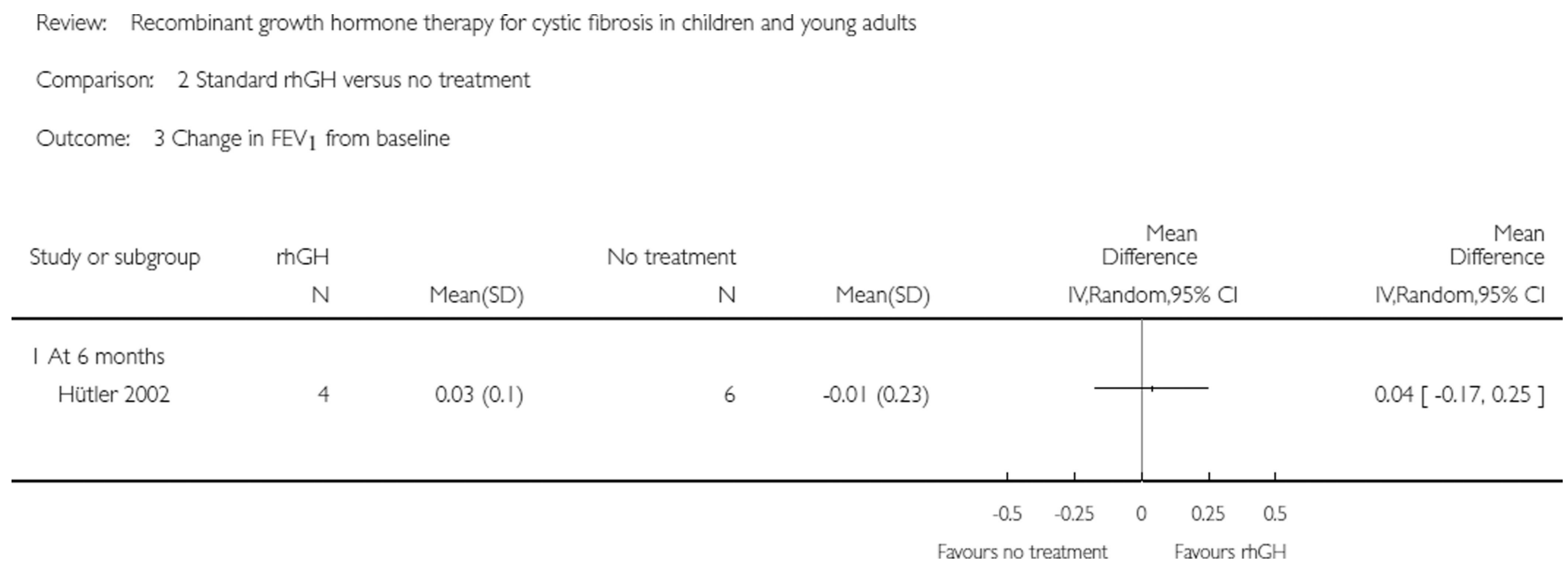

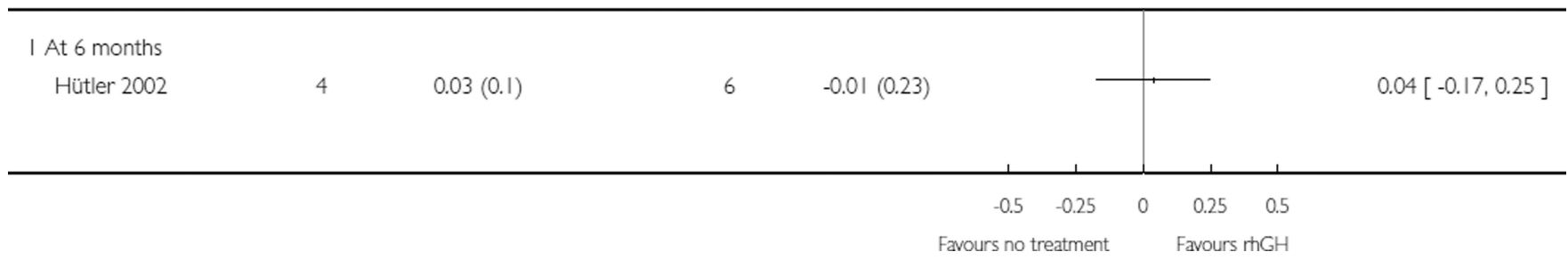

Analysis 2.3.

Comparison 2 Standard rhGH versus no treatment, Outcome 3 Change in FEV1 from baseline. 
Review: Recombinant growth hormone therapy for cystic fibrosis in children and young adults

Comparison: 2 Standard ihGH versus no treatment

Outcome: 4 FVC $\%$ predicted

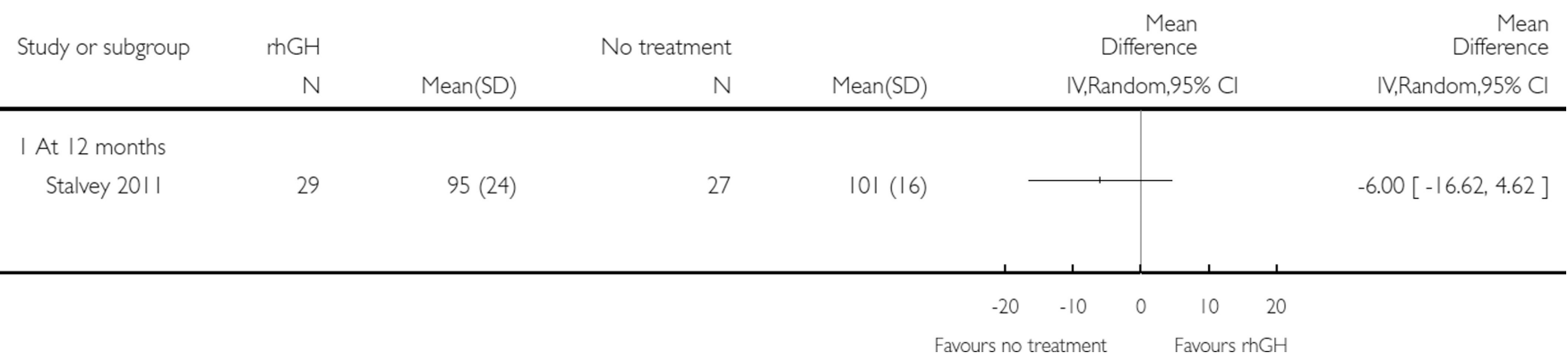

Analysis 2.4.

Comparison 2 Standard rhGH versus no treatment, Outcome 4 FVC \% predicted. 


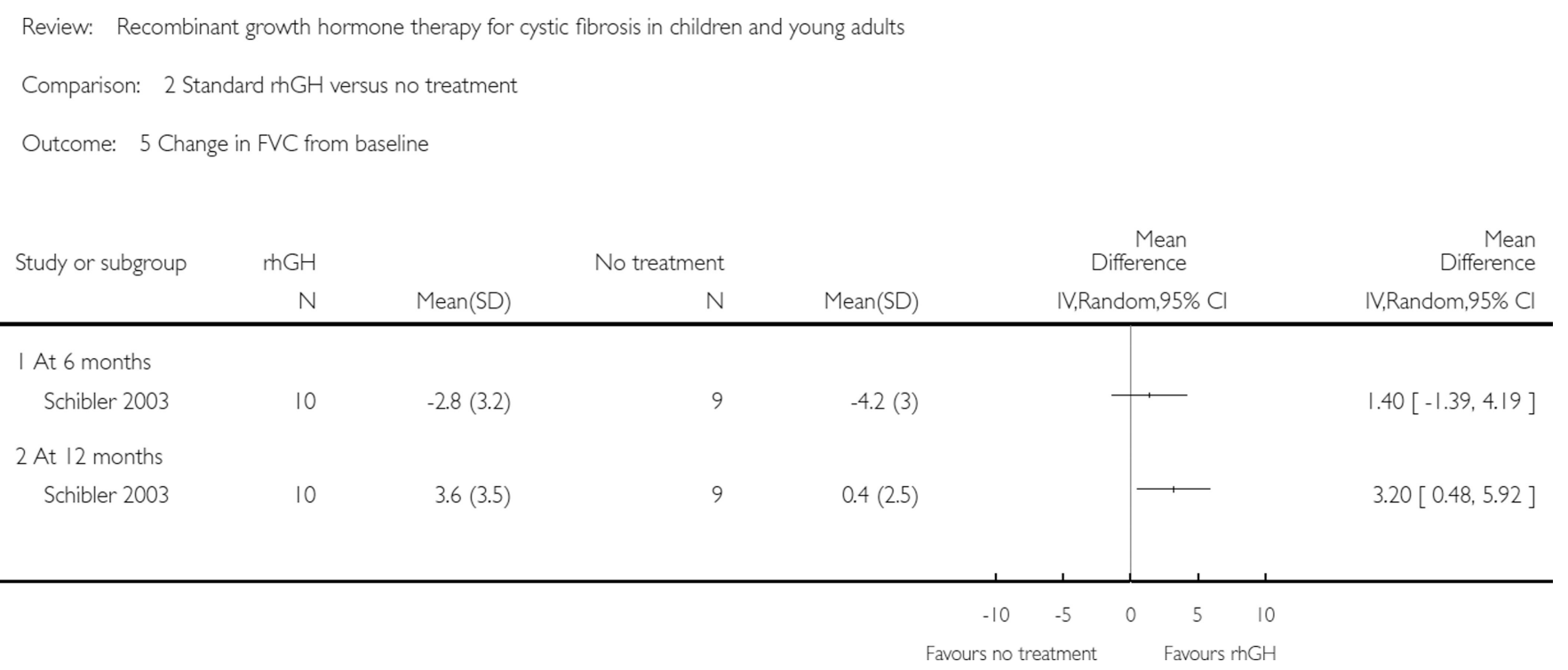

Analysis 2.5.

Comparison 2 Standard rhGH versus no treatment, Outcome 5 Change in FVC from baseline. 
Review: Recombinant growth hormone therapy for cystic fibrosis in children and young adults

Comparison: 2 Standard $\mathrm{mGH}$ versus no treatment

Outcome: 6 Height z score

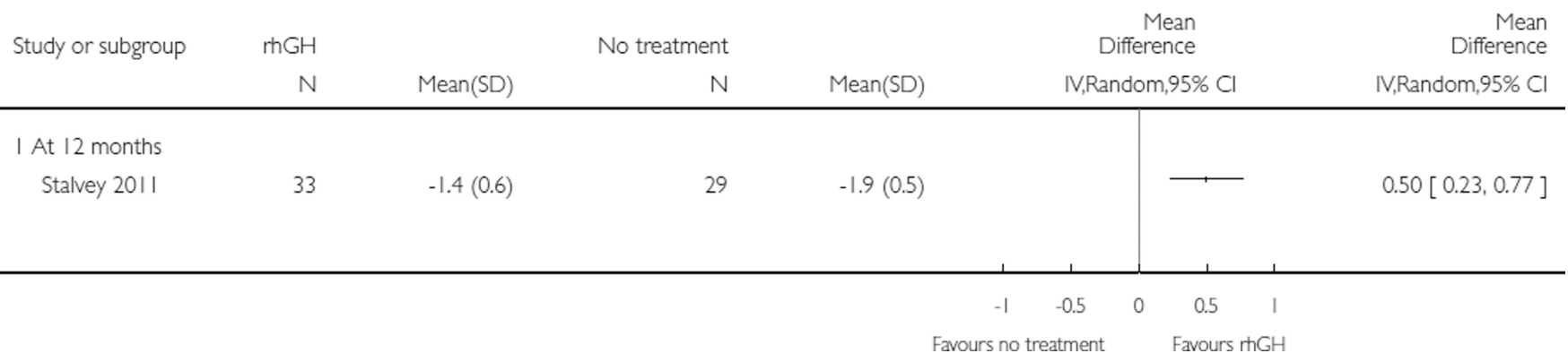

Analysis 2.6.

Comparison 2 Standard rhGH versus no treatment, Outcome 6 Height z score. 


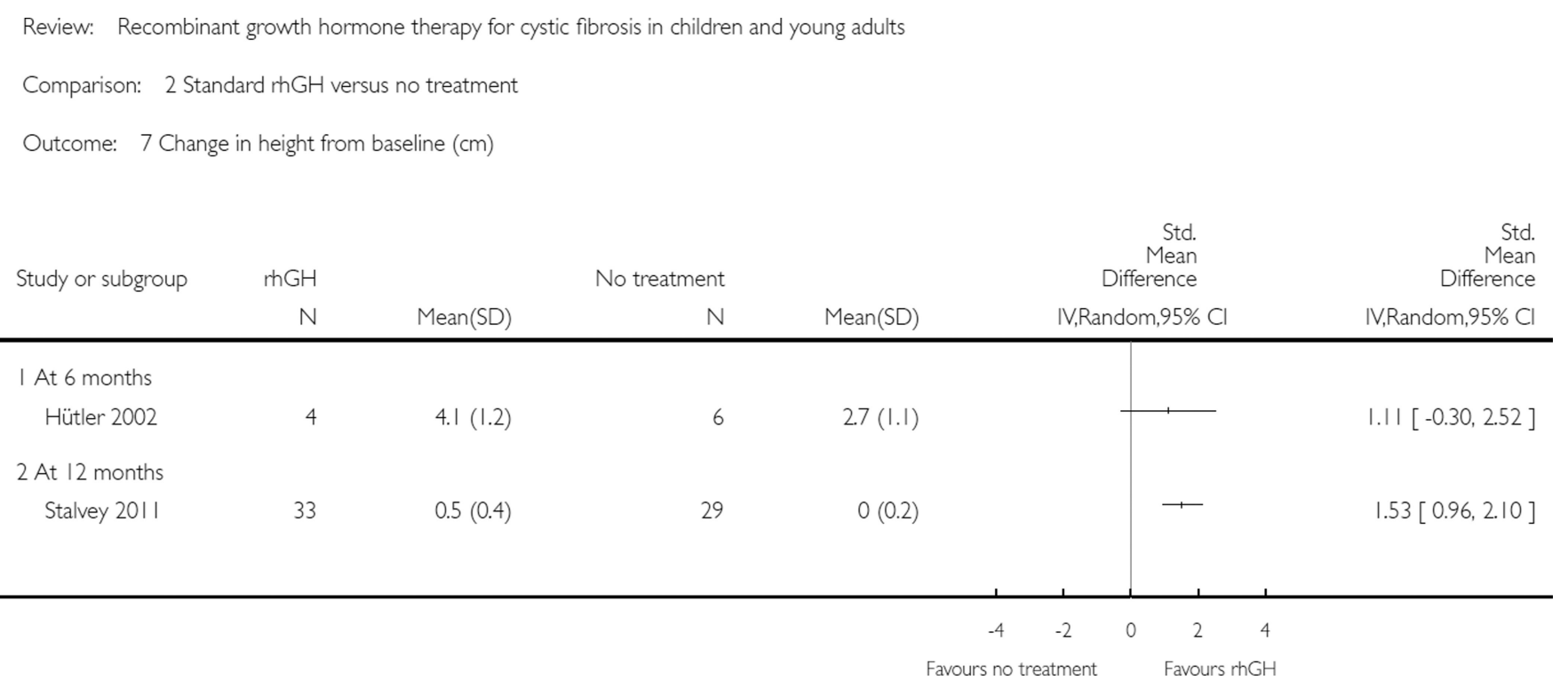

Analysis 2.7.

Comparison 2 Standard rhGH versus no treatment, Outcome 7 Change in height from baseline $(\mathrm{cm})$. 


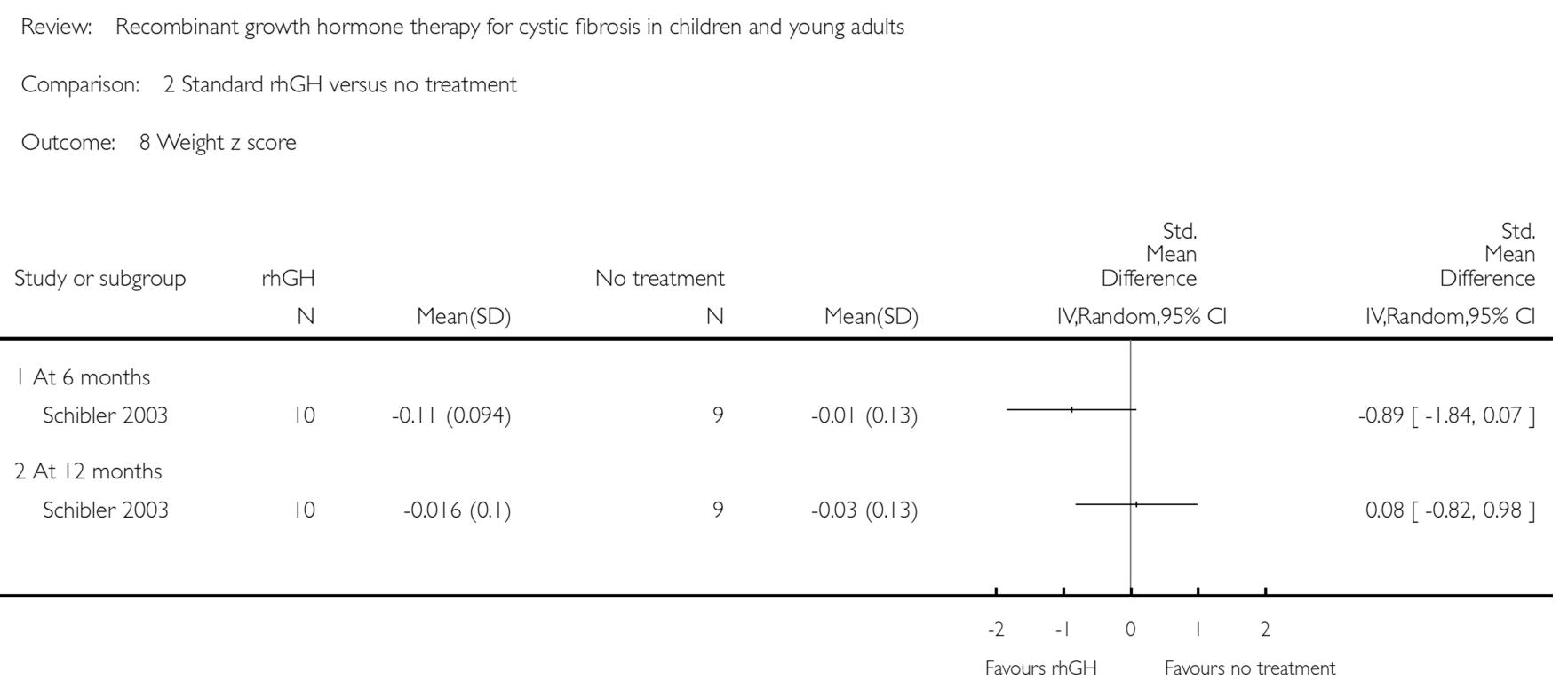

Analysis 2.8.

Comparison 2 Standard rhGH versus no treatment, Outcome 8 Weight z score. 


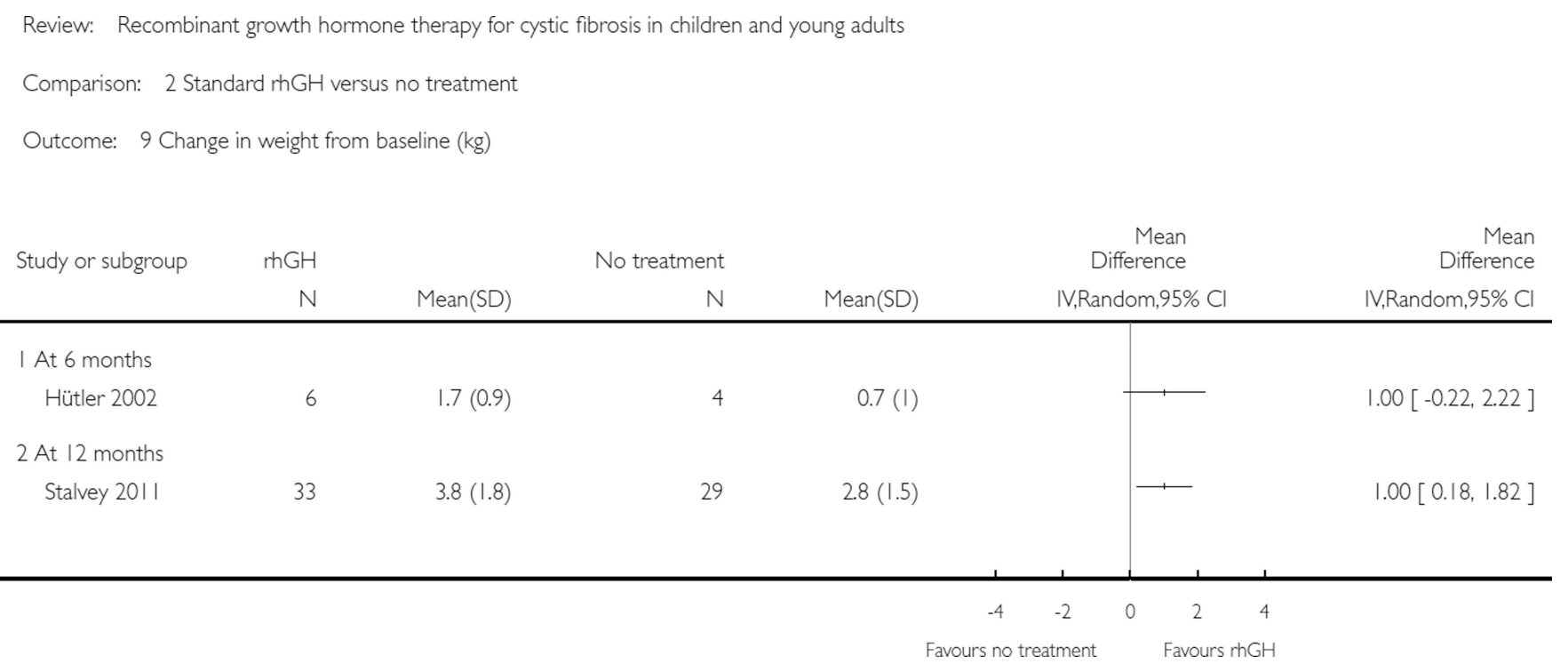

\section{Analysis 2.9.}

Comparison 2 Standard rhGH versus no treatment, Outcome 9 Change in weight from baseline $(\mathrm{kg})$. 


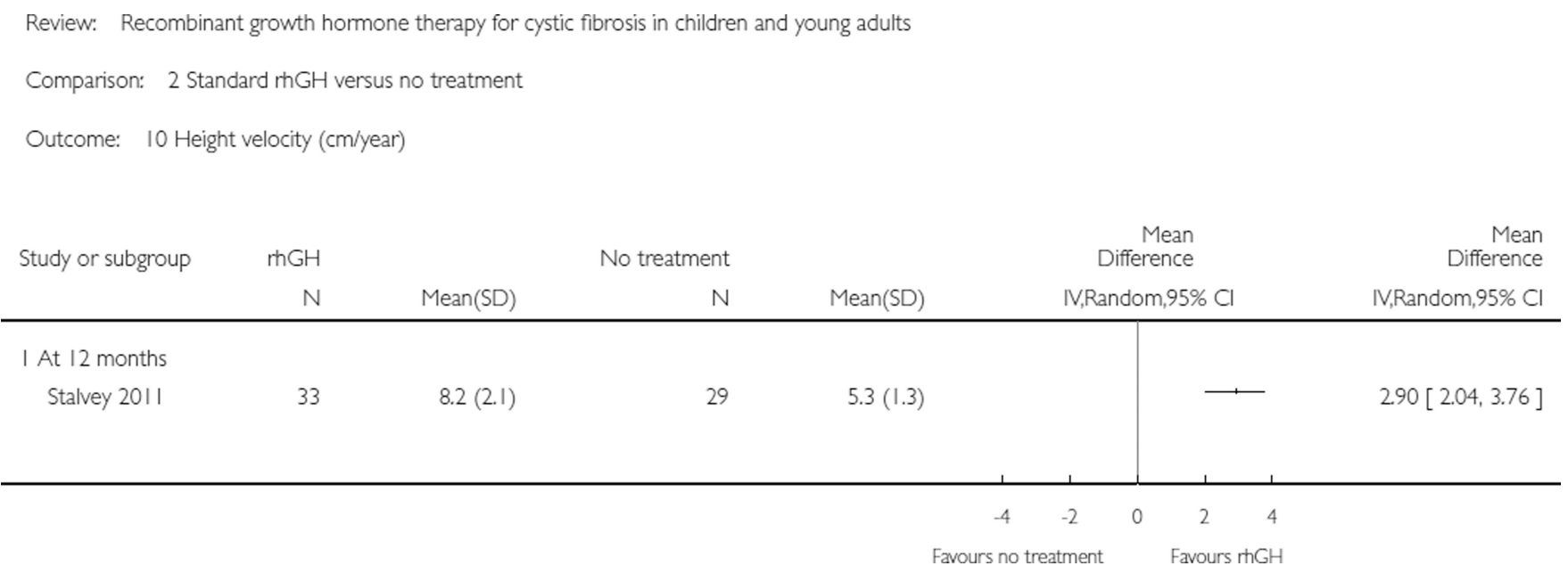

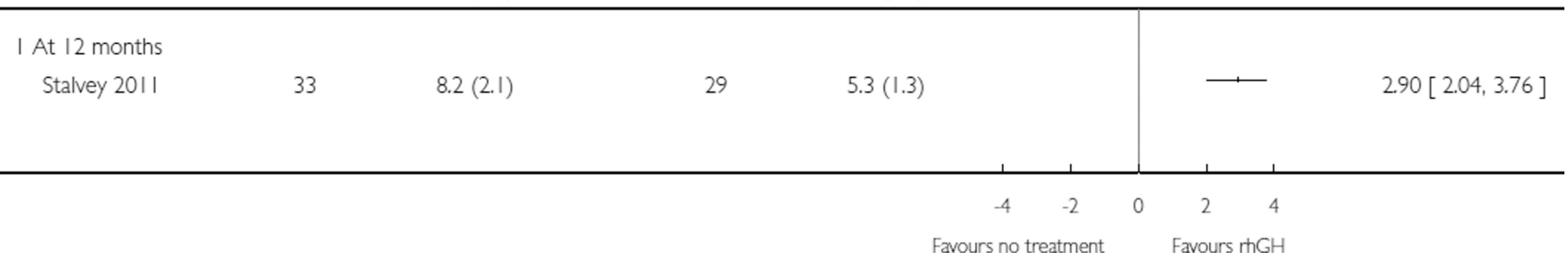

Analysis 2.10.

Comparison 2 Standard rhGH versus no treatment, Outcome 10 Height velocity (cm/year). 


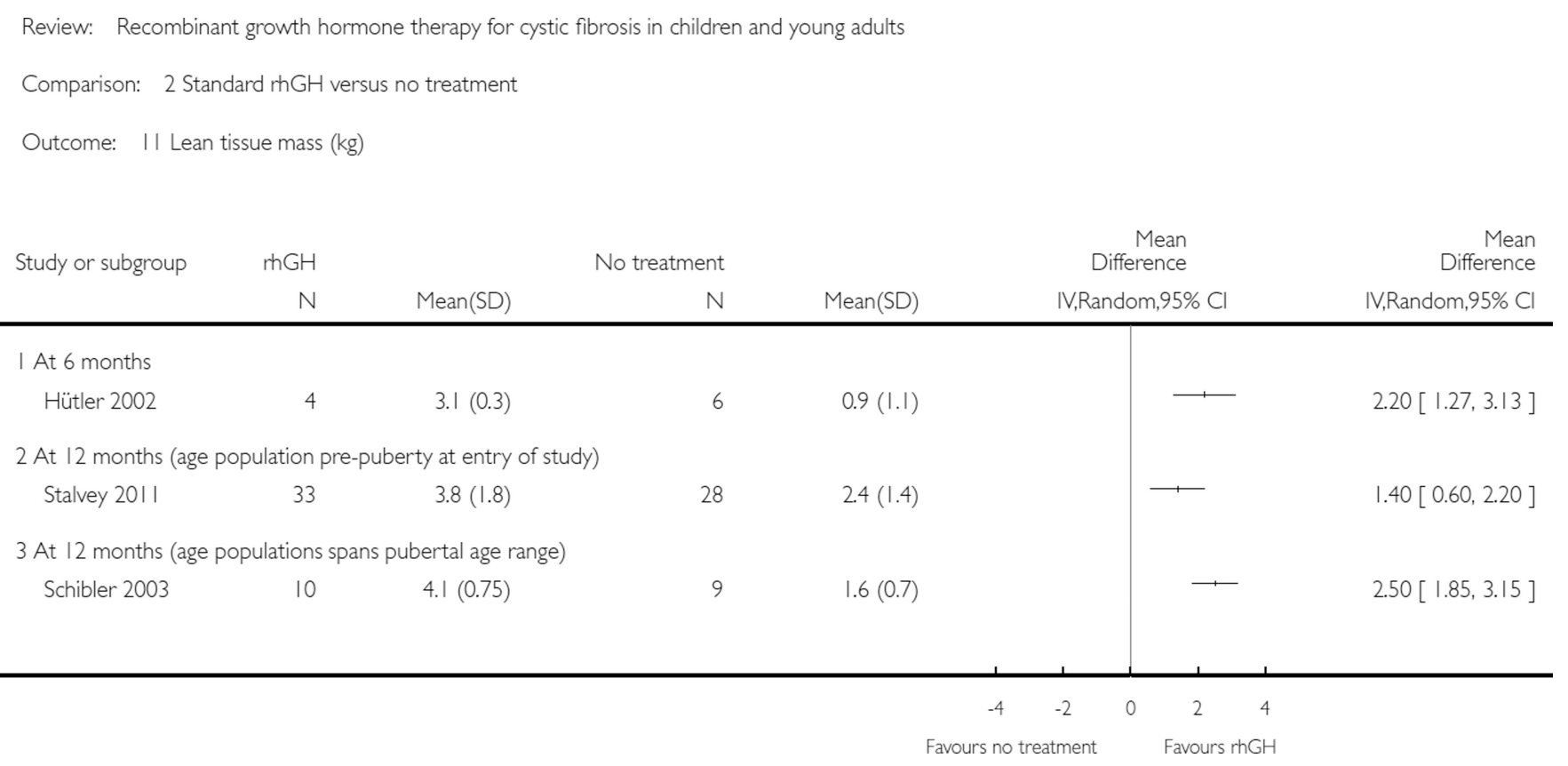

Analysis 2.11.

Comparison 2 Standard rhGH versus no treatment, Outcome 11 Lean tissue mass $(\mathrm{kg})$. 


$$
\text { Reviewe Recombinant growth hormone therapy for cystic fibrosis in childen and young adults }
$$

Cornoxisore 2 Standard ihCH versus no treatment

Outcome 12 Plasma insulin level (o U/mi)

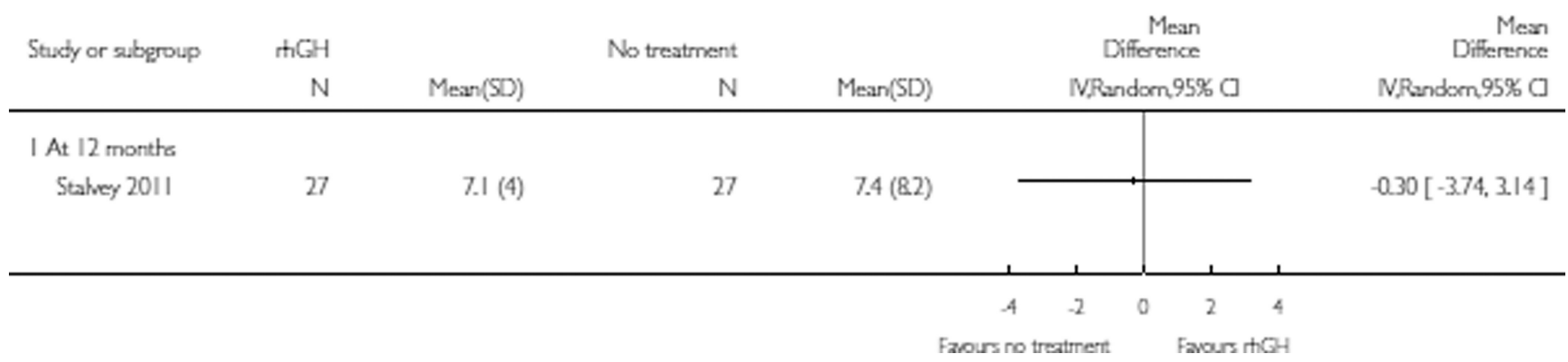

Analysis 2.12.

Comparison 2 Standard rhGH versus no treatment, Outcome 12 Plasma insulin level ( $\mu \mathrm{U} /$ $\mathrm{ml})$. 


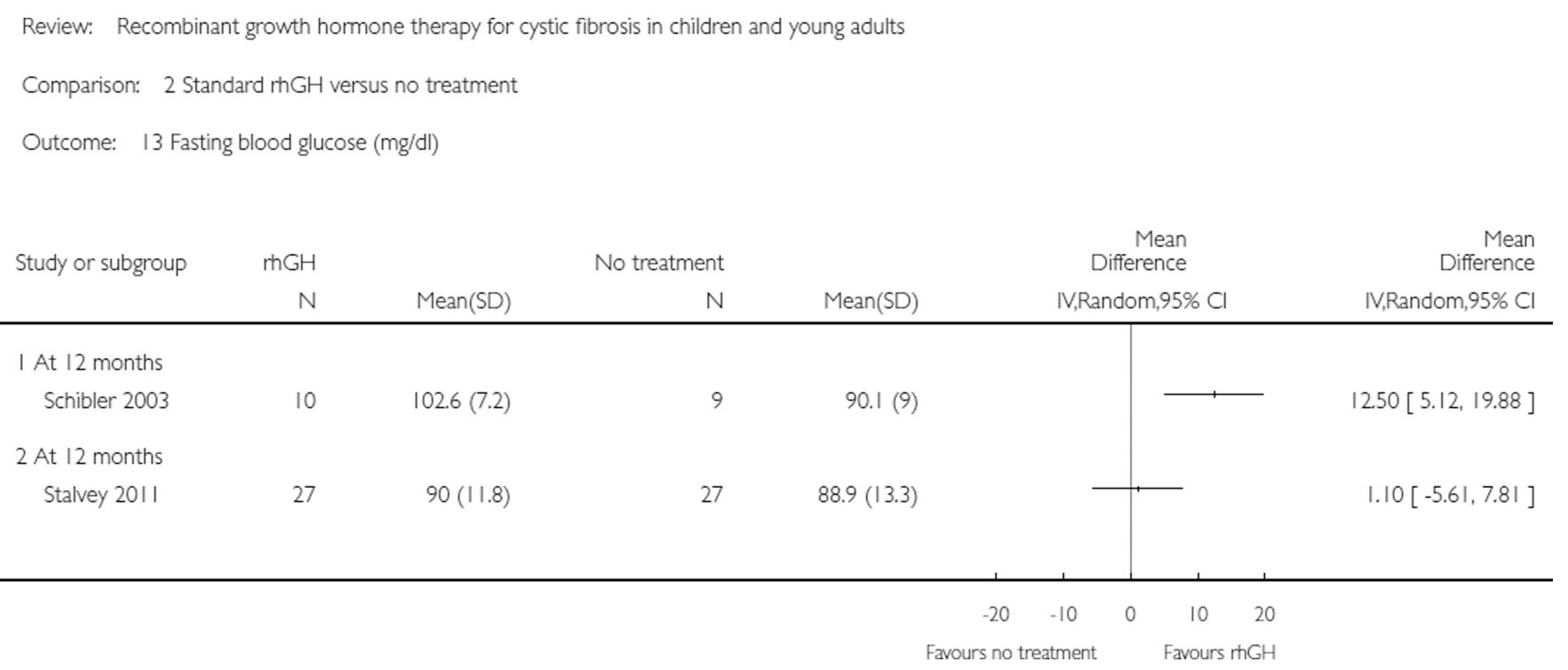

Analysis 2.13.

Comparison 2 Standard rhGH versus no treatment, Outcome 13 Fasting blood glucose (mg/ dl). 
Review: Recombinant growth hormone therapy for cystic fibrosis in children and young adults

Comparison: 2 Standard $\mathrm{mGH}$ versus no treatment

Outcome: 14 Postprandial blood glucose $(\mathrm{mg} / \mathrm{dl})$

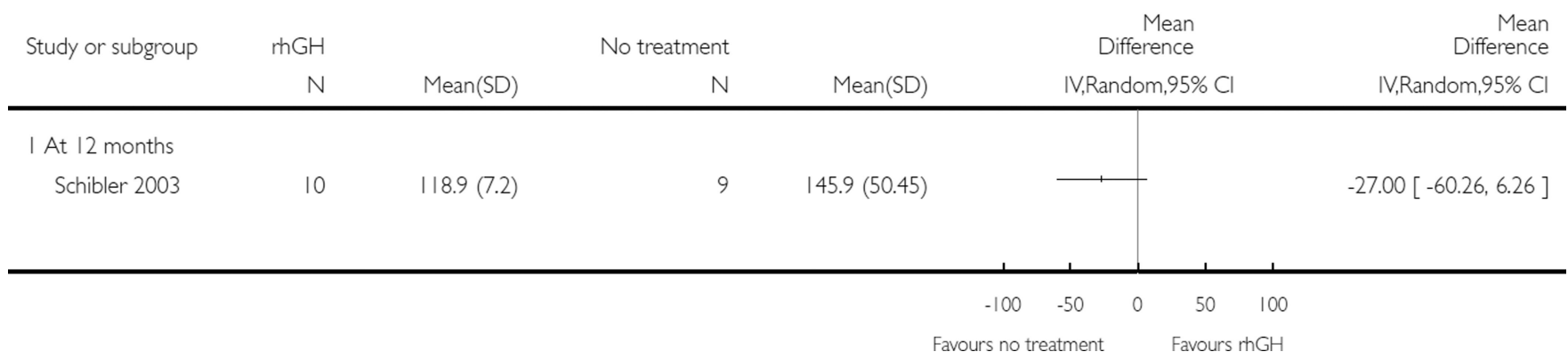

Analysis 2.14.

Comparison 2 Standard rhGH versus no treatment, Outcome 14 Postprandial blood glucose (mg/dl). 


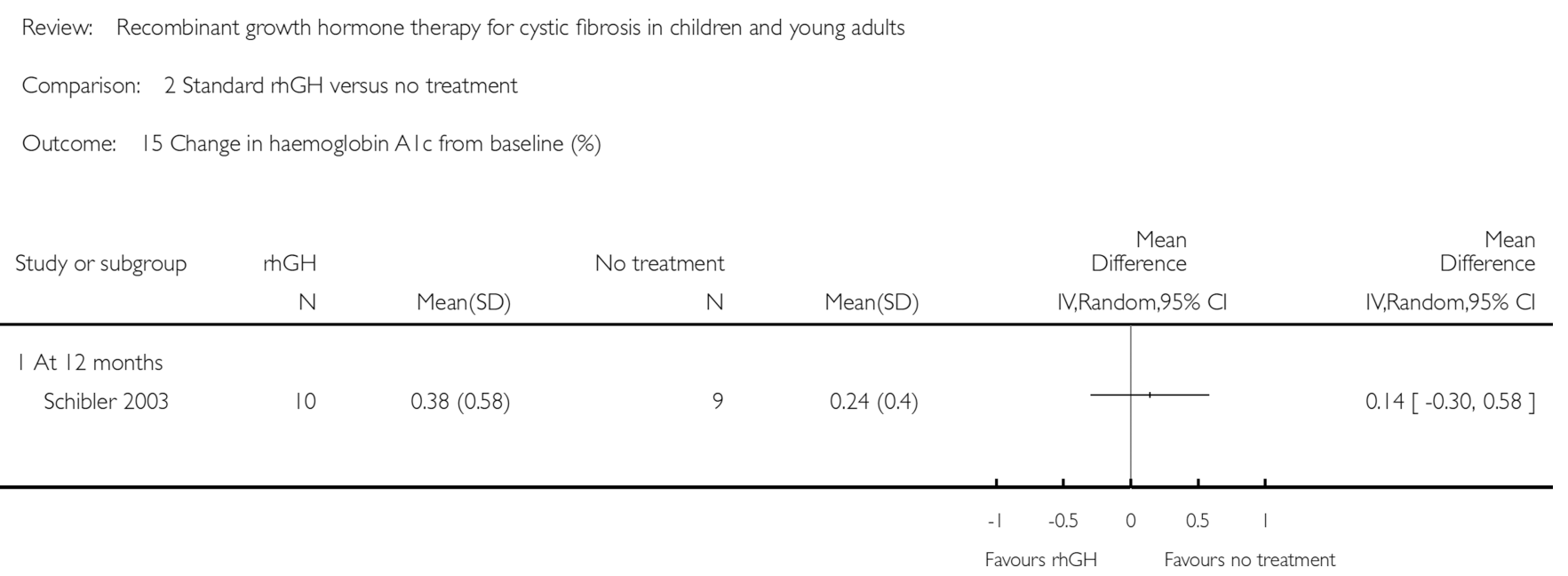

Analysis 2.15.

Comparison 2 Standard rhGH versus no treatment, Outcome 15 Change in haemoglobin A1c from baseline (\%). 


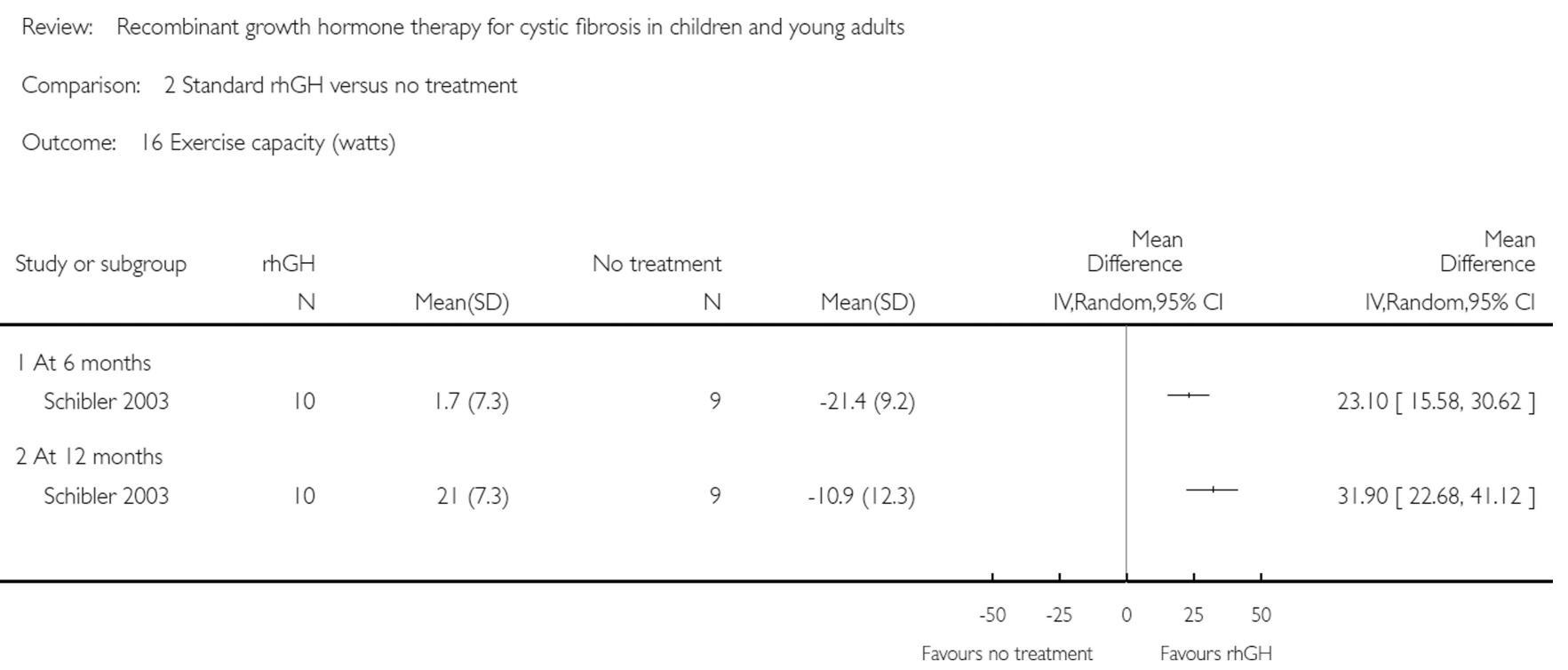

Analysis 2.16.

Comparison 2 Standard rhGH versus no treatment, Outcome 16 Exercise capacity (watts). 


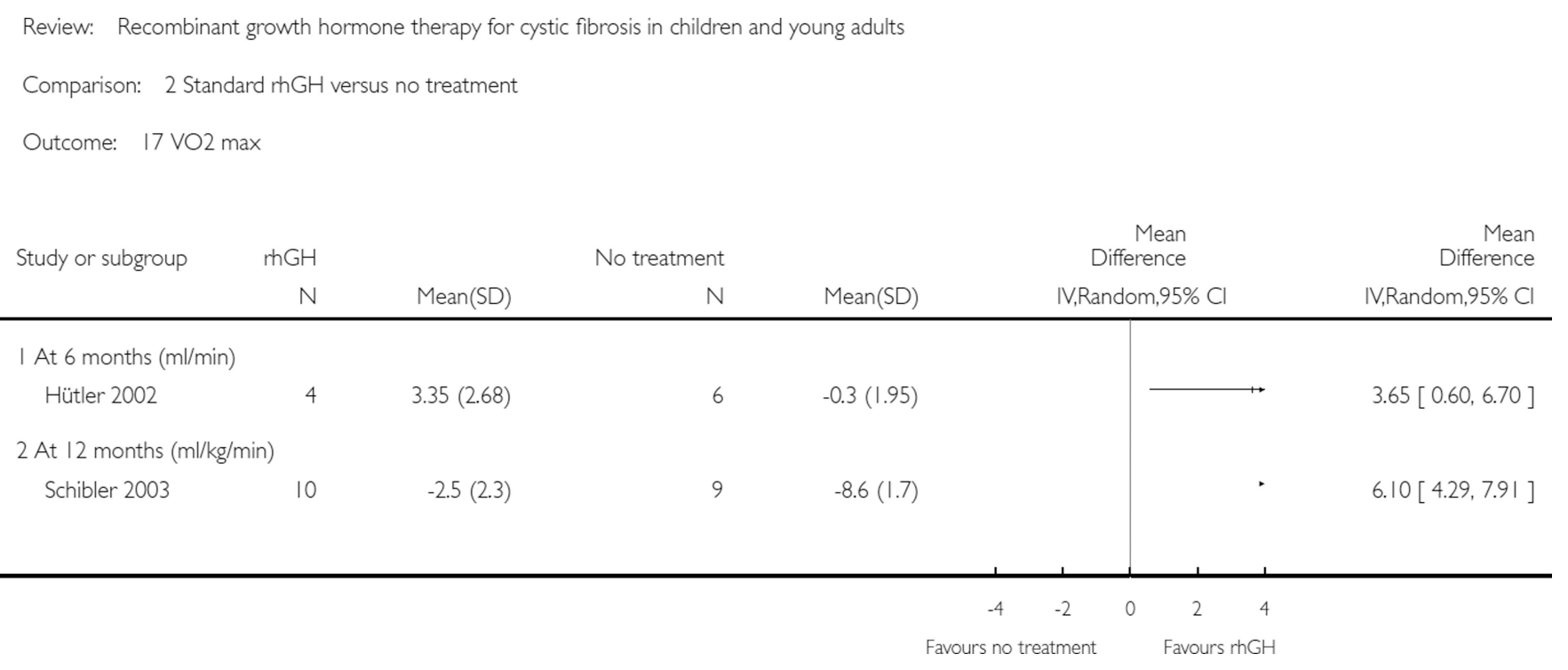

Analysis 2.17.

Comparison 2 Standard rhGH versus no treatment, Outcome 17 VO2 max. 


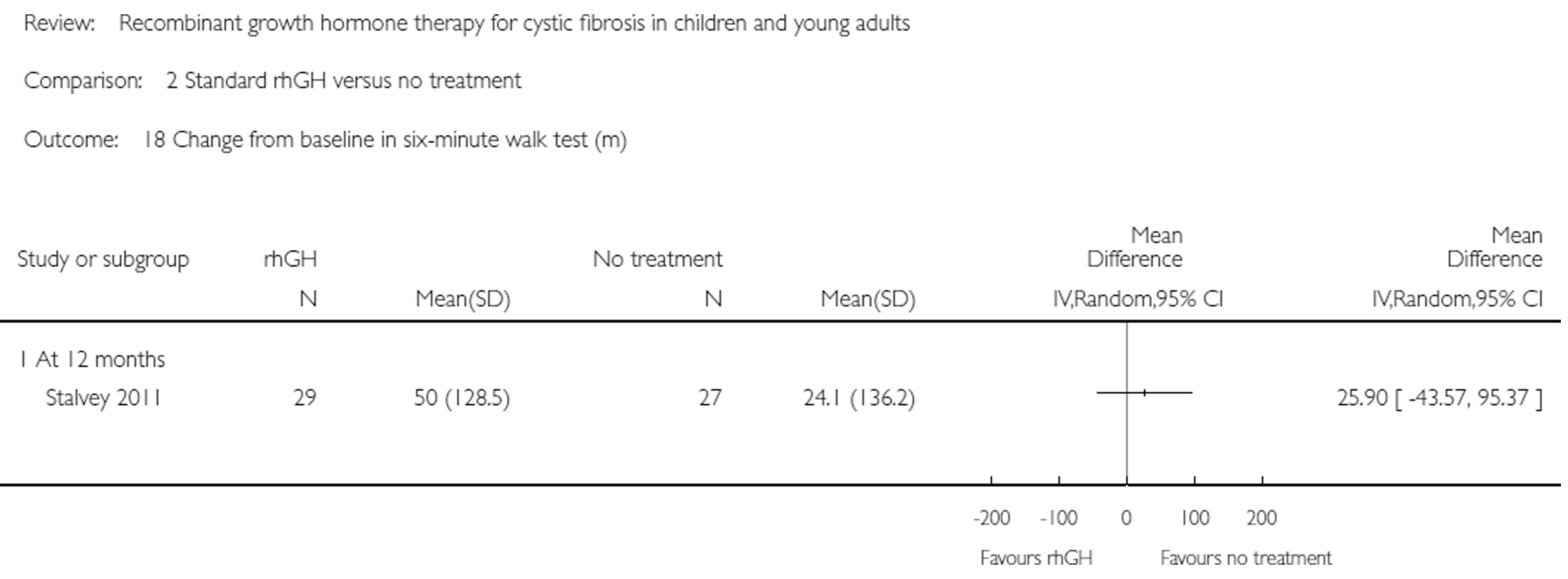

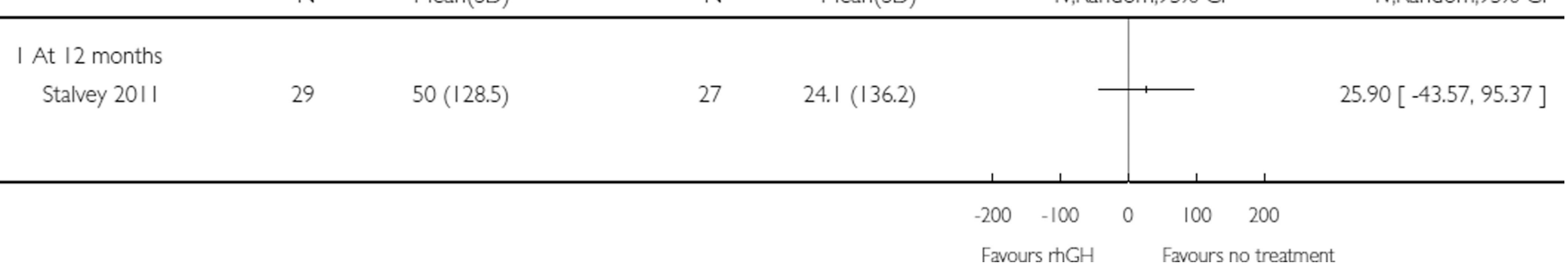

Analysis 2.18.

Comparison 2 Standard rhGH versus no treatment, Outcome 18 Change from baseline in six-minute walk test $(\mathrm{m})$. 


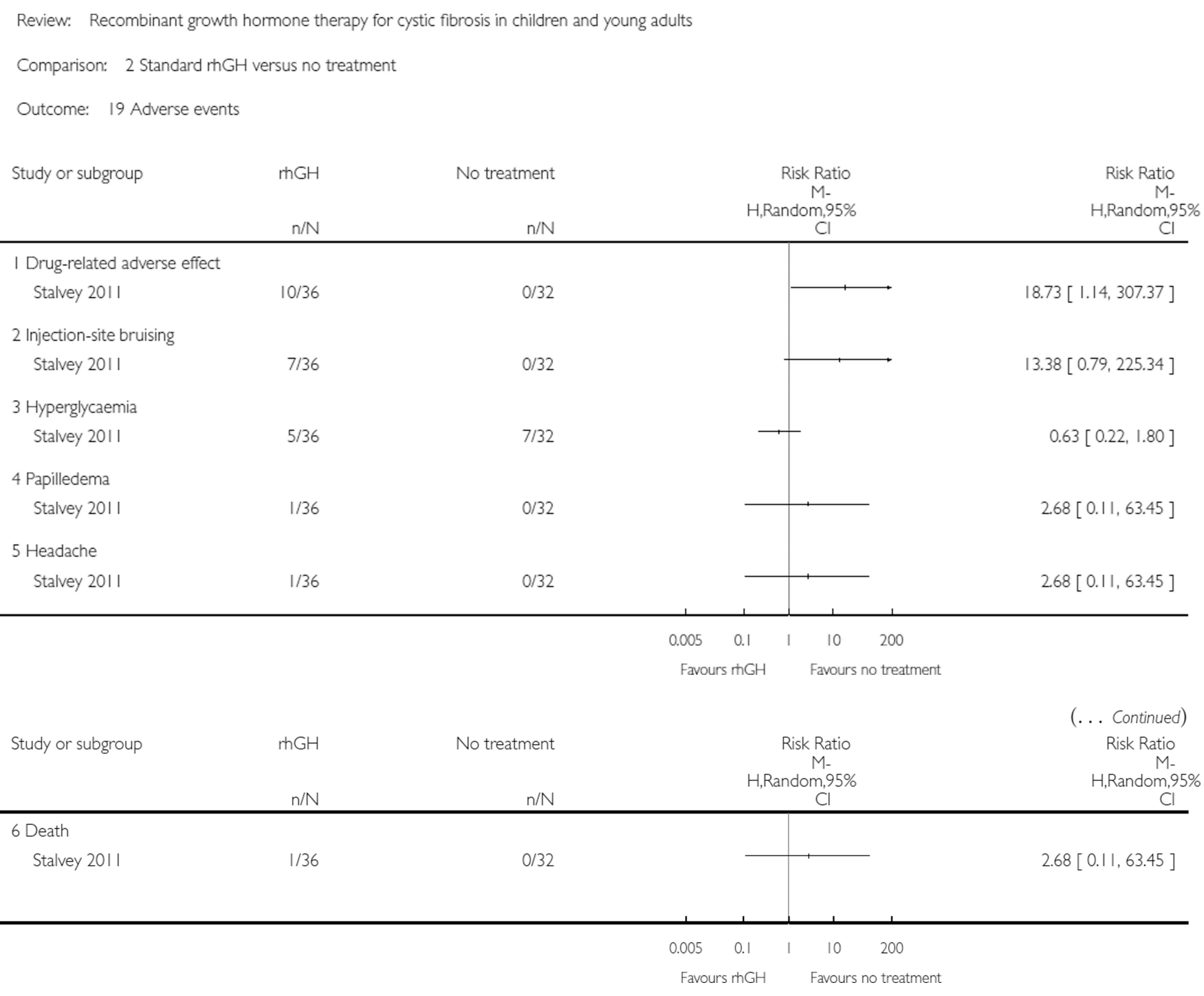

Analysis 2.19.

Comparison 2 Standard rhGH versus no treatment, Outcome 19 Adverse events. 
Review: Recombinant growth hormone therapy for cystic fibrosis in children and young adults

Comparison: 3 High-dose $\mathrm{rhGH}$ versus placebo

Outcome: I FEV 1 (\% predicted)

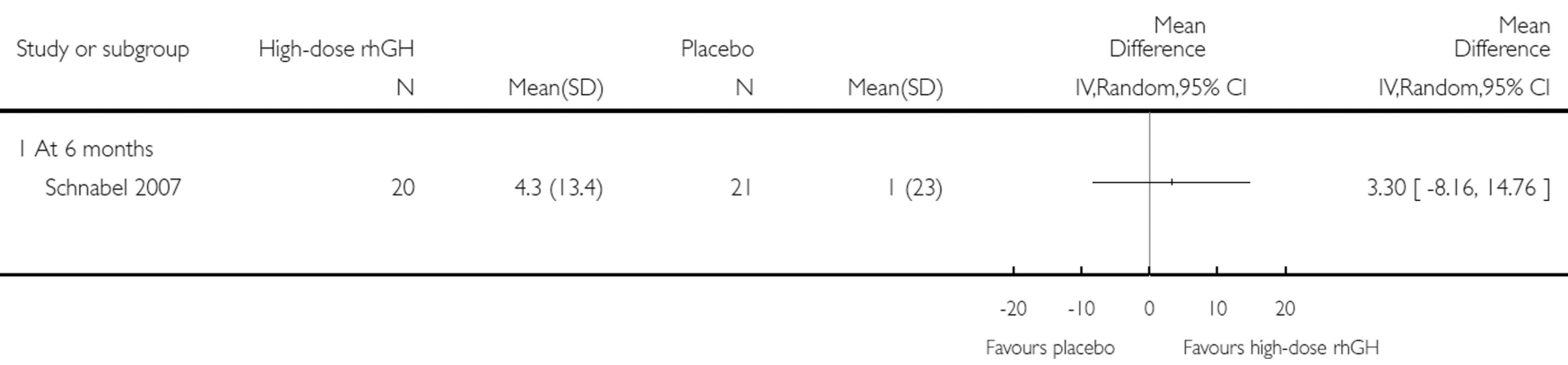

Analysis 3.1.

Comparison 3 High-dose rhGH versus placebo, Outcome 1 FEV1 (\% predicted). 


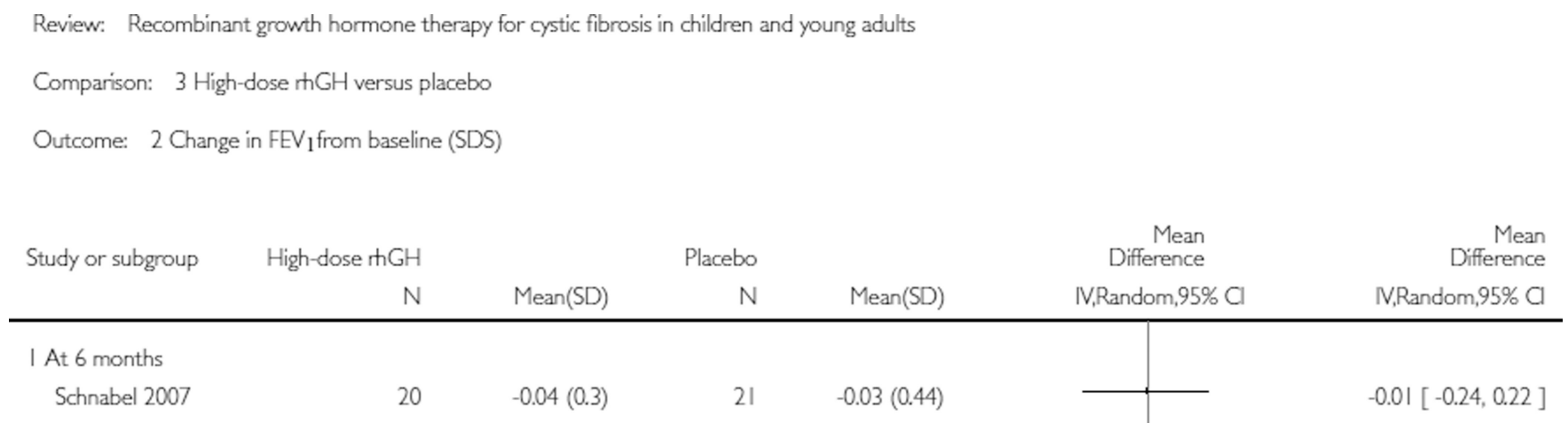

Analysis 3.2.

Comparison 3 High-dose rhGH versus placebo, Outcome 2 Change in FEV1from baseline (SDS). 
Review: Recombinant growth hormone therapy for cystic fibrosis in children and young adults

Comparison: 3 High-dose $\mathrm{rhGH}$ versus placebo

Outcome: 3 FVC (\% predicted)

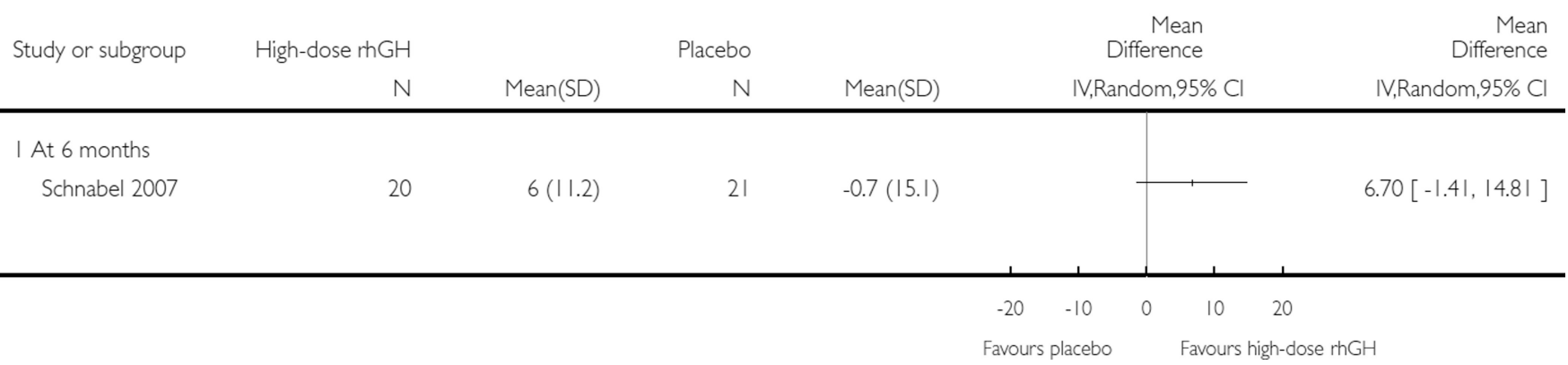

Analysis 3.3.

Comparison 3 High-dose rhGH versus placebo, Outcome 3 FVC (\% predicted). 


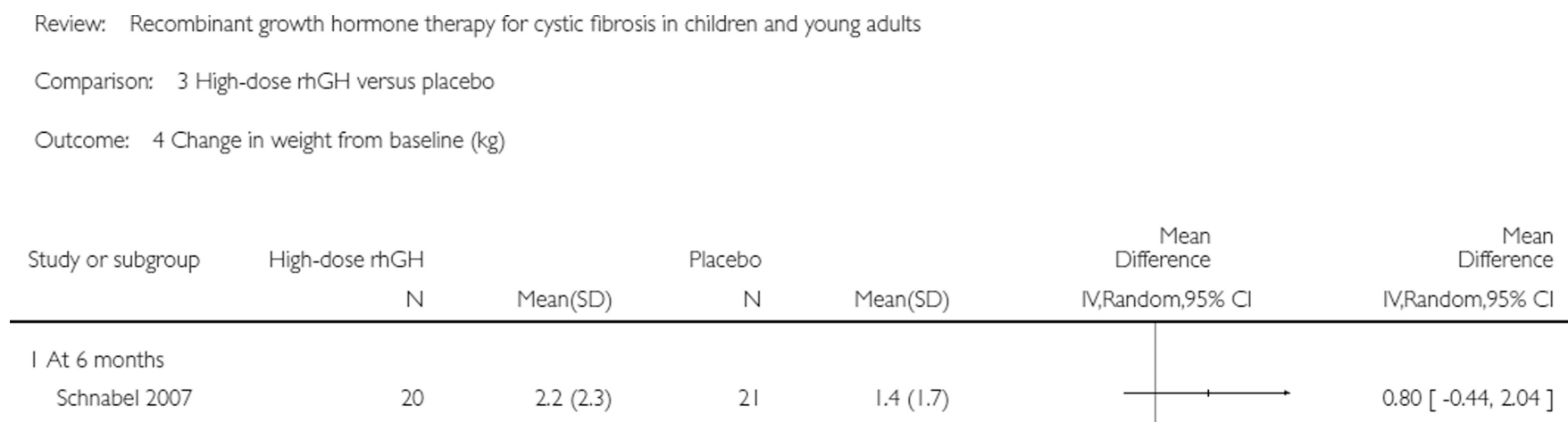

Analysis 3.4.

Comparison 3 High-dose rhGH versus placebo, Outcome 4 Change in weight from baseline $(\mathrm{kg})$. 


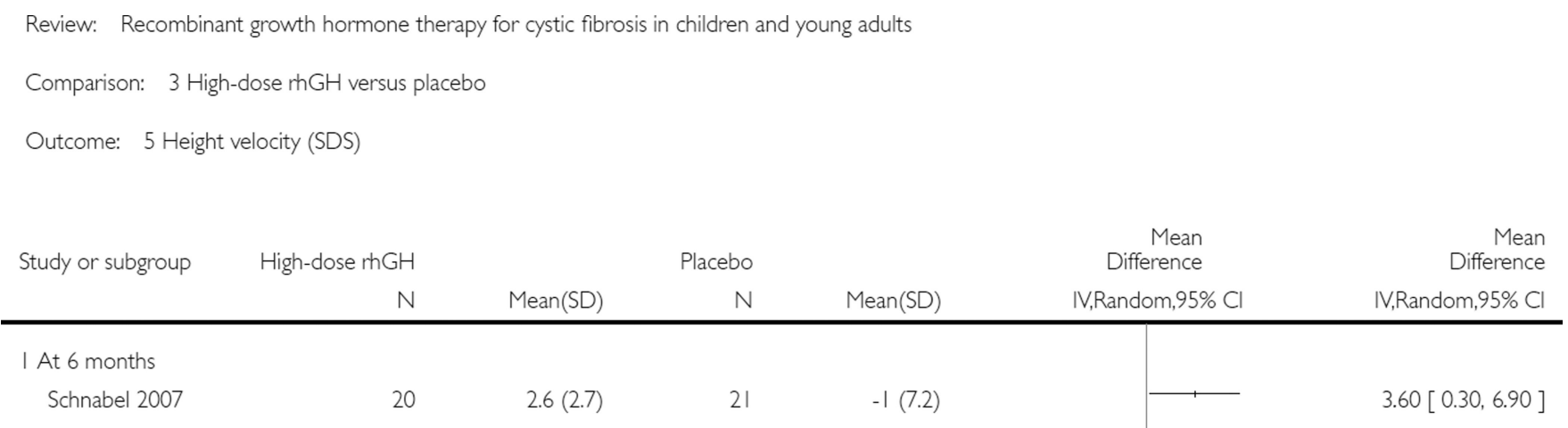

Analysis 3.5.

Comparison 3 High-dose rhGH versus placebo, Outcome 5 Height velocity (SDS). 


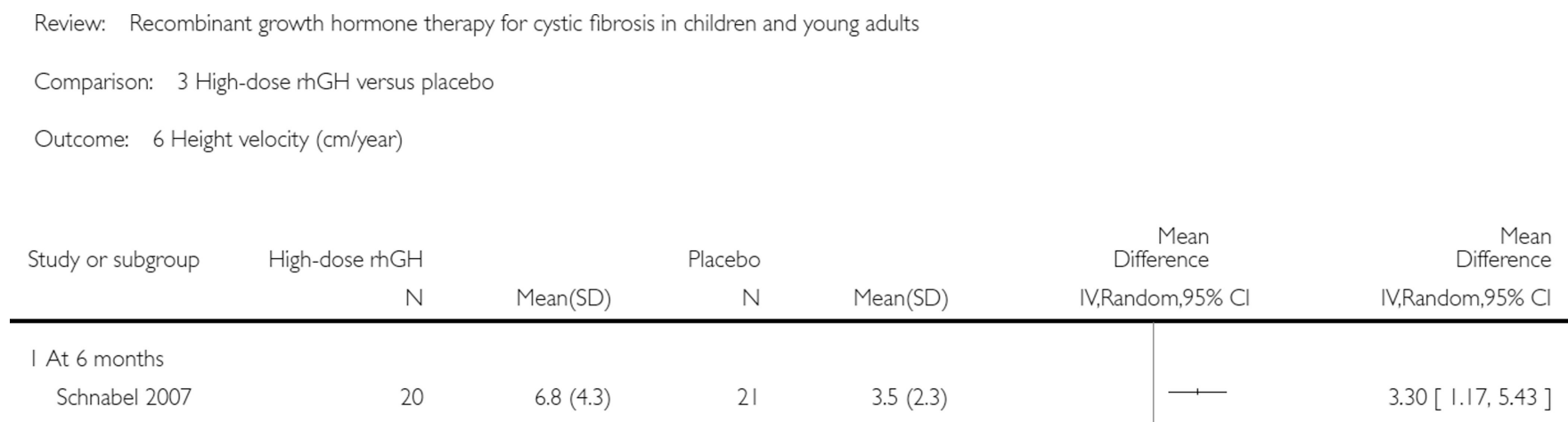

$\longrightarrow$

Analysis 3.6.

Comparison 3 High-dose rhGH versus placebo, Outcome 6 Height velocity (cm/year). 


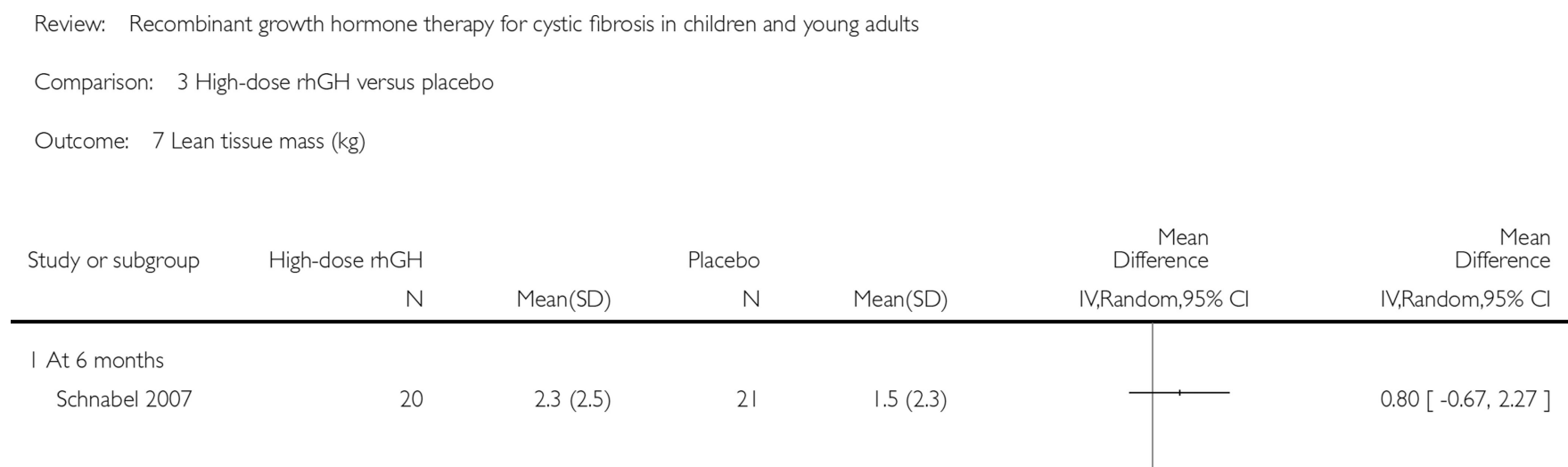

Analysis 3.7.

Comparison 3 High-dose rhGH versus placebo, Outcome 7 Lean tissue mass (kg). 


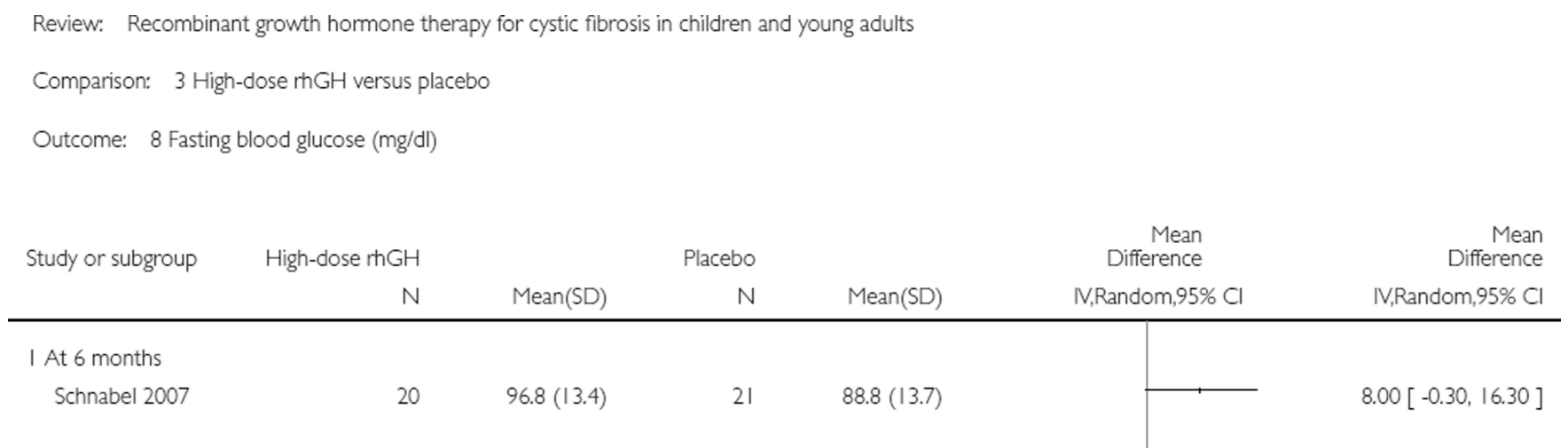

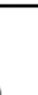

|r.

$88.8(13.7)$

$\longrightarrow 8.00[-0.30,16.30]$

Analysis 3.8.

Comparison 3 High-dose rhGH versus placebo, Outcome 8 Fasting blood glucose (mg/dl). 


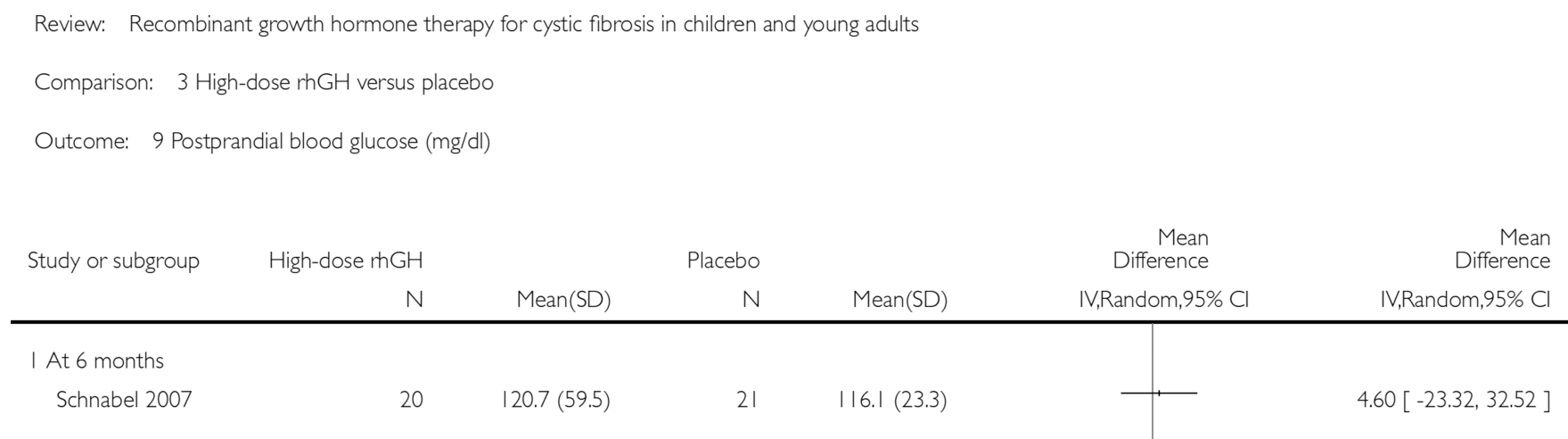

Analysis 3.9.

Comparison 3 High-dose rhGH versus placebo, Outcome 9 Postprandial blood glucose (mg/ dl). 
Review: Recombinant growth hormone therapy for cystic fibrosis in children and young adults

Comparison: 3 High-dose $\mathrm{hH} \mathrm{HH}$ versus placebo

Outcome: 10 Exercise capacity (watts)

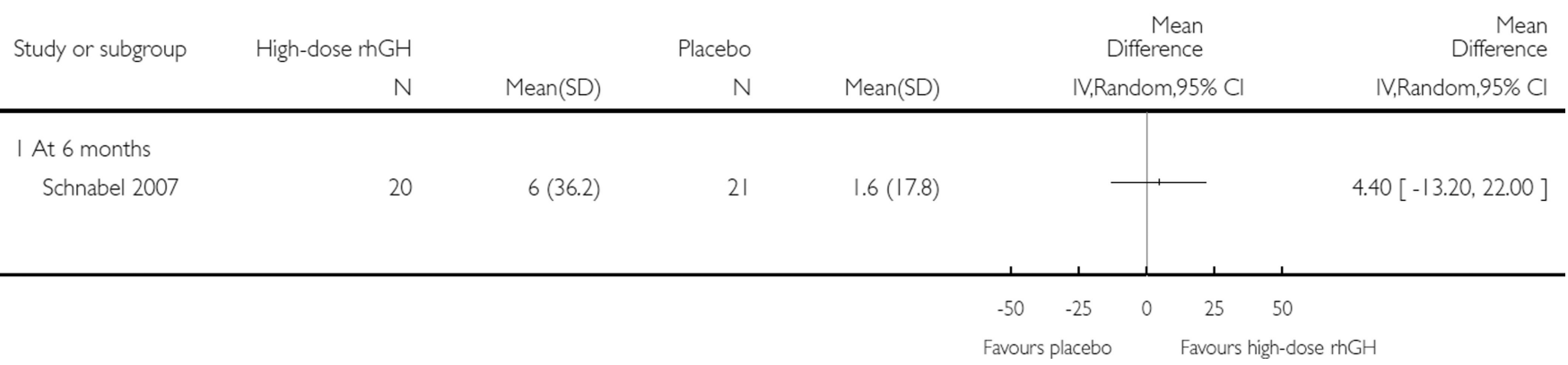

Analysis 3.10.

Comparison 3 High-dose rhGH versus placebo, Outcome 10 Exercise capacity (watts). 


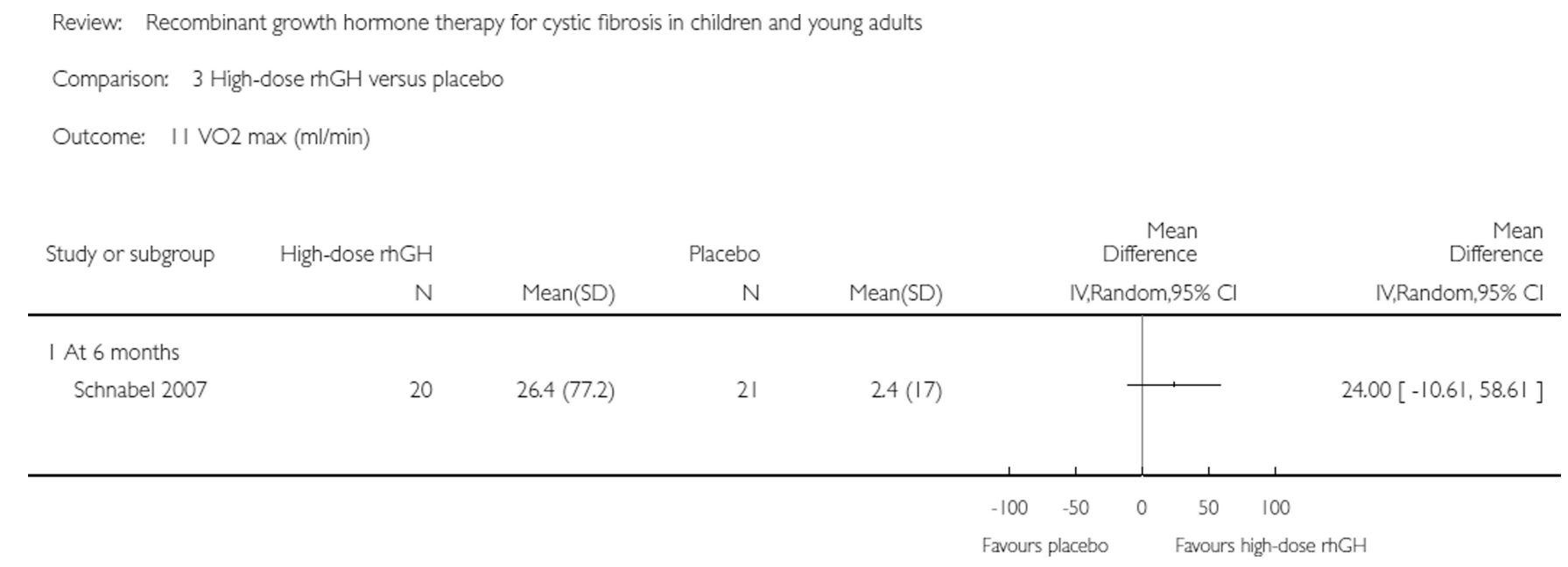

$26.4(77.2) \quad 21 \quad 2.4(17)$

Schnabel $2007 \quad 20 \quad 26.4(77,2)$

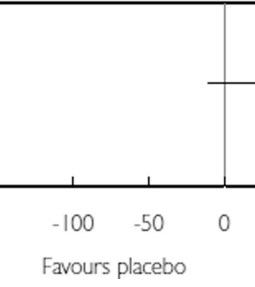

$50 \quad 100$

Favours high-dose $\mathrm{rGH}$

Analysis 3.11.

Comparison 3 High-dose rhGH versus placebo, Outcome $11 \mathrm{VO} 2 \mathrm{max}(\mathrm{ml} / \mathrm{min})$. 


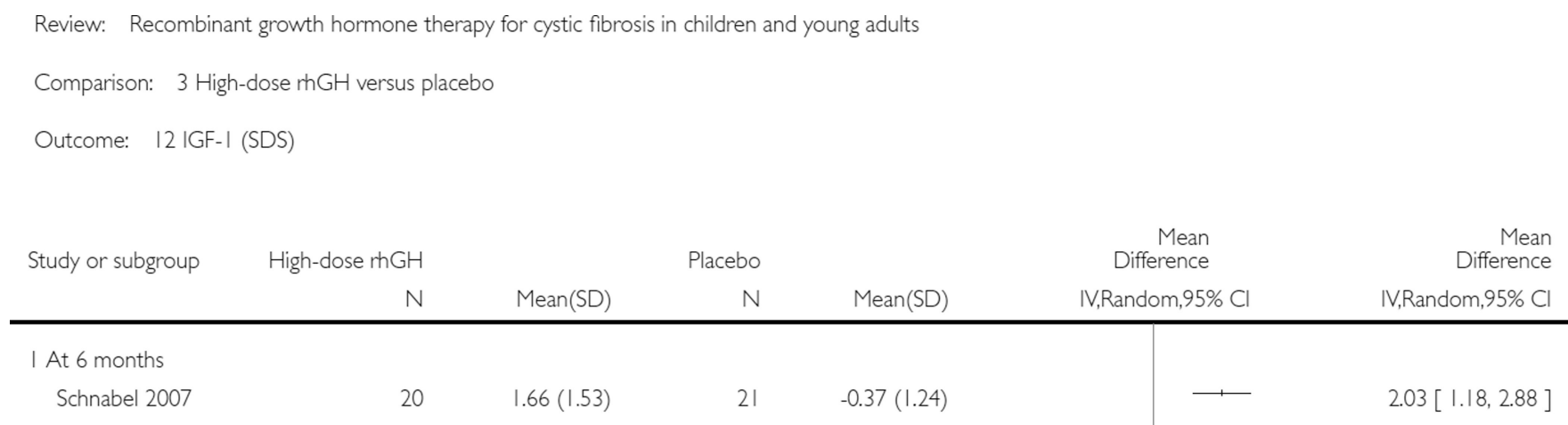

Mean(SD)

(2)

IV,Random, $95 \% \mathrm{Cl}$

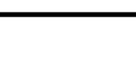

Analysis 3.12.

Comparison 3 High-dose rhGH versus placebo, Outcome 12 IGF-1 (SDS). 


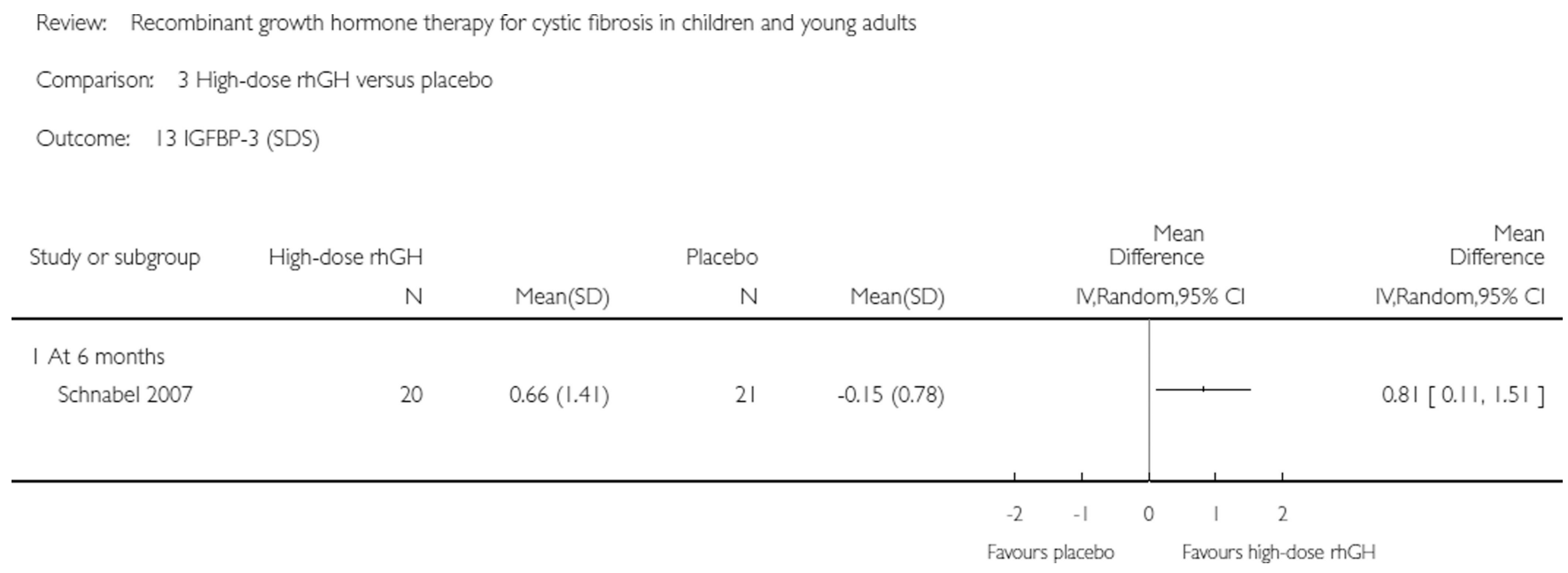

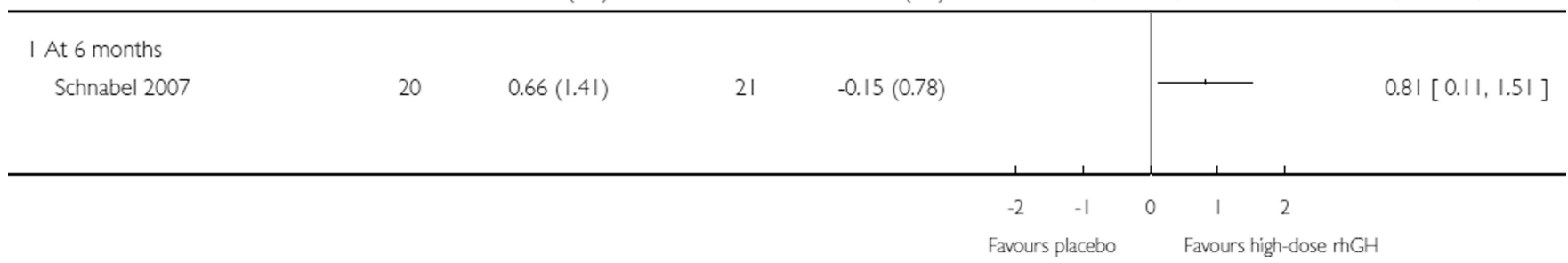

Analysis 3.13.

Comparison 3 High-dose rhGH versus placebo, Outcome 13 IGFBP-3 (SDS). 


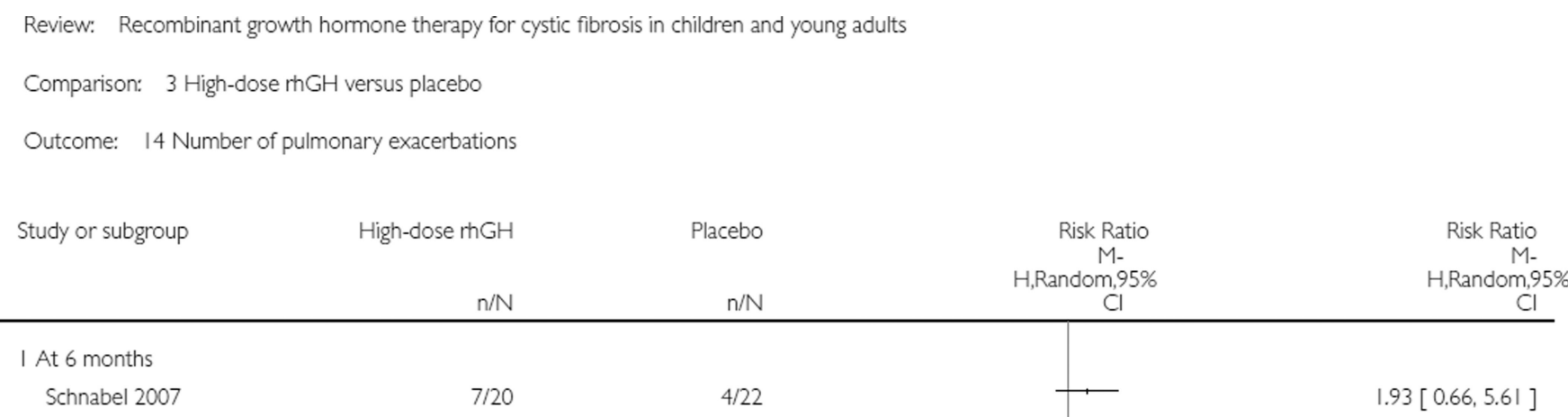

Cl

2

Analysis 3.14.

Comparison 3 High-dose rhGH versus placebo, Outcome 14 Number of pulmonary exacerbations. 


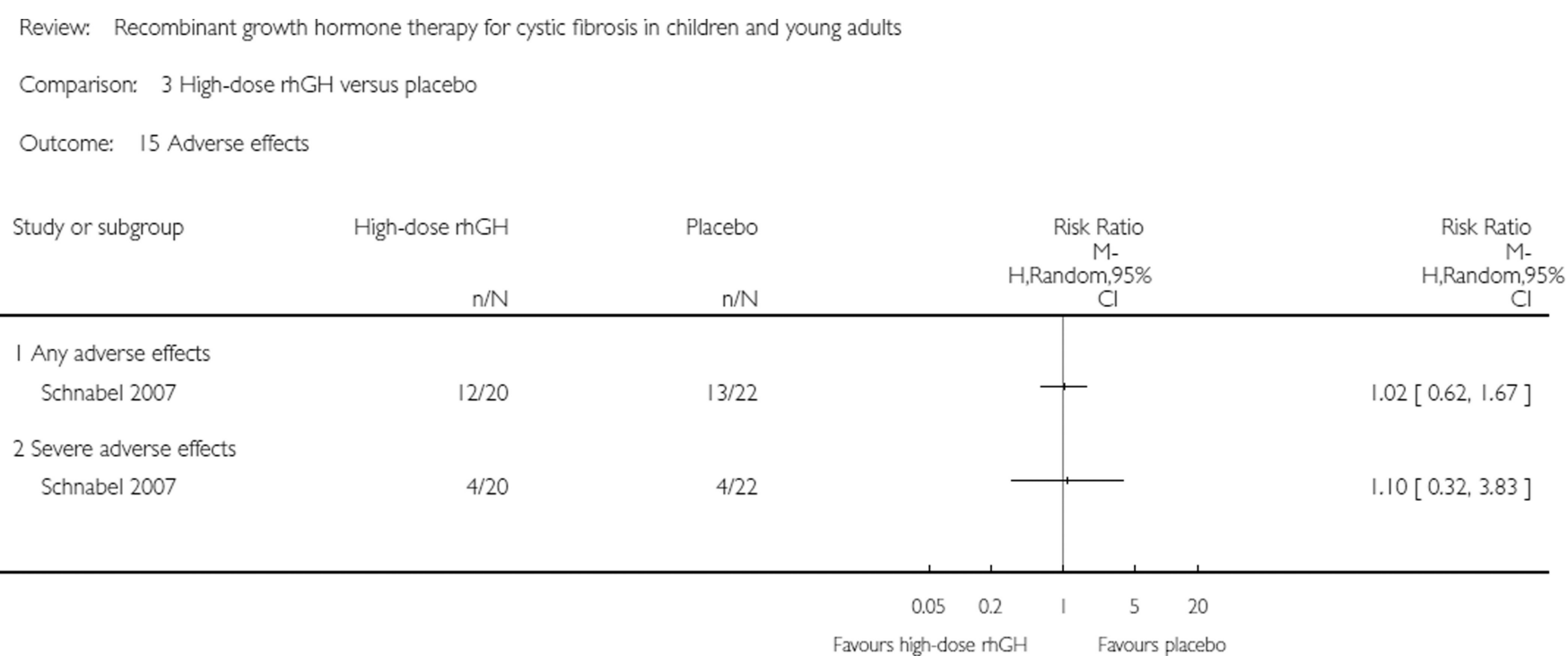

\section{Analysis 3.15.}

Comparison 3 High-dose rhGH versus placebo, Outcome 15 Adverse effects. 


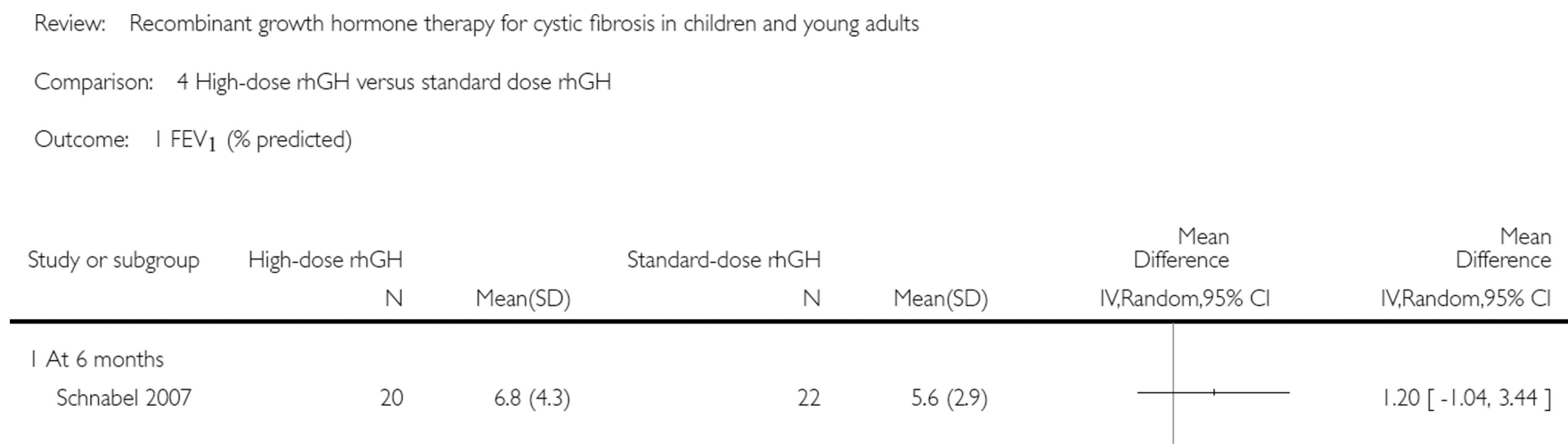

\begin{tabular}{l|l} 
&, \\
\hline &
\end{tabular}

Analysis 4.1.

Comparison 4 High-dose rhGH versus standard dose rhGH, Outcome 1 FEV1 (\% predicted). 


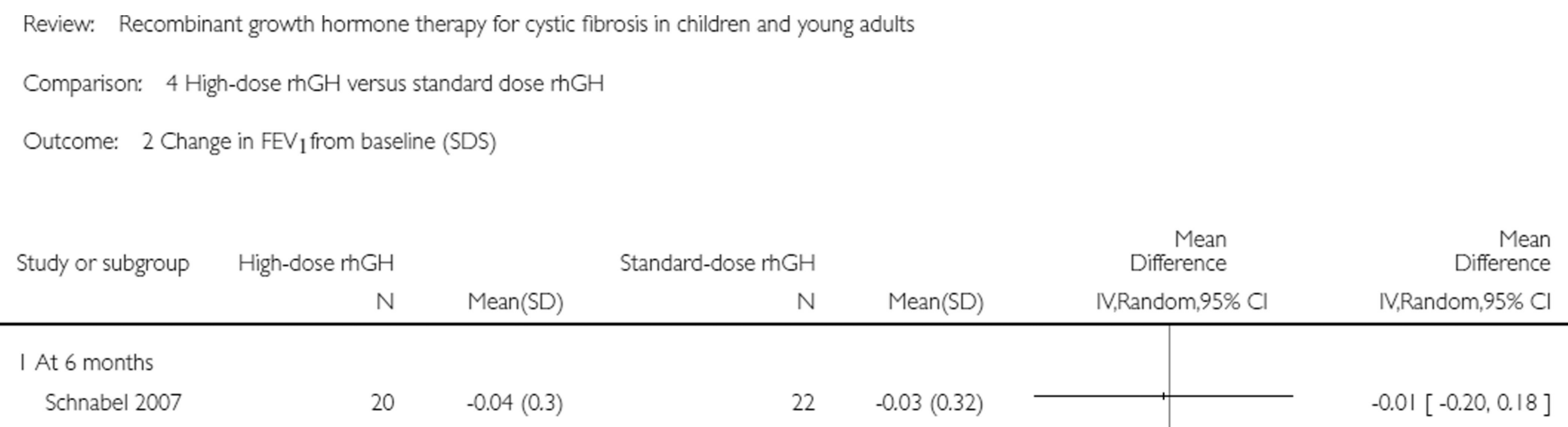

Analysis 4.2.

Comparison 4 High-dose rhGH versus standard dose rhGH, Outcome 2 Change in FEV1from baseline (SDS). 


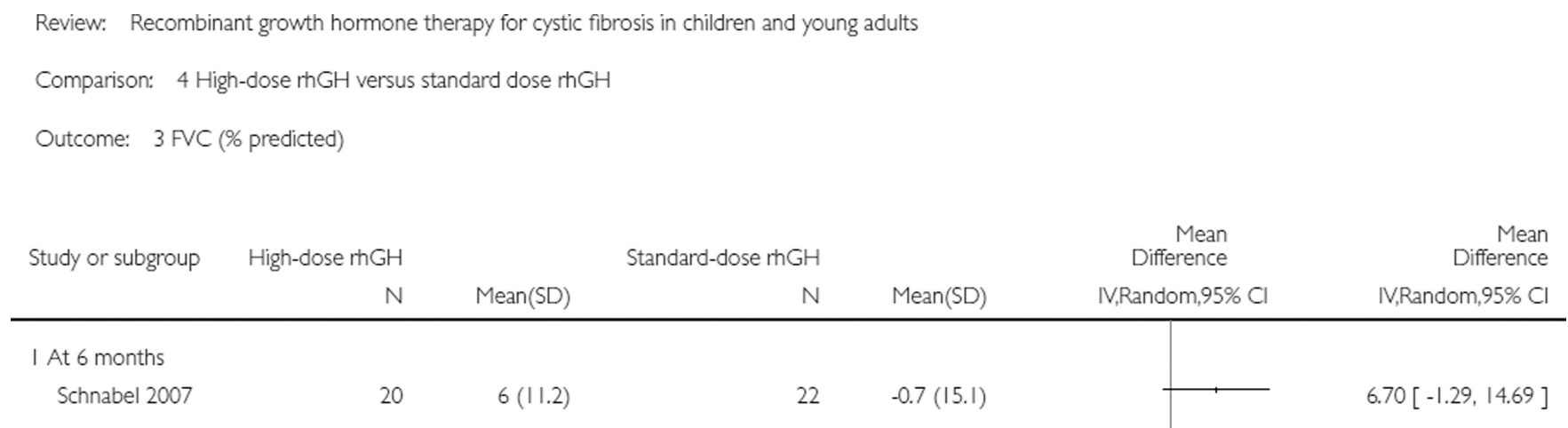

Analysis 4.3.

Comparison 4 High-dose rhGH versus standard dose rhGH, Outcome 3 FVC (\% predicted). 


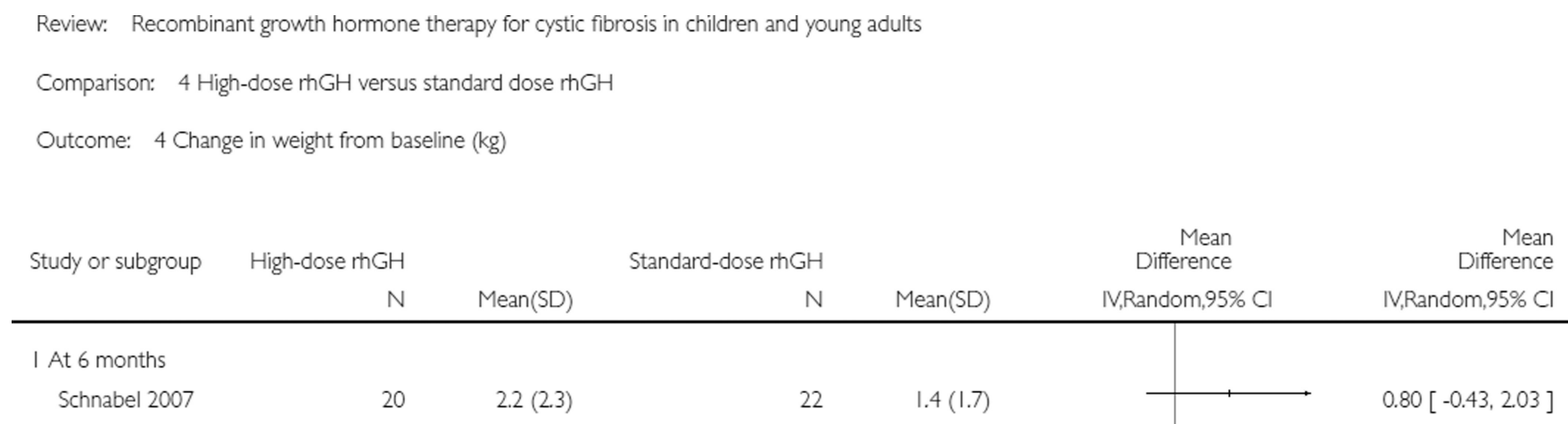

Analysis 4.4.

Comparison 4 High-dose rhGH versus standard dose rhGH, Outcome 4 Change in weight from baseline $(\mathrm{kg})$. 


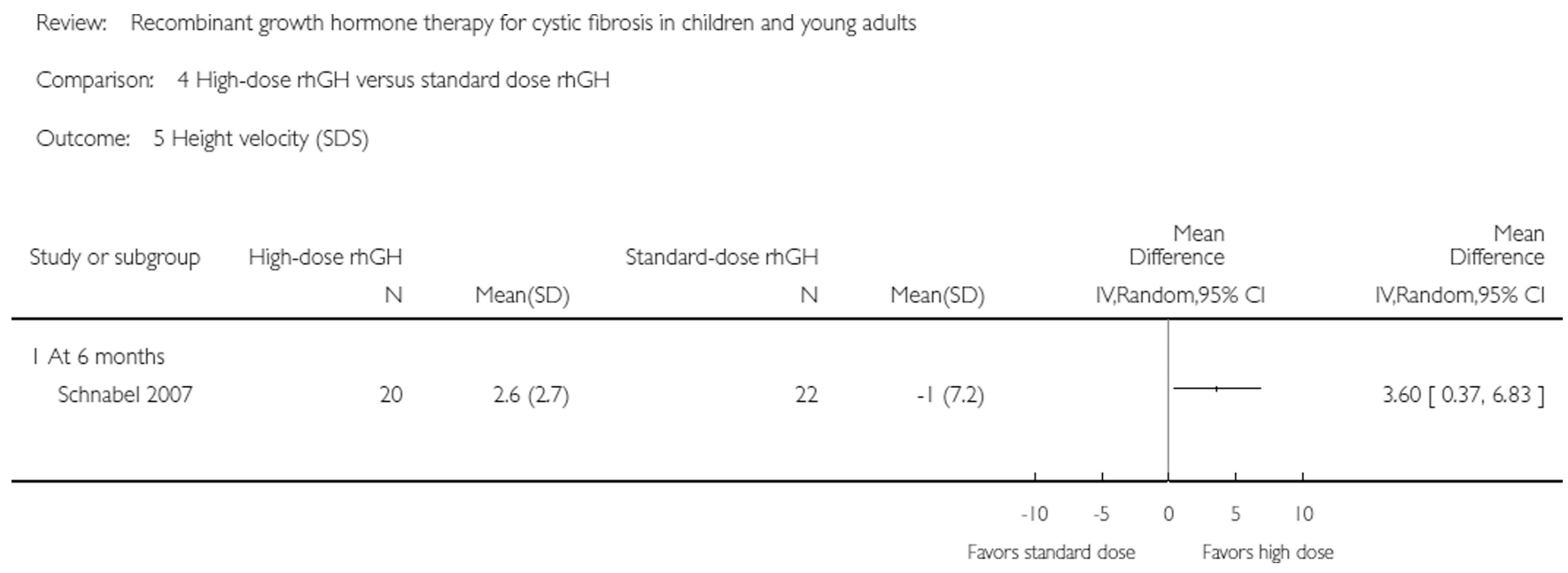

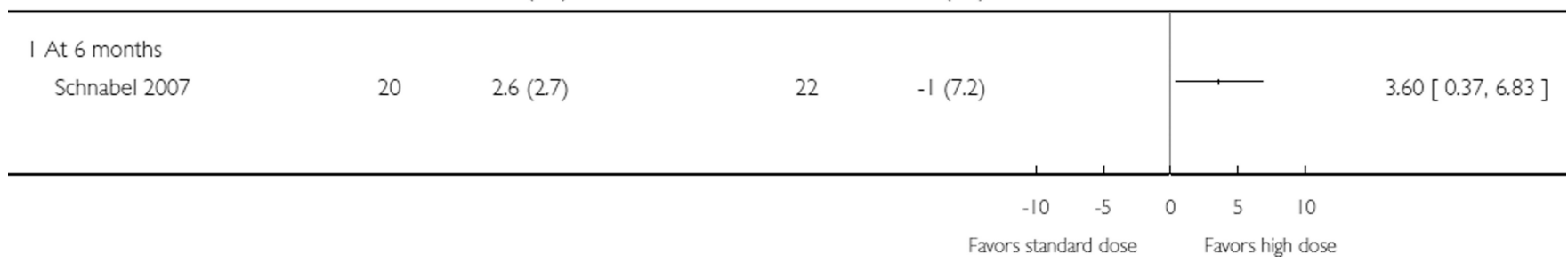

Analysis 4.5.

Comparison 4 High-dose rhGH versus standard dose rhGH, Outcome 5 Height velocity (SDS). 
Review: Recombinant growth hormone therapy for cystic fibrosis in children and young adults

Comparison: 4 High-dose $\mathrm{hGH}$ versus standard dose $\mathrm{mGH}$

Outcome: 6 Height velocity (cm/year)

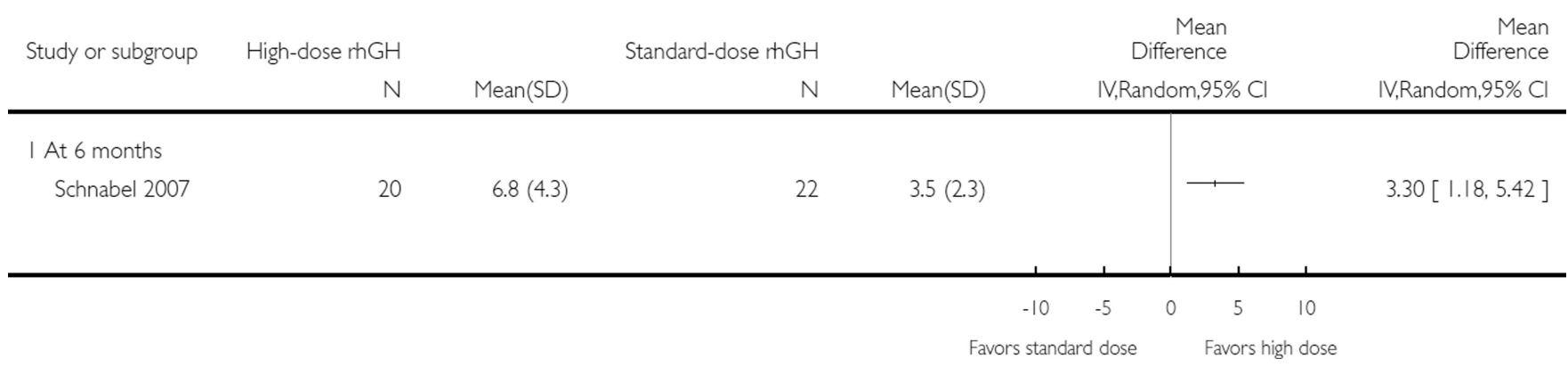

\section{Analysis 4.6.}

Comparison 4 High-dose rhGH versus standard dose rhGH, Outcome 6 Height velocity (cm/ year). 


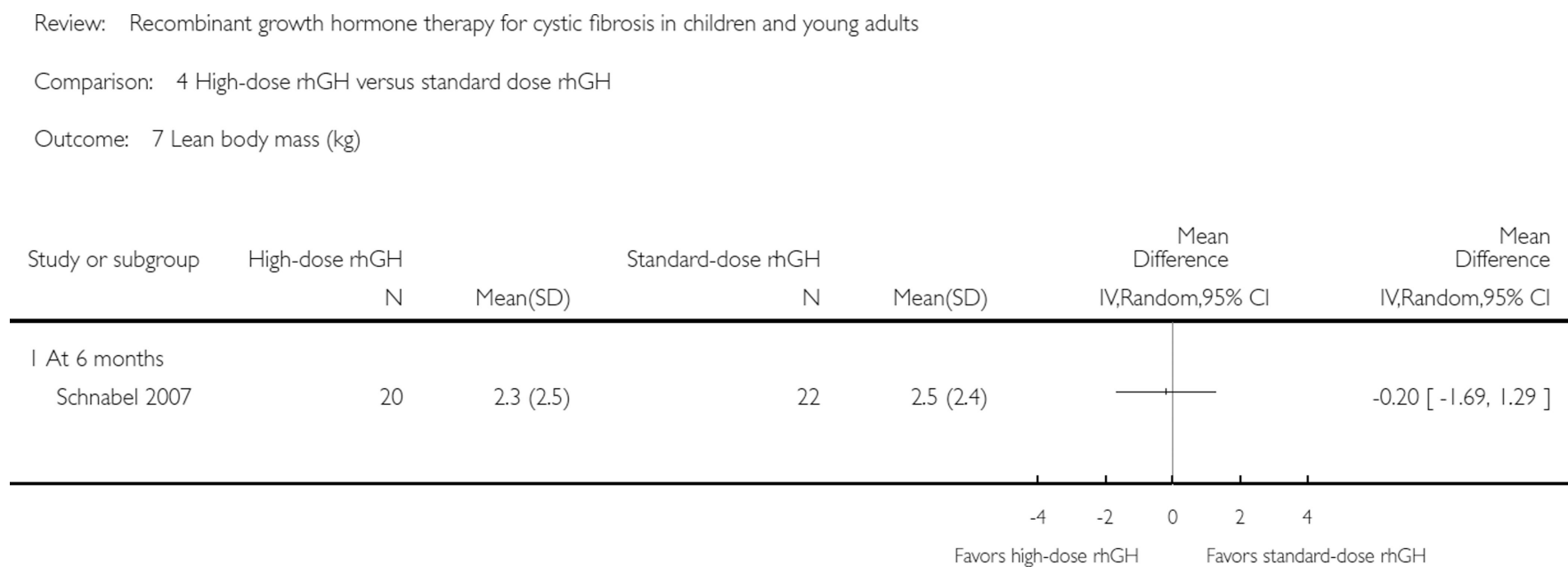

,

,

Favors high-dose rhGH Favors standard-dose rhGH

Analysis 4.7.

Comparison 4 High-dose rhGH versus standard dose rhGH, Outcome 7 Lean body mass $(\mathrm{kg})$. 


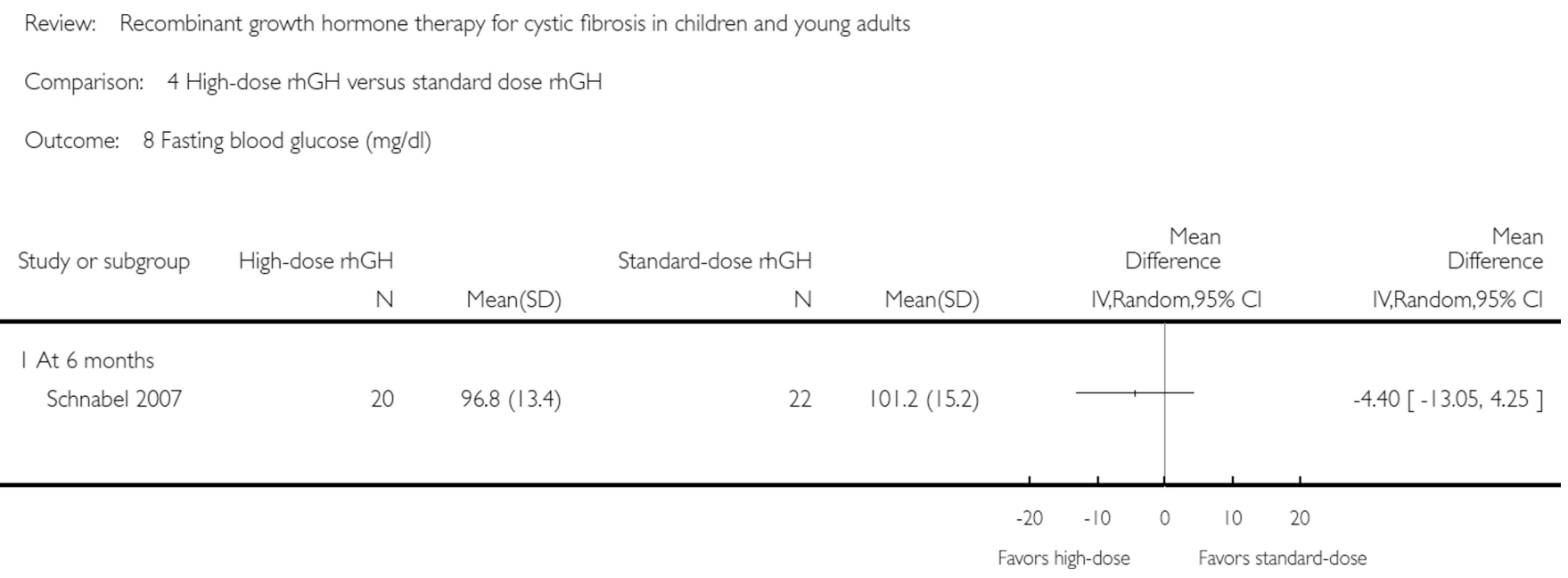




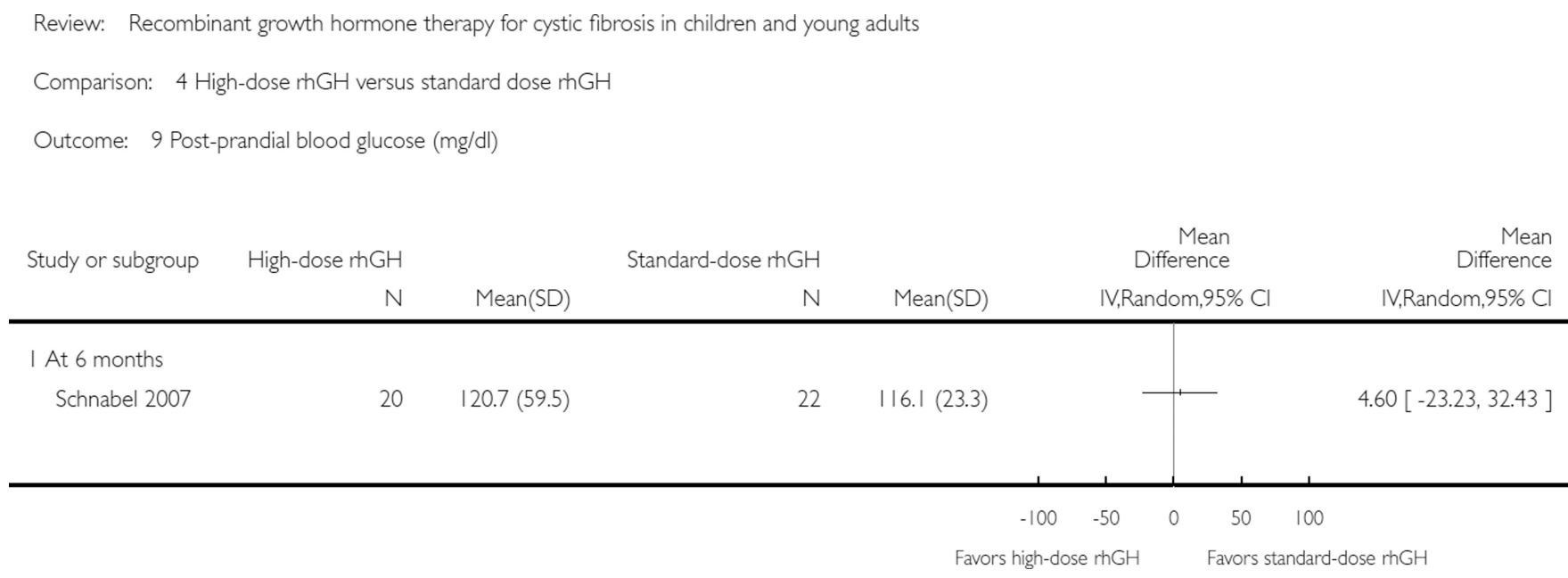

- 1.2

\begin{tabular}{l}
\hline \\
1 \\
\hline
\end{tabular}

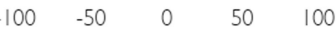

Favors high-dose rhGH Favors standard-dose rhGH

Analysis 4.9.

Comparison 4 High-dose rhGH versus standard dose rhGH, Outcome 9 Post-prandial blood glucose ( $\mathrm{mg} / \mathrm{dl})$. 


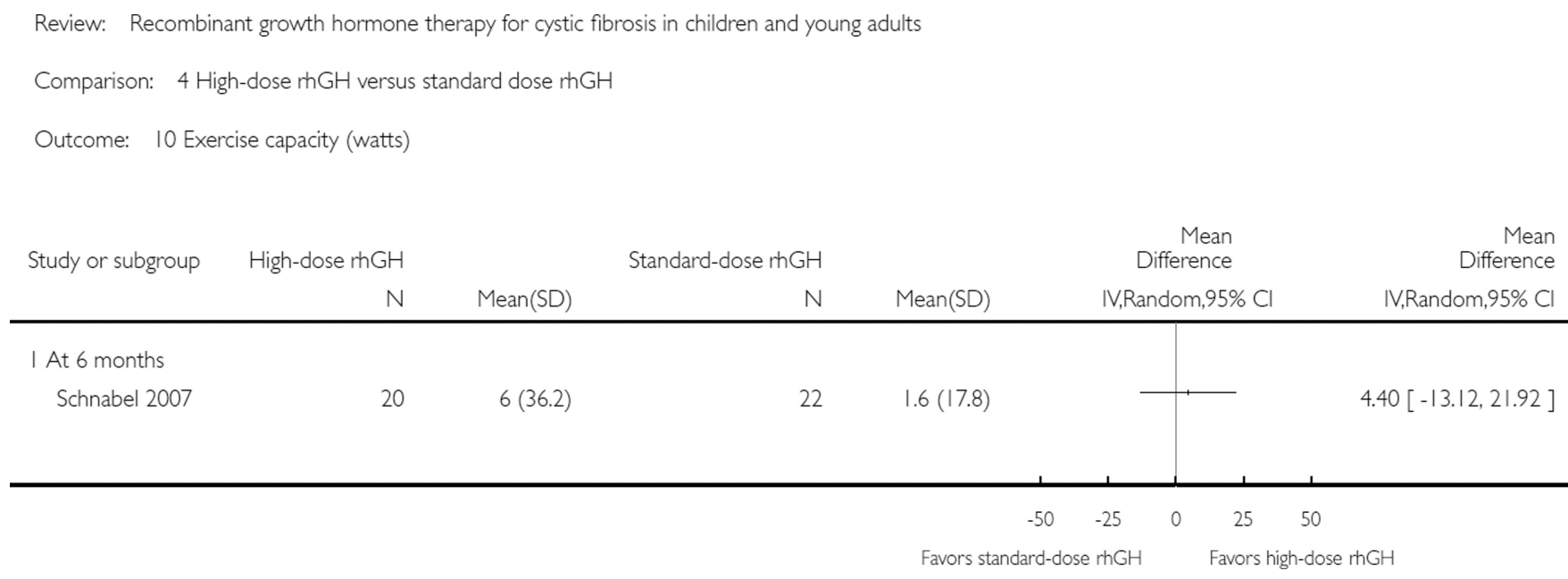

Analysis 4.10.

Comparison 4 High-dose rhGH versus standard dose rhGH, Outcome 10 Exercise capacity (watts). 


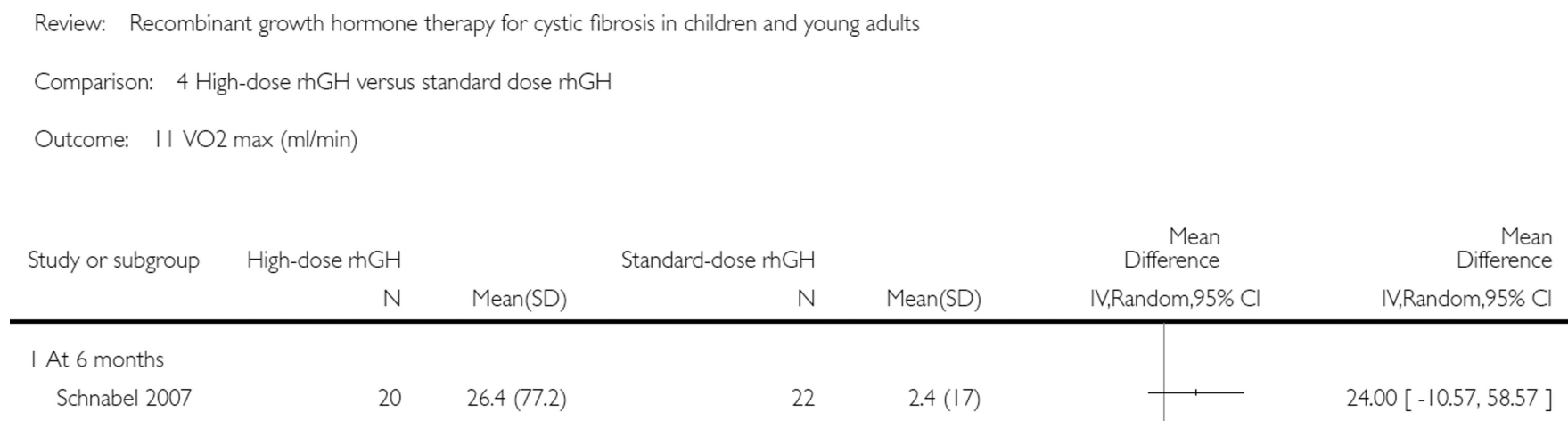

(2)

-

Analysis 4.11.

Comparison 4 High-dose rhGH versus standard dose rhGH, Outcome 11 VO2 max (ml/ $\min )$. 


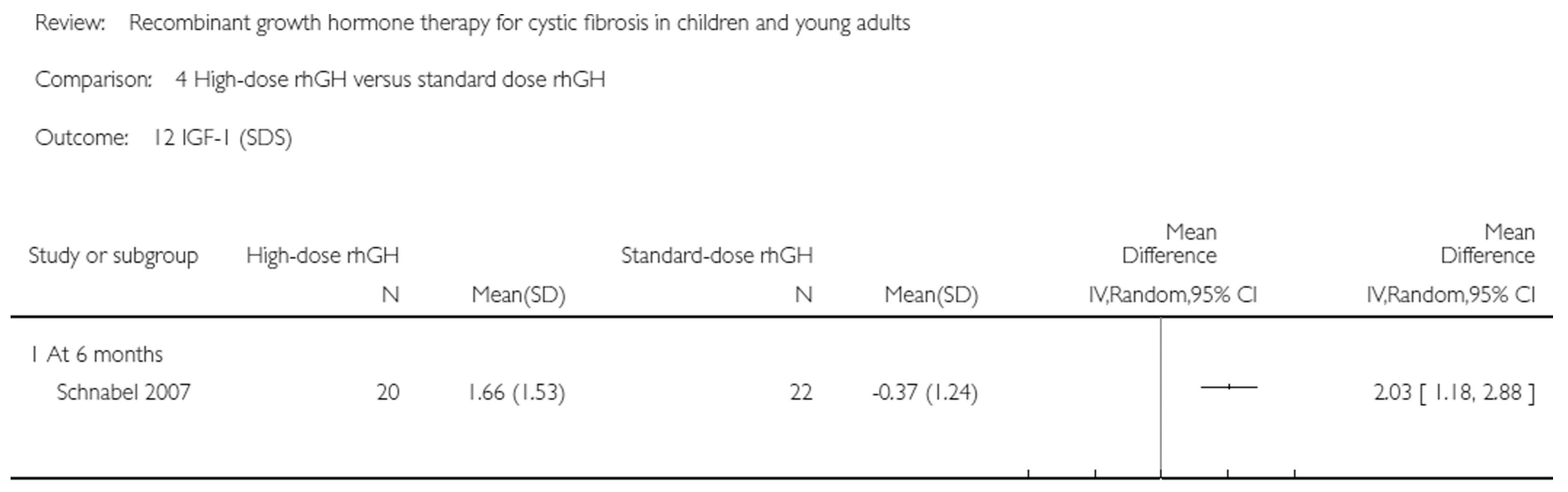

Analysis 4.12.

Comparison 4 High-dose rhGH versus standard dose rhGH, Outcome 12 IGF-1 (SDS). 


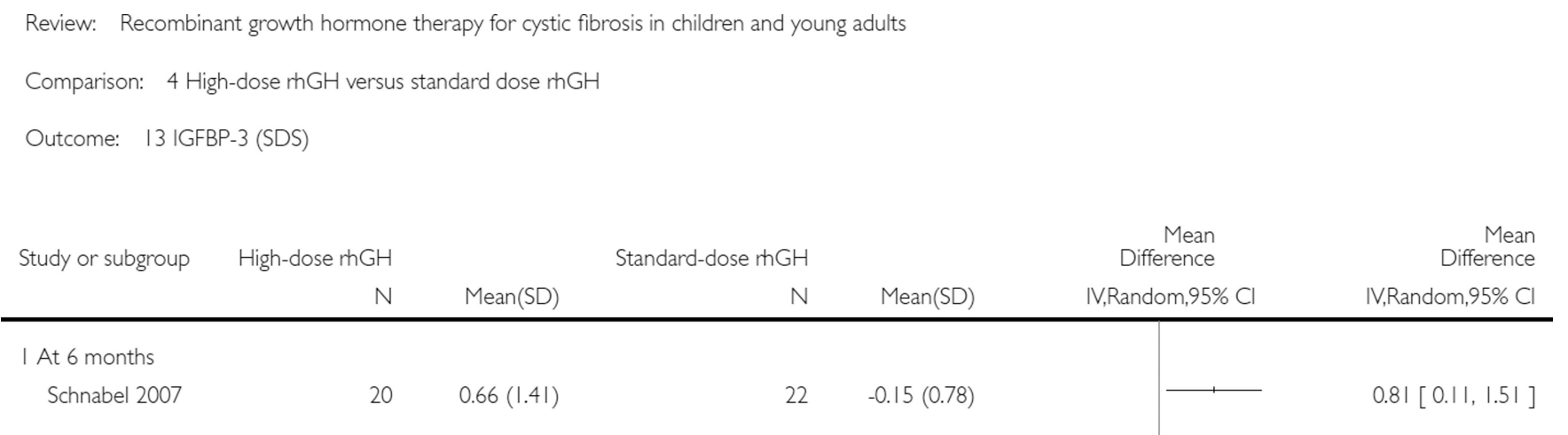

Analysis 4.13.

Comparison 4 High-dose rhGH versus standard dose rhGH, Outcome 13 IGFBP-3 (SDS). 


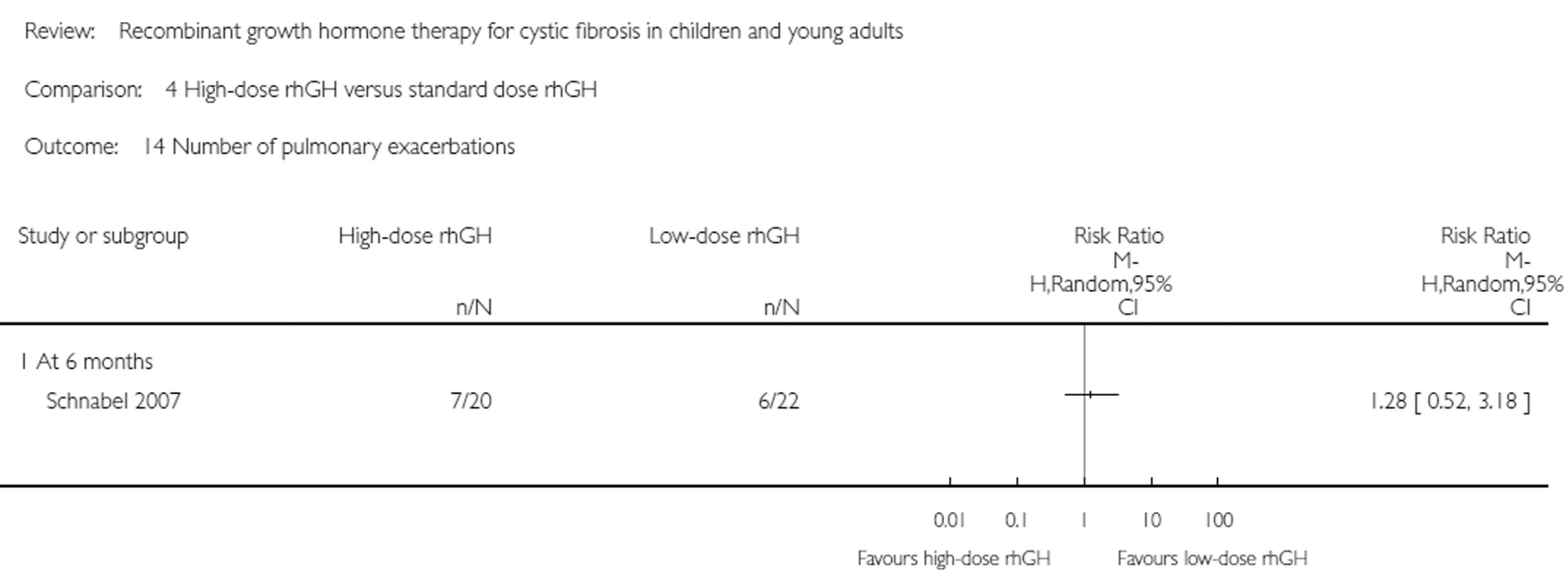

Analysis 4.14.

Comparison 4 High-dose rhGH versus standard dose rhGH, Outcome 14 Number of pulmonary exacerbations. 


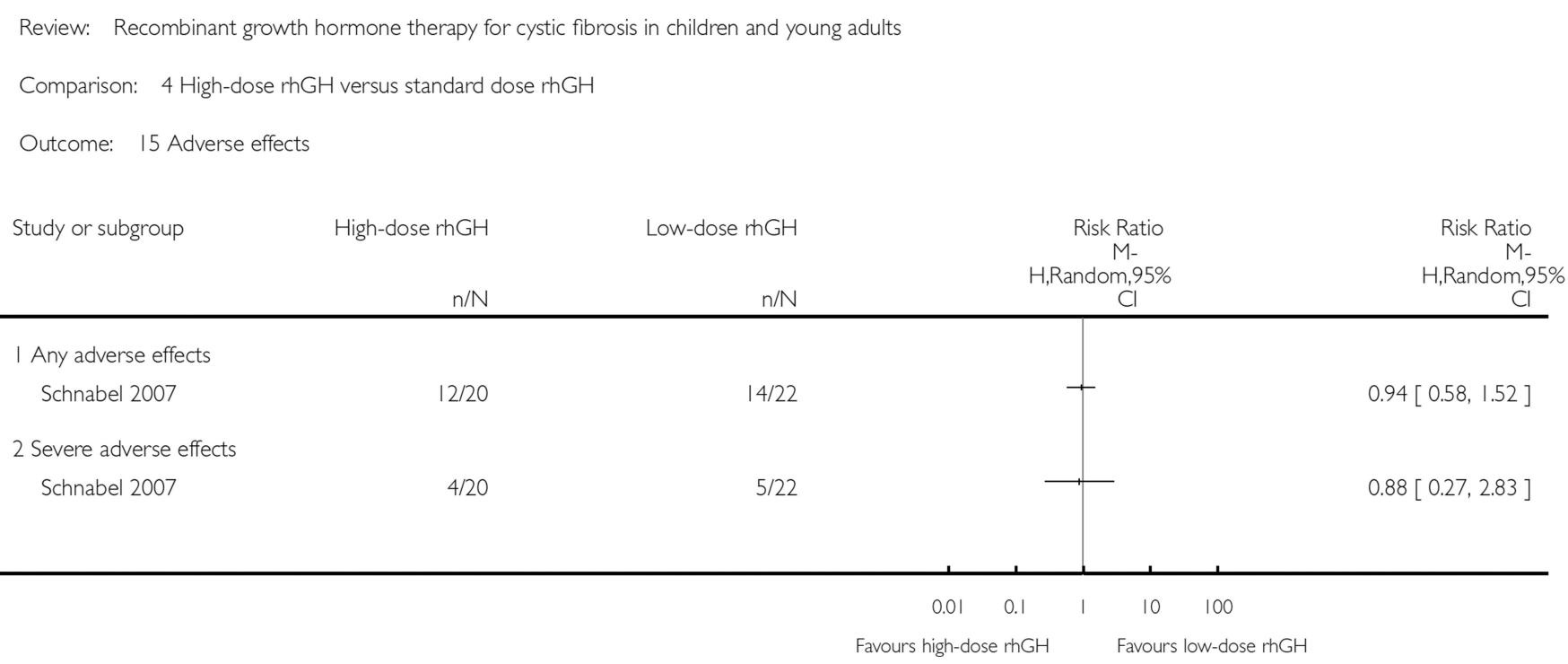

\section{Analysis 4.15.}

Comparison 4 High-dose rhGH versus standard dose rhGH, Outcome 15 Adverse effects. 


\title{
CHARACTERISTICS OF STUDIES
}

\author{
Characteristics of included studies [ordered by study ID]
}

\begin{tabular}{|c|c|c|}
\hline Methods & \multicolumn{2}{|c|}{$\begin{array}{l}\text { RCT of cross-over design ( } 2 \text { periods of } 6 \text { months each with no wash-out period in between) } \\
\text { Single centre: Children's Hospital, Humboldt University and Children's Hospital Clinic, Buch Germany }\end{array}$} \\
\hline Participants & \multicolumn{2}{|c|}{ 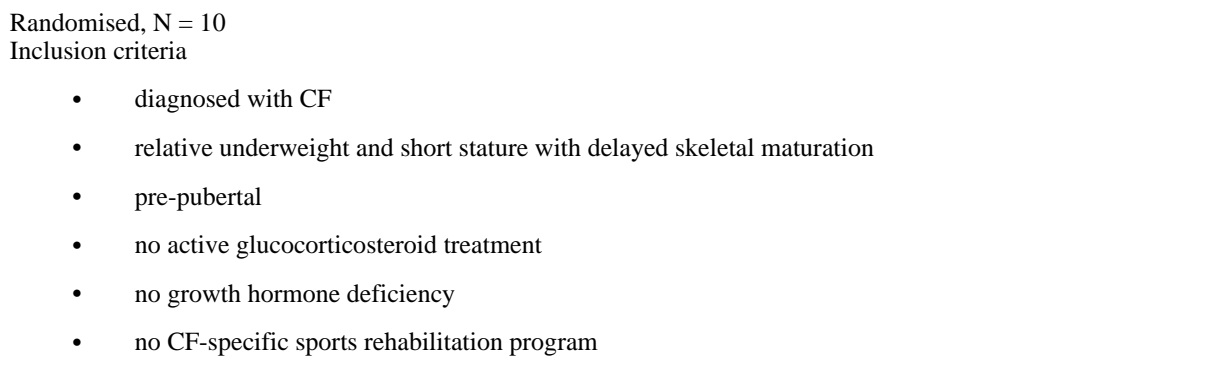 } \\
\hline Interventions & \multicolumn{2}{|c|}{$\begin{array}{l}\text { Intervention: daily SC injections of rhGH (Genotropin }{ }^{\circledR} \text {, Pharmacia GmbH, Stock-holm) in the dose of } 0.11-0.14 \\
\text { IU/kg/d } \\
\text { Control: no treatment. }\end{array}$} \\
\hline Outcomes & \multicolumn{2}{|c|}{$\begin{array}{l}\text { Primary outcomes } \\
\text { - } \quad \text { pulmonary function tests - } \mathrm{FEV}_{1}, \mathrm{FVC}, \mathrm{MEF} \\
\text { - nutritional parameters - height, lean body mass } \\
\text { Secondary outcomes } \\
\text { - muscular strength and exercise capacity }\end{array}$} \\
\hline Notes & \multicolumn{2}{|c|}{$\begin{array}{l}\text { Only published data from the first half of the study used. } \\
\text { The study was supported by a grant from the Mukoviszidose e.V Foundation. Pharmacia GmbH provided the } \\
\text { Genotropin }{ }^{\circledR} \text {. } \\
\text { The study authors disclose professional relationships with companies or manufacturers who will benefit from the } \\
\text { results of the present study }\end{array}$} \\
\hline \multicolumn{3}{|l|}{ Risk of bias } \\
\hline Bias & Authors' judgement & Support for judgement \\
\hline $\begin{array}{l}\text { Random sequence } \\
\text { generation (selection } \\
\text { bias) }\end{array}$ & Unclear risk & $\begin{array}{l}\text { Quote "Patients were randomly assigned to either the GH treatment or control period" (page } \\
568 \text { ). No details on the process of randomisation provided }\end{array}$ \\
\hline $\begin{array}{l}\text { Allocation } \\
\text { concealment (selection } \\
\text { bias) }\end{array}$ & Unclear risk & Not described. \\
\hline $\begin{array}{l}\text { Incomplete outcome } \\
\text { data (attrition bias) } \\
\text { All outcomes }\end{array}$ & Low risk & All participants included in the study completed it. No loss to follow-up \\
\hline $\begin{array}{l}\text { Selective reporting } \\
\text { (reporting bias) }\end{array}$ & Low risk & $\begin{array}{l}\text { Although the protocol is not available, all the important outcomes appear to have been } \\
\text { covered }\end{array}$ \\
\hline Other bias & Unclear risk & $\begin{array}{l}\text { The study authors disclose professional relationships with companies or manufacturers who } \\
\text { will benefit from the results of the present study }\end{array}$ \\
\hline $\begin{array}{l}\text { Blinding of } \\
\text { participants and } \\
\text { personnel } \\
\text { (performance bias) } \\
\text { All outcomes }\end{array}$ & High risk & $\begin{array}{l}\text { Participants: not possible, control: no treatment. } \\
\text { Healthcare providers: not possible, control: no treatment. }\end{array}$ \\
\hline
\end{tabular}




\begin{tabular}{|c|c|c|}
\hline $\begin{array}{l}\text { Blinding of outcome } \\
\text { assessment (detection } \\
\text { bias) } \\
\text { All outcomes }\end{array}$ & Unclear risk & Outcome assessors and data analysts: no information on blinding \\
\hline \multicolumn{3}{|l|}{ Schibler 2003} \\
\hline Methods & \multicolumn{2}{|c|}{$\begin{array}{l}\text { RCT. } \\
\text { Single centre: University Children's Hospital, Bern, Switzerland }\end{array}$} \\
\hline Participants & \multicolumn{2}{|c|}{$\begin{array}{l}\mathrm{N}=20 \text { ( } 15 \text { males, } 4 \text { females), age: } 10-23 \text { years. Age and sex-matched controls } \\
\text { The majority of this population are post-puberty. } \\
\text { Inclusion criteria } \\
\text { - diagnosed case of } \mathrm{CF} \text { - positive sweat test and presence of CFTR gene } \\
\text { Exclusion criteria } \\
\text { - insulin dependent diabetes mellitus } \\
\text { - hepatic disease or portal hypertension } \\
\text { - clinical congestive heart failure } \\
\text { Withdrawals or loss to follow-up: } 1 \text { (from control group on evaluation for lung transplantation) }\end{array}$} \\
\hline Interventions & \multicolumn{2}{|c|}{$\begin{array}{l}\text { Intervention: daily SC injections of rhGH } \text { (Saizen }^{\circledR}, \text { Merck Serono SA, Switzerland) } 1 \\
\text { IU/kg/wk. } \\
\text { Control: no treatment. } \\
\text { Concomitant therapy: Standard protocol for treatment of CF. }\end{array}$} \\
\hline Outcomes & \multicolumn{2}{|c|}{$\begin{array}{l}\text { Primary outcomes } \\
\text { - pulmonary function tests - } \mathrm{FVC}, \mathrm{FEV}_{1}, \mathrm{PI}_{\max }, \mathrm{PE}_{\max } \\
\text { - nutritional parameters - height, weight, lean body mass } \\
\text { Secondary outcomes: } \\
\text { - blood glucose abnormality - glucose tolerance test } \\
\text { - exercise capacity - cardiopulmonary exercise testing }\end{array}$} \\
\hline Notes & \multicolumn{2}{|c|}{$\begin{array}{l}\text { Treatment was randomly assigned to age and gender matched cases and controls for a period of } 1 \text { year } \\
\text { "This study was supported in part by a grant from Serono SA, Aubonne, Switzerland" }\end{array}$} \\
\hline \multicolumn{3}{|l|}{ Risk of bias } \\
\hline Bias & Authors' judgement & Support for judgement \\
\hline $\begin{array}{l}\text { Random sequence } \\
\text { generation (selection } \\
\text { bias) }\end{array}$ & Unclear risk & $\begin{array}{l}\text { Sex- and age-matched pairs of people with CF were recruited and randomly assigned to } \\
\text { treatment (page 1078) } \\
\text { Comment: insufficient detail reported about the method used to generate the allocation } \\
\text { sequence to allow a clear assessment of whether it would produce comparable groups }\end{array}$ \\
\hline $\begin{array}{l}\text { Allocation } \\
\text { concealment (selection } \\
\text { bias) }\end{array}$ & Unclear risk & $\begin{array}{l}\text { The method used to conceal the allocation sequence, that is to determine whether } \\
\text { intervention allocations could have been foreseen in advance of, or during enrolment, was } \\
\text { not reported. } \\
\text { Comment: insufficient information to permit a clear judgement }\end{array}$ \\
\hline $\begin{array}{l}\text { Incomplete outcome } \\
\text { data (attrition bias) } \\
\text { All outcomes }\end{array}$ & Low risk & $\begin{array}{l}\text { One participant from control group was dropped from the study due to assessment for lung } \\
\text { transplantation }\end{array}$ \\
\hline $\begin{array}{l}\text { Selective reporting } \\
\text { (reporting bias) }\end{array}$ & Low risk & Although protocol not available, all important outcomes have been assessed \\
\hline Other bias & Unclear risk & $\begin{array}{l}\text { Study was partly funded by Merck Serono SA, Aubonne Switzerland. The effect of this } \\
\text { funding on the results of the study are unclear }\end{array}$ \\
\hline $\begin{array}{l}\text { Blinding of } \\
\text { participants and } \\
\text { personnel } \\
\text { (performance bias) } \\
\text { All outcomes }\end{array}$ & High risk & $\begin{array}{l}\text { Participants: not possible. Control: no treatment. } \\
\text { Healthcare providers: not possible, Control: no treatment. }\end{array}$ \\
\hline $\begin{array}{l}\text { Blinding of outcome } \\
\text { assessment (detection } \\
\text { bias) }\end{array}$ & Unclear risk & $\begin{array}{l}\text { Outcome assessors and data analysts: unclear } \\
\text { if blinded. }\end{array}$ \\
\hline
\end{tabular}




\begin{tabular}{|c|c|}
\hline All outcomes & \\
\hline Schnabel 2007 & \\
\hline Methods & $\begin{array}{l}\text { RCT, double-blind, placebo-controlled, parallel-groups. } \\
\text { Multicentre: } 12 \text { German CF centres. } \\
\text { Duration : } 24 \text { weeks double-blind followed by } 24 \text { weeks open-label treatment period }\end{array}$ \\
\hline Participants & $\begin{array}{l}\text { Randomised: } \mathrm{N}=63 \text {, age } 9-20 \text { years. } \\
\text { Inclusion criteria } \\
\text { - } \quad \text { established diagnosis of } \mathrm{CF} \\
\text { - } \quad \text { bone age of } 8-18 \text { years } \\
\text { - } \quad \text { BMI }<10 \text { th or body weight }<3 \text { rd percentile despite a high caloric intake }\end{array}$ \\
\hline
\end{tabular}

Exclusion criteria

- acute pulmonary exacerbation 4 weeks prior to study entry

- $\quad$ systemic disease like diabetes, liver cirrhosis, renal failure, malignancy

- inability to perform exercise or pulmonary function test

- treatment with rhGH or steroids in the year prior to study

Withdrawals or loss to follow-up: 4 (details not described, analysis by ITT)

\begin{tabular}{|c|c|c|}
\hline Interventions & \multicolumn{2}{|c|}{$\begin{array}{l}\text { Intervention: daily SC injections of somatotropin in } 1 \text { of the } 2 \text { treatment arms }-0.070 \mathrm{mg} / \mathrm{kg} / \mathrm{day}(\sim 0.21 \mathrm{IU} / \mathrm{kg} / \mathrm{day}) \\
\text { or } 0.039 \mathrm{mg} / \mathrm{kg} / \text { day }(\sim 0.11 \mathrm{IU} / \mathrm{kg} / \mathrm{day}) \text { using a Genotropin }{ }^{\circledR} \text { pen. } \\
\text { Control: placebo injection with Genotropin }{ }^{\circledR} \text { pen. } \\
\text { At the end of } 24 \text { weeks, in the open-label phase, the two intervention groups were continued on their daily dose. The } \\
\text { control group was randomly assigned to one dose group for another } 24 \text { weeks }\end{array}$} \\
\hline Outcomes & \multicolumn{2}{|c|}{$\begin{array}{l}\text { Primary outcomes } \\
\text { - } \text { pulmonary function tests - } \mathrm{FEV}_{1}, \mathrm{FVC} \\
\text { - } \text { nutritional parameters - height, weight, height velocity, weight velocity, lean body mass } \\
\text { Secondary outcomes } \\
\text { - blood glucose abnormality - fasting and postprandial blood glucose levels } \\
\text { - exercise capacity - measured using Borg scale at the end of an exercise test } \\
\text { - IGF-1 and IGFBP-3 levels } \\
\text { - change in disease exacerbation - hospitalisation } \\
\text { - } \quad \text { report on adverse events }\end{array}$} \\
\hline \multicolumn{3}{|l|}{ Notes } \\
\hline \multicolumn{3}{|l|}{ Risk of bias } \\
\hline Bias & Authors' judgement & Support for judgement \\
\hline $\begin{array}{l}\text { Random sequence } \\
\text { generation (selection } \\
\text { bias) }\end{array}$ & Unclear risk & $\begin{array}{l}\text { Quote: "The trial was designed as a multicenter, randomised, double-blind, placebo- } \\
\text { controlled, parallel-groups study to compare the efficacy and the safety of } 2 \text { fixed dosages } \\
\text { of rhGH or placebo in patients with CF" (page e1231) } \\
\text { Comment: insufficient detail reported about the method used to generate the allocation } \\
\text { sequence to allow a clear assessment of whether it would produce comparable groups }\end{array}$ \\
\hline $\begin{array}{l}\text { Allocation } \\
\text { concealment (selection } \\
\text { bias) }\end{array}$ & Unclear risk & $\begin{array}{l}\text { The method used to conceal the allocation sequence, that is to determine whether } \\
\text { intervention allocations could have been foreseen in advance of, or during enrolment, was } \\
\text { not reported. } \\
\text { Comment: insufficient information to permit a clear judgement }\end{array}$ \\
\hline $\begin{array}{l}\text { Incomplete outcome } \\
\text { data (attrition bias) } \\
\text { All outcomes }\end{array}$ & Unclear risk & $\begin{array}{l}63 \text { of the } 67 \text { participants randomised were included in the analysis. Withdrawals have not } \\
\text { been described }\end{array}$ \\
\hline $\begin{array}{l}\text { Selective reporting } \\
\text { (reporting bias) }\end{array}$ & Low risk & Although the protocol is not available, all details appear to have been covered \\
\hline Other bias & Unclear risk & No other disclosures by authors in the manuscript. \\
\hline
\end{tabular}




\begin{tabular}{|c|c|c|}
\hline $\begin{array}{l}\text { Blinding of } \\
\text { participants and } \\
\text { personnel } \\
\text { (performance bias) } \\
\text { All outcomes }\end{array}$ & Low risk & $\begin{array}{l}\text { Participants: blinded as all participants received injections } \\
\text { Healthcare providers: no details provided, but reported as a double-blind trial and all } \\
\text { participants received injection } \\
\text { Comment: overall judgement low risk. }\end{array}$ \\
\hline $\begin{array}{l}\text { Blinding of outcome } \\
\text { assessment (detection } \\
\text { bias) } \\
\text { All outcomes }\end{array}$ & Unclear risk & Outcome assessors and data analyst blinding - unclear. \\
\hline \multicolumn{3}{|l|}{ Stalvey 2011} \\
\hline Methods & \multicolumn{2}{|c|}{$\begin{array}{l}\text { RCT open-label. } \\
\text { Multicentre study: } 24 \text { centres in United States of America. } \\
\text { Duration: } 12 \text { months of intervention; } 18 \text { months follow-up. }\end{array}$} \\
\hline Participants & \multicolumn{2}{|c|}{$\begin{array}{l}\text { Randomised, } \mathrm{N}=68 \text { ( } 36 \text { in treatment arm and } 32 \text { in control). Ages } 5-13 \text { years } \\
\text { Inclusion criteria } \\
\text { - } \text { diagnosed cases of } \mathrm{CF} \\
\text { - } \quad \text { height }<10 \text { th percentile } \\
\text { - } \quad \text { bone age }<11 \text { years } \\
\text { - Tanner } 1 \text { sexual maturity stage } \\
\text { - } \quad \text { adequate nutrition per CF Foundation guidelines }\end{array}$} \\
\hline Interventions & \multicolumn{2}{|c|}{$\begin{array}{l}\text { Intervention: daily SC injections of rhGH } 0.3 \mathrm{mg} / \mathrm{kg} / \mathrm{week} \text {. } \\
\text { Control: no treatment. }\end{array}$} \\
\hline Outcomes & \multicolumn{2}{|c|}{$\begin{array}{l}\text { Analysis was divided into efficacy analysis and safety analysis } \\
\text { Efficacy analysis: } 33 \text { participants in the treatment arm and } 29 \text { controls were included } \\
\text { Primary outcomes } \\
\text { - } \quad \text { pulmonary function tests - } \mathrm{FEV}_{1}, \mathrm{FVC}, \mathrm{FEV}_{1} / \mathrm{FVC} \\
\text { - } \quad \text { nutritional parameters - height, weight, lean body mass }\end{array}$} \\
\hline
\end{tabular}

Secondary outcomes

\begin{tabular}{|c|c|c|}
\hline Notes & & \\
\hline \multicolumn{3}{|l|}{ Risk of bias } \\
\hline Bias & Authors' judgement & Support for judgement \\
\hline $\begin{array}{l}\text { Random sequence } \\
\text { generation (selection } \\
\text { bias) }\end{array}$ & Low risk & $\begin{array}{l}\text { Quote: "Permuted block randomisation scheme was developed by an interactive voice } \\
\text { response development system for group assignment at each site" (page 2) }\end{array}$ \\
\hline $\begin{array}{l}\text { Allocation } \\
\text { concealment (selection } \\
\text { bias) }\end{array}$ & High risk & Paper states "For this open-label trial, there was no allocation concealment." \\
\hline $\begin{array}{l}\text { Incomplete outcome } \\
\text { data (attrition bias) } \\
\text { All outcomes }\end{array}$ & Low risk & $\begin{array}{l}\text { ITT method of analysis used. } 68 \text { participants randomised, } 62 \text { included in the efficacy } \\
\text { analysis. Details of the participants excluded from the analysis described in the study }\end{array}$ \\
\hline $\begin{array}{l}\text { Selective reporting } \\
\text { (reporting bias) }\end{array}$ & Low risk & Although the protocol is not available, all details appear to have been covered \\
\hline Other bias & Unclear risk & $\begin{array}{l}4 \text { of the } 5 \text { authors have received consultancy fees from Genentech Inc.. } 2 \text { authors are current } \\
\text { or former employees of Genetech Inc. and own stock in the company }\end{array}$ \\
\hline $\begin{array}{l}\text { Blinding of } \\
\text { participants and } \\
\text { personnel } \\
\text { (performance bias) } \\
\text { All outcomes }\end{array}$ & High risk & $\begin{array}{l}\text { Open-labelled study. } \\
\text { Participants: no. } \\
\text { Control: no treatment. } \\
\text { Healthcare providers: not possible (control: no treatment). }\end{array}$ \\
\hline $\begin{array}{l}\text { Blinding of outcome } \\
\text { assessment (detection } \\
\text { bias) }\end{array}$ & Unclear risk & Outcome assessors and data analysts: unclear if blinded. \\
\hline
\end{tabular}


All outcomes

1

B. cepacia: Burkholderia cepacia

BMI: body mass index

CF: cystic fibrosis

CFTR: cystic fibrosis transmembrane regulator

$\mathrm{FEV}_{1}$ : forced expiratory volume in one second

FVC: forced vital capacity

ITT: intention to treat

IU: international units

MEF: mid-expiratory flow

$\mathrm{PE}_{\max }$ : maximal expiratory pressure

$\mathrm{PI}_{\max }$ : maximal inspiratory pressure

QoL: quality of life

RCT: randomised controlled trial

rhGH: recombinant human growth hormone

SC: subcutaneous

Tx: treatment 
Characteristics of excluded studies [ordered by study ID]

\begin{tabular}{|l|l|}
\hline Study & Reason for exclusion \\
\hline Alemzadeh 1998 & Non-RCT. \\
\hline Darmaun 2004 & $\begin{array}{l}\text { Each participant was given randomised treatments of glutamine, rhGH or both with 2-week wash-out periods in between. } \\
\text { Although the order of treatments was randomised, use of glutamine with rhGH excludes the study }\end{array}$ \\
\hline Eubanks 2002 & Study of appetite stimulant megestrol acetate and not rhGH. \\
\hline Hardin 1997 & Retrospective chart review, non-RCT. \\
\hline Hardin 1998 & Non-RCT. \\
\hline Hardin 2005c & Retrospective study, non-RCT. \\
\hline Huseman 1996 & Case series, non-RCT. \\
\hline Kissner 2000 & Not a study of rhGH. \\
\hline Marchand 2000 & Study of appetite stimulant megestrol acetate and not rhGH. \\
\hline Sackey 1995 & Non-RCT. \\
\hline Safai-Kutti 1991 & Study of zinc supplementation and not rhGH. \\
\hline Vanderwel 2006 & Retrospective study, non-RCT. \\
\hline
\end{tabular}

RCT: randomized controlled trial

rhGH: recombinant growth hormone 
Characteristics of studies awaiting assessment [ordered by study ID]

\begin{tabular}{|c|c|}
\hline Methods & $\begin{array}{l}\text { Double-blind, placebo-controlled cross-over study ( } 6 \text { months of treatment followed by } 6 \text {-month washout period followed by } 6 \\
\text { months of alternative treatment) }\end{array}$ \\
\hline Participants & 7 pre-pubertal children aged 9.6 to 13 years of age ( 5 boys, 2 girls) \\
\hline Interventions & IGF-1 versus placebo. \\
\hline Outcomes & $\begin{array}{l}\text { Primary outcome measure: linear growth rate. } \\
\text { Secondary outcome measures: changes in BMI, body composition (DEXA scan), } \mathrm{FEV}_{1} \text {, blood glucose/insulin ratio. }\end{array}$ \\
\hline \multicolumn{2}{|l|}{ Notes } \\
\hline \multicolumn{2}{|l|}{ Hardin 2001} \\
\hline Methods & $\begin{array}{l}\text { RCT, } 1 \text { year duration. } \\
\text { Multicentre: CF Centres at Texas Children's Hospital, Houston and Cook's Children's Hospital, Forth Worth }\end{array}$ \\
\hline Participants & $\begin{array}{l}\text { Randomised: } \mathrm{N}=19 \text { ( } 10 \text { males, } 9 \text { females), age } 8-13 \text { years. } \\
\text { Inclusion criteria } \\
\text { - } \quad \text { diagnosed cases of } \mathrm{CF} \\
\text { - } \text { height and weight < } 10 \text { th percentile } \\
\text { - } \quad \text { adequate caloric intake } \\
\text { Exclusion criteria } \\
\text { - } \quad \text { glucose intolerance or cystic fibrosis-related diabetes } \\
\text { - infection with } \text { B. cepacia } \\
\text { - } \quad \text { weight loss }>3 \% \text { in the } 3 \text { months prior to the study } \\
\text { - treatment with systemic or oral steroids in the prior } 6 \text { weeks } \\
\text { poor adherence to nutritional feeding } \\
\text { Withdrawals/losses to follow-up: } \mathrm{n}=2 \text {, group assignment unknown }\end{array}$ \\
\hline Interventions & $\begin{array}{l}\text { Intervention: daily SC injection of rhGH (Nutropin } \mathrm{AQ}^{\circledR} \text { ) } 0.3 \mathrm{mg} / \mathrm{kg} / \mathrm{week} \text {, adjusted every } 3 \text { months for weight gain. } \\
\text { Control: no therapy. } \\
\text { Concomitant therapy: standard GH care, antibiotics and hospitalised as needed }\end{array}$ \\
\hline Outcomes & $\begin{array}{l}\text { Primary outcomes } \\
\text { - } \text { pulmonary function tests } \\
\text { nutritional parameters - height, weight, height velocity, weight } \\
\text { velocity, lean body mass } \\
\text { Secondary outcomes } \\
\text { - blood glucose abnormality - haemoglobin A1c, fasting and } \\
\text { postprandial blood glucose, insulin level } \\
\text { IGF-1 levels } \\
\text { disease exacerbation - hospitalisation frequency and intravenous } \\
\text { antibiotics }\end{array}$ \\
\hline Notes & $\begin{array}{l}\text { "Supported by a grants from Genentech Foundation and from NIH grant MO1-RR-02558 (University of Texas Clinical } \\
\text { Research Center)". Data could not be verified }\end{array}$ \\
\hline \multicolumn{2}{|l|}{ Hardin 2005a } \\
\hline Methods & $\begin{array}{l}\text { RCT, cross-over design ( } 1 \text { year of treatment and control; year } 2 \text { of both groups with treatment) } \\
\text { Multicentre: CF Centre at Children's Medical Center, Dallas TX; Baylor College of Medicine, Houston TX; Indiana } \\
\text { University School of Medicine, Indianapolis IN; Washington University, St. Louis WA }\end{array}$ \\
\hline Participants & $\begin{array}{l}\text { Randomised: } \mathrm{N}=18 \text { (gender unspecified), age } 8-13 \text { years. } \\
\text { Inclusion criteria }\end{array}$ \\
\hline
\end{tabular}




\begin{tabular}{|c|c|}
\hline & $\begin{array}{l}\text { - diagnosed cases of } \mathrm{CF} \\
\text { - } \text { height and weight }<10 \text { th percentile } \\
\text { - compliant with nutritional therapy } \\
\text { Exclusion criteria } \\
\text { - treatment with systemic corticosteroid therapy in past } 6 \text { weeks } \\
\text { - colonisation with } B \text {. cepacia } \\
\text { Withdrawal or loss to follow-up: none reported. }\end{array}$ \\
\hline Interventions & $\begin{array}{l}\text { Intervention: daily SC injection of rhGH (Nutropin } \mathrm{AQ}^{\circledR} \text { ) } 0.3 \mathrm{mg} / \mathrm{kg} / \mathrm{week} \text {; dose adjusted every } 3 \text { months for weight gain } \\
\text { Control: no treatment. } \\
\text { Concomitant treatment: pancreatic enzyme treatment. } \\
9 \text { participants received rhGH treatment in the first year and } 9 \text { received no treatment. All received treatment with rhGH in the } \\
\text { 2nd year of study }\end{array}$ \\
\hline Outcomes & $\begin{array}{l}\text { Primary outcomes } \\
\text { - pulmonary function tests }\left(\mathrm{FEV}_{1}, \mathrm{FVC}\right) \\
\text { - nutritional parameters - height, weight, height velocity, weight velocity, lean body mass } \\
\text { Secondary outcomes } \\
\text { - blood glucose abnormality - casual blood glucose (but no comparison with controls) } \\
\text { - IGF-1 levels } \\
\text { - changes in disease exacerbation - hospitalisation, outpatient antibiotic use }\end{array}$ \\
\hline Notes & $\begin{array}{l}\text { Data from the 1st year of treatment could be used in the review, once data verified. Bone mineral content is additional outcome } \\
\text { of interest reported in this study but not in the review } \\
\text { "Supported in part by the Genetech Center for Clinical Research." }\end{array}$ \\
\hline \multicolumn{2}{|l|}{ Hardin $2005 b$} \\
\hline Methods & $\begin{array}{l}\text { Quasi-randomised study. Control data for BMC was derived from age, gender and ethnicity matched healthy children, but } \\
\text { participants with CF randomised into treatment and non-treatment groups }\end{array}$ \\
\hline Participants & $\begin{array}{l}\text { Randomised: } \mathrm{N}=32,(17 \text { males, } 15 \text { females }) \text {, age } 7-12 \text { years. } \\
\text { Inclusion criteria } \\
\text { - } \quad \text { stable } \mathrm{CF} \text {, not on systemic steroids } \\
\text { - height }<10 \text { th percentile, weight }<90 \% \text { of the } 50 \text { th percentile } \\
\text { bone age } 9.6-9.9 \text { years } \\
\text { Exclusion criteria: not specified in the manuscript. } \\
\text { Withdrawals or loss to follow-up: none reported. }\end{array}$ \\
\hline Interventions & $\begin{array}{l}\text { Intervention: daily } \mathrm{SC} \text { injections rhGH }\left(\text { Nutropin } \mathrm{AQ}^{\circledR} \text { ) } 0.3 \mathrm{mg} / \mathrm{kg} / \text { week. }\right. \\
\text { Control: no treatment. } \\
32 \text { participants of which } 16 \text { were randomly assigned to receive treatment for } 1 \text { year. It appears that control data from normal } \\
\text { children was used for bone mineral content comparison only. Anthropometric data appears to be compared in the treatment and } \\
\text { non-treatment group of the selected } 32 \mathrm{CF} \text { children }\end{array}$ \\
\hline Outcomes & $\begin{array}{l}\text { Primary outcomes } \\
\text { - nutritional parameters - height, weight, lean body mass } \\
\text { Secondary outcomes } \\
\text { - IGF-1 level }\end{array}$ \\
\hline Notes & $\begin{array}{l}\text { Bone mineral content is outcome of importance reported in this study, but not in our review Study supported by: NIH: } 1 \text { K08 } \\
\text { DK02365-01 and MO1-RR-02558, a grant from the National Cystic Fibrosis Foundation, a grant from Genentech Center for } \\
\text { Research and the US Department of Agriculture Agreement 58-6250-1-003 }\end{array}$ \\
\hline \multicolumn{2}{|l|}{ Hardin 2006} \\
\hline Methods & $\begin{array}{l}\text { RCT of cross-over design ( } 2 \text { periods of } 1 \text { year each). } \\
\text { Multicentre: } 10 \text { geographically dispersed centres in United States of America }\end{array}$ \\
\hline
\end{tabular}




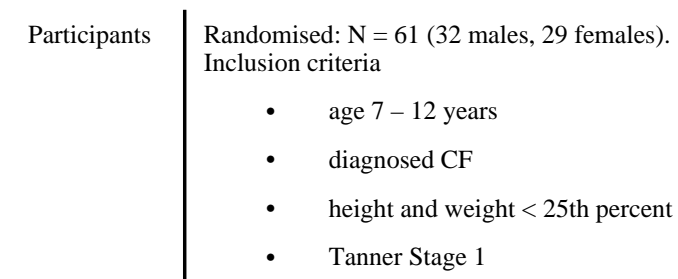

Exclusion criteria

- $\quad$ pre-existing diabetes

- $\quad$ systemic corticosteroid use within 6 months

- $\quad$ colonisation with B. cepacia

- addition of oral, enteral or parenteral supplementation within the past year

Withdrawals or loss to follow-up: 4 ( 2 from treatment and 2 from control group)

\begin{tabular}{|c|c|}
\hline Interventions & $\begin{array}{l}\left.\text { Intervention: daily SC injections of rhGH (Nutropin } \mathrm{AQ}^{\circledR}\right) 0.3 \mathrm{mg} / \mathrm{kg} / \text { week. } \\
\text { Control: no treatment. } \\
\text { Concomittant treatment permitted } \\
\text { - } \quad \text { pancreatic enzyme replacement } \\
\text { - } \quad \text { vitamin supplementation } \\
\text { - } \quad \text { inhaled bronchodilators and mucolytic } \\
\text { - clinically indicated antibiotics } \\
\text { Participant groups were crossed over after } 1 \text { year of treatment }\end{array}$ \\
\hline Outcomes & $\begin{array}{l}\text { Primary outcomes } \\
\text { - pulmonary function tests - change in FVC, change in } \mathrm{FEV}_{1} \\
\text { - nutritional parameters - height, weight, height velocity, weight velocity, lean body mass } \\
\text { - QoL - Health-Related QoL Questionnaire (HRQoL) } \\
\text { Secondary outcomes } \\
\text { - blood glucose abnormality - random blood glucose measurement } \\
\text { - change in disease exacerbation - hospitalisation frequency and need for antibiotics }\end{array}$ \\
\hline Notes & $\begin{array}{l}\text { Data from year } 1 \text { may be included in the review after verification of data } \\
\text { Bone mineral content reported as an additional outcome of significance, not in this review }\end{array}$ \\
\hline \multicolumn{2}{|l|}{ Schnabel 1997} \\
\hline Methods & 6-month study, cross-over design, not clear if randomised. Single centre \\
\hline Participants & 12 participants with $\mathrm{CF}$ (3 female, 9 male), mean (SD) age 12.2 (2.3) years \\
\hline Interventions & GH therapy $(0.11-0.14 \mathrm{IU} / \mathrm{kg} /$ day $)$ compared to high calorie diet \\
\hline Outcomes & Lean tissue mass, fat mass, weight. \\
\hline Notes & Await full translation and further details from authors. \\
\hline
\end{tabular}

B. cepacia: Burkholderia cepacia

BMC: bone mineral content

BMI: body mass index

CF: cystic fibrosis

$\mathrm{FEV}_{1}$ : forced expiratory volume in one second

FVC: forced vital capacity

GH: growth hormone

IU: international units

QoL: quality of life

RCT: randomised controlled trial

rhGH: recombinant human growth hormone 
SD: standard deviation

SC: subcutaneous 
Characteristics of ongoing studies [ordered by study ID]

\begin{tabular}{|c|c|}
\hline Trial name or title & Phase II Study of Growth Hormone in Children With Cystic Fibrosis \\
\hline Methods & $\begin{array}{l}\text { Randomised, multicentre cross-over study. } \\
\text { ( } 2 \text { periods of } 1 \text { year each). }\end{array}$ \\
\hline Participants & $\begin{array}{l}\text { Inclusion criteria } \\
\text { - } \text { ages } 5-12 \text { years } \\
\text { - } \\
\text { - } \\
\text { - } \text { height and weight }<25 \text { th percentile } \\
\text { - } \text { no colonization with } \text { B. cepacia } \\
\text { Exclusion criteria } \\
\text { - } \quad \text { prior or concurrent insulin therapy } \\
\text { - } \\
\text { haematologic, hepatic, renal disease }\end{array}$ \\
\hline Interventions & $\begin{array}{l}\text { Intervention: daily SC injections of rhGH. } \\
\text { Control: no treatment. }\end{array}$ \\
\hline Outcomes & $\begin{array}{l}\text { Primary outcomes } \\
\text { - pulmonary function tests } \\
\text { - nutritional parameters: height, weight, height velocity, lean body mass } \\
\text { Secondary outcome: } \\
\text { - QoL }\end{array}$ \\
\hline Starting date & 2001 \\
\hline Contact information & Dana Hardin, MD, Southwest Medical Center at Dallas \\
\hline \multicolumn{2}{|l|}{ Notes } \\
\hline \multicolumn{2}{|l|}{ Lippe 2008} \\
\hline Trial name or title & A Study to Evaluate Nutropin AQ for the Treatment of Growth Restriction in Children With Cystic Fibrosis \\
\hline Methods & Multicentre, randomised controlled, open-label study \\
\hline Participants & $\begin{array}{ll}\text { Inclusion criteria } \\
\text { - } & \text { ages } 5-13 \text { years } \\
\text { - } & \text { established diagnosis of } \mathrm{CF} \\
\text { - } & \text { able to perform pulmonary function test } \\
\text { - } & \text { height }<10 \text { th percentile } \\
\text { - } & \text { prepubertal, Tanner stage } 1 \\
\text { - } & \text { bone age } \leq 10 \text { years for girls, } \triangle 1 \text { years for boys } \\
\text { - } & \text { adequate caloric intake } \\
\text { Exclusion criteria } \\
\text { - } \\
\text { - } \\
\text { - } \text { grior or current rhGH use } \\
\text { - } \text { Infection with B. cepacia } \\
\text { disease exacerbation in } 14 \text { days prior to the study }\end{array}$ \\
\hline
\end{tabular}




\begin{tabular}{|c|c|}
\hline Interventions & Daily SC injection of rhGH (Nutropin $\mathrm{AQ}^{\circledR}$ ) \\
\hline Outcomes & $\begin{array}{l}\text { Primary outcomes } \\
\text { - } \text { safety and efficacy of Nutropin } \mathrm{AQ}^{\circledR} \text { in those with } \mathrm{CF} \\
\text { - change in lean body mass in those with } \mathrm{CF} \\
\text { Secondary outcomes } \\
\text { - } \text { pulmonary function tests } \\
\text { - disease related exacerbation } \\
\text { - }\end{array}$ \\
\hline Starting date & 2003 \\
\hline Contact information & Barbara Lippe, MD, Genentech Inc. \\
\hline Notes & This study has been completed. No published data available yet \\
\hline
\end{tabular}

B. cepacia: Burkholderia cepacia

CF: cystic fibrosis

CFRD: cystic fibrosis-related diabetes

$\mathrm{FEV}_{1}$ : forced expiratory volume in one second

QoL: quality of life

rhGH: recombinant human growth hormone

SC: subcutaneous 